\title{
Economic Forecasting with an Agent-based Model
}

\author{
Sebastian Poledna ${ }^{\mathrm{a}, \mathrm{b}, \mathrm{f}}$, Michael Gregor Miess $\mathrm{s}^{\mathrm{e}, \mathrm{a}, \mathrm{c}, \mathrm{g}}$, Cars Hommes $^{\mathrm{d}, \mathrm{h,i}, \mathrm{i}, *}$ \\ ${ }^{a}$ International Institute for Applied Systems Analysis, Schlossplatz 1, 2361 Laxenburg, Austria \\ ${ }^{b}$ Institute for Advanced Study, University of Amsterdam, Oude Turfmarkt 147, 1012 GC Amsterdam, The Netherlands \\ ${ }^{c}$ Institute for Advanced Studies, Josefstädter Straße 39, 1080 Wien, Austria \\ ${ }^{d}$ CeNDEF, University of Amsterdam, Amsterdam, Netherlands \\ ${ }^{e}$ Institute for Ecological Economics, Vienna University of Economics and Business, Welthandelsplatz 1, 1020 Wien, Austria \\ ${ }^{f}$ Earthquake Research Institute, The University of Tokyo, Bunkyo-ku, Tokyo, Japan \\ ${ }^{g}$ Complexity Science Hub Vienna, Josefstädter Straße 39, 1080 Wien, Austria \\ ${ }^{h}$ Tinbergen Institute, Amsterdam, Netherlands \\ ${ }^{i}$ Bank of Canada, Ottawa, Canada
}

\begin{abstract}
We develop the first agent-based model (ABM) that can compete with benchmark VAR and DSGE models in out-ofsample forecasting of macro variables. Our ABM for a small open economy uses micro and macro data from national and sector accounts, input-output tables, government statistics, census and business demography data. The model incorporates all economic activities as classified by the European System of Accounts as heterogeneous agents. The detailed structure of the ABM allows for a breakdown into sector level forecasts. Potential applications of the model include stress-testing and predicting the effects of changes in monetary, fiscal, or other macroeconomic policies.
\end{abstract}

Keywords: agent-based models, behavioral macro, macroeconomic forecasting, micro data JEL: E70, E32, E37

The dominant theory-driven approach to modeling the economy over recent decades has been the dynamic stochastic general equilibrium (DSGE) model. In particular, models following the New Keynesian paradigm, that include financial and real frictions to replicate phenomena observed in empirical data, have become a new standard in macroeconomics (Christiano et al., 2010; Brunnermeier et al., 2013). Together with structural econometric and vector autoregressive (VAR) models of various types and sizes, DSGE models are the workhorse framework of central banks and other institutions engaging in economic forecasting, especially since the advent of Bayesian DSGE models such as Smets and Wouters (2003, 2007), exhibiting good forecasting capabilities when compared to simple time series models. One of the main reasons for the evident success of DSGE models is their rigorous micro-foundations rooted in economic theory, which have been complemented by Bayesian parameter estimation techniques to reach a better empirical fit (An and Schorfheide, 2007; Fernandez-Villaverde, 2010; Linde et al., 2016). However, in the light of the financial crisis of 2007-2008 and the subsequent Great Recession, these models have been criticized by several prominent voices within the economic profession, coming from different schools of economic thought. The limits of the DSGE approach at the core of the New Neoclassical Synthesis have been discussed in detail, for example, in (Vines and Wills, 2018). ${ }^{1}$ As an alternative, some economists are pushing forward with agent-based models (ABMs)potentially to complement DSGE models-as a new promising direction for economic modelling. ${ }^{2}$ Farmer and Foley (2009), in particular, suggest that it might be possible to conduct economic forecasts with a macroeconomic ABM, although they consider this to be ambitious.

\footnotetext{
${ }^{*}$ Corresponding author

Email addresses: poledna@iiasa.ac . at (Sebastian Poledna), michael.gregor.miess@wu.ac . at (Michael Gregor Miess), c.h.hommes@uva.nl (Cars Hommes)

${ }^{1}$ For earlier critiques see e.g., Canova and Sala (2009), Colander et al. (2009), Kirman (2010), Krugman (2011), Stiglitz (2011, 2018), Blanchard (2016), Romer (2016). See also the recent response defending DSGE models by Christiano et al. (2018).

${ }^{2}$ Some examples include Freeman (1998), Gintis (2007), Colander et al. (2008), LeBaron and Tesfatsion (2008), Farmer and Foley (2009), Trichet (2010), Stiglitz and Gallegati (2011), and Haldane and Turrell (2018).
} 
ABMs have two distinguishing features: they are "agent-based," that is, they model individual agents—households, firms, banks, etc. - and they are simulation models because they are too detailed and complex to be handled analytically. The dynamic properties of the aggregate system are derived "from the bottom up," namely, they emerge from the micro-behavior of individual agents and the structure of their interactions. Macroeconomic ABMs typically replicate a number of macroeconomic and microeconomic empirical stylized facts, such as time series properties of output fluctuations and growth, as well as cross-sectional distributional characteristics of firms (Dosi et al., 2017; Axtell, 2018). Macroeconomic ABMs relax two key assumptions at the core of the New Neoclassical Synthesis-the single, representative agent and the rational, or model-consistent, expectations hypothesis (Haldane and Turrell, 2018). Representative agents are replaced by individual "agents" who follow well-defined behavioral rules of thumb, and rational expectations are relaxed to bounded rationality (i.e., agents make decisions based on partial information and limited computational ability). Relaxation of these assumptions allows greater flexibility in the design of ABMs because the strong consistency requirements entailed in simplistic models - all actions and beliefs must be mutually consistent at all times - are no longer necessary. ABMs occupy a middle ground on a spectrum where micro-founded DSGE models lie at one end and statistical models lie at the other (Haldane and Turrell, 2018). ${ }^{3,4}$ Macroeconomic ABMs, however, suffer from a number of problems that impede major applications in economics, such as economic forecasting and empirically founded policy evaluation. The lack of a commonly accepted basis for the modeling of bounded rational behavior has raised concerns about the "wilderness of bounded rationality" (Sims, 1980). Research on econometric estimation of ABMs has been growing recently, though most of it still remains at the level of proof of concept (Lux and Zwinkels, 2018). Empirical validation of ABMs remains a difficult task. Due to over-parameterization and the corresponding degrees of freedom, almost any simulation output can be generated with an ABM, and thus replication of stylized facts only represents a weak test for the validity of ABMs (Fagiolo and Roventini, 2017).

The main goal of this paper is to develop an ABM that fits microeconomic data of a small open economy and allows out-of-sample forecasting of the aggregate macro variables, such as GDP (including its components), inflation and interest rates. 5 The model is based on Assenza et al. (2015) who developed a stylized ABM with households, firms (upstream and downstream), and a bank, that replicates a number of stylized facts. Our ABM includes all institutional sectors (financial firms, non-financial firms, households, and a general government), where the firm sector is composed of 64 industry sectors according to national accounting conventions and the structure of inputoutput tables. The model is based on micro and macro data from national accounts, sector accounts, input-output tables, government statistics, census data, and business demography data. Model parameters are either taken directly from data or calculated from national accounting identities. For exogenous processes such as imports and exports, parameters are estimated. The model furthermore incorporates all economic activities, as classified by the European System of Accounts (ESA) (productive and distributive transactions) and all economic entities; namely, all juridical and natural persons are represented by heterogenous agents. The model includes a complete GDP identity, where GDP as a macroeconomic aggregate is calculated from the market value of all final goods and services produced by individual agents and market value emerges from trading or, alternatively, according to the aggregate expenditure or income of individual agents. Markets are fully decentralized and characterized by a continuous search-and-matching process, which allows for trade frictions. Agent forecasting behavior is modeled by parameter-free adaptive learning, where agents act as econometricians who estimate the parameters of their model and make forecasts using their estimates (Evans and Honkapohja, 2001). We follow the approach of Hommes and Zhu (2014), where agents learn the optimal parameters of simple parsimonious AR(1) rules in a complex environment ${ }^{6}$.

\footnotetext{
${ }^{3}$ There is also a large literature on DSGE models with heterogeneous agents that maintains the rational expectations hypothesis. See e.g., the collection of chapters in Schmedders and Judd (2013).

${ }^{4}$ In recent years another large literature has appeared on behavioral macro-models with boundedly rational agents and heterogeneous expectations. See the recent overview in Hommes (2018).

${ }^{5}$ A related model that does not allow out-of-sample forecasting of macro variables was used for estimating indirect economic losses from natural disasters in (Poledna et al., 2018).

${ }^{6}$ Brayton et al. (1997) discuss the role of expectations in FRB/US macroeconomic models. One approach is that expectations are given by small forecasting models such as a VAR model. Our choice of AR(1) models is simply the most parsimonious yet empirically relevant choice, where, for each relevant variable, agents learn the parameters of an AR(1) rule consistent with the observable sample mean and autocorrelation. Slobodyan and Wouters (2012) estimated the Smets and Wouters (2007) DSGE model with expectations modelled by a simple AR(2) forecasting rule under time-varying beliefs and show that this leads to an improvement in the empirical fit of the model and its ability to capture the short-term momentum in the macroeconomic variables. Hommes et al. (2019) estimate the benchmark 3 equations New Keynesian model with optimal AR(1) rules for inflation and output gap and find a better fit than under rational expectations.
} 
The objectives of this paper are twofold. First, we develop the first ABM that fits the microeconomic data of a small open economy and allows out-of-sample forecasting of the aggregate macro variables, such as GDP (including its components), inflation and interest rates. Second, as an empirical validation, we compare the forecast performance of the ABM to that of autoregressive (AR), VAR, and DSGE models. For this purpose, we conduct a series of forecasting exercises where we evaluate the out-of-sample forecast performance of the different model types using a traditional measure of forecast error (root mean squared error). In a first exercise, we validate the ABM against unconstrained VAR models that are estimated on the same dataset as the ABM. We find that the ABM delivers a similar forecast performance to the VAR model for short- to medium-term horizons up to two years, and improves on VAR forecasts for longer horizons up to three years. In a second exercise, we compare the forecast performance of the $\mathrm{ABM}$ to that of AR models and a standard DSGE model for the main macroeconomic aggregates, GDP growth and inflation, as well as to household consumption and investment as main components of GDP. For a DSGE model, we have employed the standard DSGE model of Smets and Wouters (2007), adapted to the Austrian economy by Breuss and Rabitsch (2009). Here, we find that the ABM delivers a similar forecast performance to that of the standard DSGE model. Both the ABM and the standard DSGE model improve on the AR models in forecasting household consumption and investment. In a third forecasting setup, we generate forecasts conditional on exogenous paths for imports, exports, and government consumption, corresponding to a small open economy setting and exogenous policy decisions. In this forecast exercise, the detailed economic structure incorporated into the ABM improves its forecasting ability, especially in comparison with the DSGE model. We perform two more forecasting exercises exploring the detailed sectoral structure of our ABM. With these three forecast exercises, we achieve comparability of the ABM to the forecasting performance of standard modeling approaches. To the best of our knowledge, this is the first ABM able to compete in out-of-sample forecasting of macro variables.

The remainder of the manuscript is structured as follows. Section 1 elaborates on the characteristics of ABMs, and critiques of them, and gives a brief summary of the related literature. Section 2 provides an overview of the model describing agents' behavior and the data used. Section 3 describes the forecast performance of the ABM, where we validate the ABM against VAR, DSGE, and AR models in different forecasting setups, and delivers applications to more detailed decompositions of the ABM forecasts. Section 4 concludes. The details of our ABM are given in Appendix A to Appendix C.

\section{Related literature}

Since their beginnings in the $1930 \mathrm{~s},{ }^{7} \mathrm{ABMs}$ have found widespread application as an established method in various scientific disciplines (Haldane and Turrell, 2018), for example, military planning, the physical sciences, operational research, biology, ecology, but less so in economics and finance. The use of ABMs in the latter two fields to date remains quite limited in comparison to other disciplines. An early exception is Orcutt (1957), who constructed a first simple economically motivated ABM to obtain aggregate relationships from the interaction of individual heterogeneous units via simulation. Other examples include topics such as racial segregation patterns (Schelling, 1969), financial markets (Arthur et al., 1997), or more recently the housing market (Geanakoplos et al., 2012; Baptista et al., 2016). Since the financial crisis of 2007-2008, ABMs have increasingly been applied to research in macroeconomics. Furthermore, in recent years, several ABMs have been developed that depict entire national economies and are designed to deliver macroeconomic policy analysis. The European Commission (EC) has in part supported this endeavor. One example of a large research project funded by the EC is the Complexity Research Initiative for Systemic Instabilities (CRISIS), ${ }^{8}$ an open source collaboration between academics, firms, and policymakers (Klimek et al., 2015). Another is EURACE ${ }^{9}$ a large micro-founded macroeconomic model with regional heterogeneity (Cincotti et al., 2010).

In a recent overview Dawid and Delli Gatti (2018) identified seven main families of macroeconomic $\mathrm{ABMs}^{10}$ : (1) the framework developed by Ashraf, Gershman, and Howitt (2017); (2) the family of models proposed by Delli Gatti et al. (2011) in Ancona and Milan exploiting the notion of Complex Adaptive Trivial Systems (CATS); (3)

\footnotetext{
${ }^{7}$ The first ABM reportedly was constructed (by hand) by Enrico Fermi in the 1930s to model the problem of neutron transport.

${ }^{8}$ FP7-ICT grant 288501, http://cordis . europa.eu/project/rcn/101350_en.html. (Last accessed November 30 ${ }^{\text {th }}, 2018$ )

${ }^{9}$ FP6-STREP grant 035086, http://cordis.europa.eu/project/rcn/79429_en.html. See also: http://www.wiwi. uni-bielefeld.de/lehrbereiche/vwl/etace/Eurace_Unibi/ (Last accessed November $30^{\text {th }}, 2018$ )

${ }^{10}$ For another recent overview on macroeconomic ABMs see Fagiolo and Roventini (2017).
} 
the framework developed by Dawid et al. (2018) in Bielefeld as an offspring of the EURACE project, known as Eurace@Unibi; (4) the EURACE framework maintained by Cincotti et al. (2010) in Genoa; (5) the Java Agent based MacroEconomic Laboratory developed by Seppecher, Salle, and Lavoie (2018); (6) the family of models developed by Dosi et al. (2017) in Pisa, known as the "Keynes meeting Schumpeter" framework; and (7) the LAGOM model developed by Jaeger et. al (2013). What unites all these families of models is their ability to generate endogenous long-term growth and short- to medium-term business cycles. These business cycles are the macroeconomic outcome of the micro-level interaction of heterogeneous agents in the economy as a complex system subject to non-linearities (Dawid and Delli Gatti, 2018). All these models assume bounded rationality for their agents, and thus suppose adaptive expectation in an environment of fundamental uncertainty. Typically, they minimally depict firm, household, and financial (banking) sectors populated by numerous agents of these types (or classes), and agents exhibit additional heterogeneity within one or more of the different classes. All results are obtained by performing extensive Monte Carlo simulations and averaging over simulation outcomes. The great majority of models are calibrated and validated with respect to a (smaller or larger) variety of stylized empirical economic facts (Fagiolo and Roventini, 2017). However, despite their level of sophistication, all these models suffer from one or more impediments: they serve as a theoretical explanatory tool constructed for a hypothetical economy; the choice of the number of agents is arbitrary or left unexplained; time units may have no clear interpretation; validation with respect to stylized empirical facts cannot solve the potential problem of over-parameterization; the choice of parameter values is often not pinned down by clear-cut empirical evidence; and most of these models exhibit an extended transient or burn-in phase that is discarded before analysis.

To address these concerns we develop an ABM that fits microeconomic data of a small open economy and allows out-of-sample forecasting of the aggregate macro variables, such as GDP (including its components), inflation and interest rates. This model is based on micro and macro data from national accounts, input-output tables, government statistics, census data, and business demography data. Model parameters are either taken directly from data or are calculated from national accounting identities. For exogenous processes, such as imports and exports, parameters are estimated. As an empirical validation, we compare the out-of-sample forecast performance of the ABM to that of AR, VAR, and DSGE models.

\section{An agent-based model for a small open economy}

In this section we give a short overview of the model; for details, see Appendix A to Appendix C. Following the sectoral accounting conventions of the ESA, Eurostat (2013), the model economy is structured into four mutually exclusive domestic institutional sectors: (1) non-financial corporations (firms); (2) households; (3) the general government; and (4) financial corporations (banks), including (5) the central bank. These four sectors make up the total domestic economy and interact with (6) the rest of the world (RoW) through imports and exports. Each sector is populated by heterogeneous agents, who represent natural persons or legal entities (corporations, government entities, and institutions). We use a scale of 1:1 between model and data, so that each agent in the model represents a natural or legal person in reality. This has the advantage that our ABM is directly linked to microeconomic data and that scaling or fine tuning of parameters and size is not needed; rather, parameters are pinned down by data or calculated from accounting identities. All individual agents have separate balance sheets, depicting assets, liabilities, and ownership structures. The balance sheets of the agents, and the economic flows between them, are set according to data from national accounts.

The firm sector is composed of 64 industry sectors according to the NACE/CPA classification by ESA and the structure of input-output tables. The firm population of each sector is derived from business demography data, while firm sizes follow a power law distribution, which approximately corresponds to the firm size distribution in Austria. Each firm is part of a certain industry and produces industry-specific output by means of labor, capital, and intermediate inputs from other sectors-employing a fixed coefficient (Leontief) production technology with constant coefficients. These productivity and technology coefficients are calculated directly from input-output tables. Firms are subject to fundamental uncertainty regarding their future sales, market prices, the availability of inputs for production, input costs, and cash flow and financing conditions. Based on partial information about their current status quo and its past development, firms have to form expectations to estimate future demand for their products, their future input costs, and their future profit margin. According to these expectations-which are not necessarily realized in the future-firms set prices and quantities. We assume that firms form these expectations using simple autoregressive time 
series models (AR(1) expectations). These expectations are parameter-free, as agents learn the optimal AR(1) forecast rule that is consistent with two observable statistics, the sample mean and the sample autocorrelation (Hommes and Zhu, 2014). Output is sold to households as consumption goods or investment in dwellings and to other firms as intermediate inputs or investment in capital goods, or it is exported. Firm investment is conducted according to the expected wear and tear on capital. Firms are owned by investors (one investor per firm), who receive part of the profits of the firm as dividend income.

The household sector consists of employed, unemployed, investor, and inactive households, with the respective numbers obtained from census data. Employed households supply labor and earn sector-specific wages. Unemployed households are involuntarily idle, and receive unemployment benefits, which are a fraction of previous wages. Investor households obtain dividend income from firm ownership. Inactive households do not participate in the labor market and receive social benefits provided by the government. Additional social transfers are distributed equally to all households (e.g., child care payments). All households purchase consumption goods and invest in dwellings which they buy from the firm sector. Due to fundamental uncertainty, households also form AR(1) expectations about the future that are not necessarily realized. Specifically, they estimate inflation using an optimal AR(1) model to calculate their expected net disposable income available for consumption.

The main activities of the government sector are consumption on retail markets and the redistribution of income to provide social services and benefits to its citizens. The amount and trend of both government consumption and redistribution are obtained from government statistics. The government collects taxes, distributes social as well as other transfers, and engages in government consumption. Government revenues consist of (1) taxes: on wages (income tax), capital income (income and capital taxes), firm profit income (corporate taxes), household consumption (valueadded tax), other products (sector-specific, paid by industry sectors), firm production (sector-specific), as well as on exports and capital formation; (2) social security contributions by employees and employers; and (3) other net transfers such as property income, investment grants, operating surplus, and proceeds from government sales and services. Government expenditures are composed of (1) final government consumption; (2) interest payments on government debt; (3) social benefits other than social benefits in kind; (4) subsidies; and (5) other current expenditures. A government deficit adds to its stock of debt, thus increasing interest payments in the periods thereafter.

The banking sector obtains deposits from households as well as from firms, and provides loans to firms. Interest rates are set by a fixed markup on the policy rate, which is determined according to a Taylor rule. Credit creation is limited by minimum capital requirements, and loan extension is conditional on a maximum leverage of the firm, reflecting the bank's risk assessment of a potential default by its borrower. Bank profits are calculated as the difference between interest payments received on firm loans and deposit interest paid to holders of bank deposits, as well as write-offs due to credit defaults (bad debt). The central bank sets the policy rate based on implicit inflation and growth targets, provides liquidity to the banking system (advances to the bank), and takes deposits from the bank in the form of reserves deposited at the central bank. Furthermore, the central bank purchases external assets (government bonds) and thus acts as a creditor to the government. To model interactions with the rest of the world, a segment of the firm sector is engaged in import-export activities. As we model a small open economy, whose limited volume of trade does not affect world prices, we obtain trends of exports and imports from exogenous projections based on national accounts.

The parameters of our ABM are summarized in Table 1; for details see Appendix B. For the forecasting exercise in Section 3, parameters were initially calculated and estimated over the sample 1997:Q1 to 2010:Q1 and then, respectively, re-estimated and recalculated, every quarter until 2013:Q4. Here we show, as an example, parameter values for 2010:Q4. Data sources include micro and macro data from national accounts, sector accounts, input-output tables, government statistics, census data, and business demography data; for details, see Appendix B and Table B.6. Model parameters are either taken directly from data or calculated from national accounting identities. Parameters that specify the number of agents are taken directly from census and business demography data. Model parameters concerning productivity and technology coefficients, as well as capital formation and consumption coefficients, are taken directly from input-output tables, or are derived from them. Tax rates and marginal propensities to consume or invest are calculated from national accounting identities. These rates are set such that the financial flows observed in input-output tables, government statistics, and sector accounts are matched. Capital ratios and the inflation target of the monetary authority are set according to the literature. For exogenous processes such as imports and exports, parameters are estimated from national accounts (main aggregates). 
Table 1: Model parameters

\begin{tabular}{|c|c|c|c|}
\hline Parameter & Description & Value & Source \\
\hline$G / S$ & Number of products/industries & 62 & \multirow{6}{*}{ 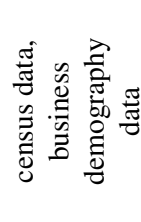 } \\
\hline$H^{\text {act }}$ & Number of economically active persons & 4729215 & \\
\hline$H^{\text {inact }}$ & Number of economically inactive persons & 4130385 & \\
\hline$J$ & Number of government entities & 152820 & \\
\hline$L$ & Number of foreign consumers & 305639 & \\
\hline$I_{s}$ & Number of firms/investors in the $s^{\text {th }}$ industry & see Table B.7 & \\
\hline $\bar{\alpha}_{i}$ & Average productivity of labor of the $i^{\text {th }}$ firm & see Appendix B.1 & \multirow{14}{*}{ 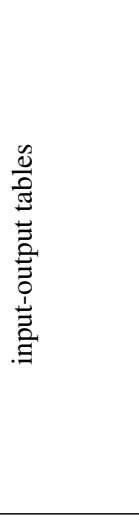 } \\
\hline$\kappa_{i}$ & Productivity of capital of the $i^{\text {th }}$ firm & see Appendix B.1 & \\
\hline$\beta_{i}$ & Productivity of intermediate consumption of the $i^{\text {th }}$ firm & see Appendix B.1 & \\
\hline$\delta_{i}$ & Depreciation rate for capital of the $i^{\text {th }}$ firm & see Appendix B.1 & \\
\hline $\bar{w}_{i}$ & Average wage rate of firm $i$ & see Appendix B.1 & \\
\hline$a_{s g}$ & Technology coefficient of the $g^{\text {th }}$ product in the $s^{\text {th }}$ industry & see Appendix B.1 & \\
\hline$b_{g}^{\mathrm{CF}}$ & Capital formation coefficient of the $g^{\text {th }}$ product (firm investment) & see Table B.7 & \\
\hline$b_{g}^{\mathrm{CFH}}$ & Household investment coefficient of the $g^{\text {th }}$ product & see Table B.7 & \\
\hline$b_{g}^{\mathrm{HH}}$ & Consumption coefficient of the $g^{\text {th }}$ product of households & see Table B.7 & \\
\hline$c_{g}^{\mathrm{G}}$ & Consumption of the $g^{\text {th }}$ product of the government in mln. Euro & see Table B.7 & \\
\hline$c_{g}^{\mathrm{E}}$ & Exports of the $g^{\text {th }}$ product in mln. Euro & see Table B.7 & \\
\hline$c_{g}^{1}$ & Imports of the $g^{\text {th }}$ product in $\mathrm{mln}$. Euro & see Table B.7 & \\
\hline$\tau_{i}^{Y}$ & Net tax rate on products of the $i^{\text {th }}$ firm & see Appendix B.3 & \\
\hline$\tau_{i}^{\mathrm{K}}$ & Net tax rate on production of the $i^{\text {th }}$ firm & see Appendix B.3 & \\
\hline$\tau^{\mathrm{INC}}$ & Income tax rate & 0.2134 & \multirow{14}{*}{ 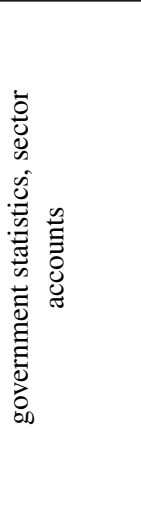 } \\
\hline$\tau^{\mathrm{FIRM}}$ & Corporate tax rate & 0.0779 & \\
\hline$\tau^{\mathrm{VAT}}$ & Value-added tax rate & 0.1529 & \\
\hline$\tau^{\mathrm{SIF}}$ & Social insurance rate (employers' contributions) & 0.2122 & \\
\hline$\tau^{\mathrm{SIW}}$ & Social insurance rate (employees' contributions) & 0.1711 & \\
\hline$\tau^{\mathrm{EXPORT}}$ & Export tax rate & 0.003 & \\
\hline$\tau^{\mathrm{CF}}$ & Tax rate on capital formation & 0.2521 & \\
\hline$\tau^{\mathrm{G}}$ & Tax rate on government consumption & 0.0091 & \\
\hline$r^{\mathrm{G}}$ & Interest rate on government bonds & 0.0087 & \\
\hline$\mu$ & Risk premium on policy rate & 0.0256 & \\
\hline$\psi$ & Fraction of income devoted to consumption & 0.9079 & \\
\hline$\psi^{\mathrm{H}}$ & Fraction of income devoted to investment in housing & 0.0819 & \\
\hline$\theta^{\mathrm{UB}}$ & Unemployment benefit replacement rate & 0.3586 & \\
\hline$\theta^{\mathrm{DIV}}$ & Dividend payout ratio & 0.7953 & \\
\hline$\theta$ & Rate of installment on debt & 0.05 & \multirow{5}{*}{ 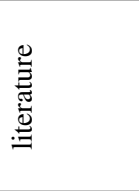 } \\
\hline$\zeta$ & Banks' capital requirement coefficient & 0.03 & \\
\hline$\zeta^{\mathrm{LTV}}$ & Loan-to-value (LTV) ratio & 0.6 & \\
\hline$\zeta^{b}$ & Loan-to-capital ratio for new firms after bankruptcy & 0.5 & \\
\hline$\pi^{*}$ & Inflation target of the monetary authority & 0.02 & \\
\hline$\alpha^{\mathrm{G}}$ & Autoregressive coefficient for government consumption & 0.9832 & \multirow{14}{*}{ 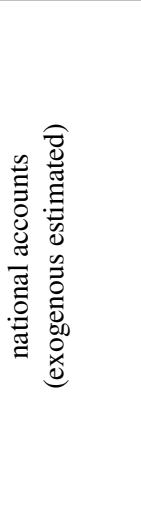 } \\
\hline$\beta^{\mathrm{G}}$ & Scalar constant for government consumption & 0.1644 & \\
\hline$\alpha^{\mathrm{E}}$ & Autoregressive coefficient for exports & 0.9679 & \\
\hline$\beta^{\mathrm{E}}$ & Scalar constant for exports & 0.3436 & \\
\hline$\alpha^{\mathrm{I}}$ & Autoregressive coefficient for imports & 0.9736 & \\
\hline$\beta^{\mathrm{I}}$ & Scalar constant for imports & 0.2813 & \\
\hline$\alpha^{\mathrm{Y}^{\mathrm{EA}}}$ & Autoregressive coefficient for euro area GDP & 0.9681 & \\
\hline$\beta^{\mathrm{Y}^{\mathrm{EA}}}$ & Scalar constant for euro area GDP & 0.4706 & \\
\hline$\alpha^{n^{\mathrm{EA}}}$ & Autoregressive coefficient for euro area inflation & 0.3198 & \\
\hline$\beta^{\pi^{\mathrm{EA}}}$ & Scalar constant for euro area inflation & 0.0028 & \\
\hline$\rho$ & Adjustment coefficient of the policy rate & 1.0028 & \\
\hline$r^{*}$ & Real equilibrium interest rate & -0.0617 & \\
\hline$\xi^{\pi}$ & Weight of the inflation target & -17.7004 & \\
\hline$\xi^{\gamma}$ & Weight of economic growth & -40.9463 & \\
\hline
\end{tabular}

Notes: Model parameters are calculated for 2010:Q4. Exogenous autoregressive parameters are estimated starting in 1997:Q1. 


\section{Forecast performance}

To validate the $\mathrm{ABM}$, we conduct a series of forecasting exercises in which we evaluate the out-of-sample forecast performance of the ABM in comparison with standard macroeconomic modeling approaches. ${ }^{11}$

\subsection{Comparison with VAR models}

In this section, we compare the out-of-sample forecast performance of the ABM with that of various unconstrained (non-theoretical) VAR models estimated on the same observable macro time series in a traditional out-of-sample root mean squared error (RMSE) $)^{12}$ forecast exercise. We compare the ABM with three standard VAR models of lag order one to three, estimated using the same eight observable time series. Observable time series include the real GDP, inflation, real government consumption, real exports and real imports of Austria, as well as real GDP and inflation of the euro area (EA), and the Euro Interbank Offered Rate (Euribor). To allow the data to decide on the degree of persistence and cointegration, in the VAR models we enter GDP, government consumption, exports, imports, and GDP of the EA in log levels. For this exercise, the VAR models and the ABM were initially estimated over the sample 1997:Q1 to 2010:Q1. The models were then used to forecast the eight time series from 2010:Q2 to 2016:Q4; the models were re-estimated every quarter. ABM results are obtained as an average over 500 Monte Carlo simulations.

Table 2 reports the out-of-sample RMSEs for different forecast horizons of 1, 2, 4, 8, and 12 quarters over the period 2010:Q2 to 2016:Q4. These out-of-sample forecast statistics demonstrate the good forecast performance of the ABM relative to the VAR models of different lag orders. For GDP and inflation, the ABM delivers a similar forecast performance to that of the VAR(1) for short- to medium-term horizons up to two years, and improves on it for longer horizons up to three years. For the other five variables (government consumption, exports, imports, GDP and inflation EA, Euribor), the ABM does better than the different VAR models by a considerable margin for almost all horizons. The forecast performances of the $\operatorname{VAR}(2)$ and especially the $\operatorname{VAR}(3)$ model clearly deteriorate for longer horizons.

\subsection{Comparison with DSGE and AR models}

In this section, we compare the out-of-sample forecast performance of the ABM to that of a standard DSGE model. As variables for this comparison, we choose the major macroeconomic aggregates: real GDP growth, inflation, and the main components of GDP-real household consumption and real investment. As a DSGE model, we employ a standard DSGE model of Smets and Wouters (2007), which is a widely cited New Keynesian DSGE model for the US economy with sticky prices and wages, adapted to the Austrian economy. For this purpose, we use the twocountry model of Breuss and Rabitsch (2009), which is a New Open Economy Macro model for Austria as part of the European Monetary Union (EMU). ${ }^{13}$ The DSGE model is estimated on the following set of 13 variables for the same time period as the ABM (1997:Q1-2010:Q1): log difference of real GDP, real consumption, real investment and the real wage, log hours worked, the log difference of the GDP deflator (six each for Austria and the EA), as well as the three-month Euribor. As standard time series models for comparing the forecast performance of the ABM and DSGE models, we estimate AR models of lag orders one to three on the log levels of real GDP, real household consumption, real investment, and the log difference of the GDP deflator (inflation). Again, all models are initially estimated over the sample 1997:Q1 to 2010:Q1, and the models are then used to forecast the four time series from 2010:Q2 to 2016:Q4, with the models being re-estimated every quarter. ABM results are obtained as an average over 500 Monte Carlo simulations and the DSGE model is estimated using Bayesian methods. ${ }^{14}$

Table 3 shows comparisons between the ABM and the DSGE and AR models of different lag orders for forecast horizons of 1, 2, 4, 8, and 12 quarters over the period 2010:Q2 to 2016:Q4. Similar to the forecast exercise above,

\footnotetext{
${ }^{11}$ This out-of-sample prediction performance evaluation is constructed along the lines of Smets and Wouters (2007), who compare a Bayesian DSGE model to unconstrained VAR as well as Bayesian VAR (BVAR) models.

${ }^{12}$ The root mean squared error is defined as follows: $R M S E=\sqrt{\frac{1}{n} \sum_{t=1}^{T}\left(\hat{x}_{t}-x_{t}\right)^{2}}$, where $\hat{x}_{t}$ is the forecast value and $x_{t}$ is the observed data point for time period $t$.

${ }^{13}$ See Appendix F.1 for additional information on the DSGE model. We would like to thank Katrin Rabitsch for providing us with the improved version of the DSGE model in Breuss and Rabitsch (2009) for this manuscript.

${ }^{14}$ DSGE estimations are done with Dynare, see http://www. dynare.org/ (Last accessed November $30^{\text {th }}, 2018$ ). A sample of 250,000 draws was created (neglecting the first 50,000 draws).
} 
Table 2: Out-of-sample forecast performance

\begin{tabular}{|c|c|c|c|c|c|c|c|c|}
\hline & GDP & Inflation & $\begin{array}{l}\text { Government } \\
\text { consumption }\end{array}$ & Exports & Imports & GDP EA & Inflation EA & Euribor \\
\hline $\operatorname{VAR}(1)$ & \multicolumn{8}{|c|}{ RMSE-statistic for different forecast horizons } \\
\hline $1 \mathrm{q}$ & 0.66 & 0.39 & 0.98 & 1.88 & 2.16 & 0.58 & 0.15 & 0.09 \\
\hline $2 q$ & 0.89 & 0.38 & 1.35 & 2.35 & 2.82 & 0.89 & 0.13 & 0.15 \\
\hline $4 q$ & 1.29 & 0.36 & 2.05 & 2.67 & 3.02 & 1.49 & 0.17 & 0.24 \\
\hline $8 \mathrm{q}$ & 1.55 & 0.36 & 3.13 & 3.22 & 3.22 & 2.77 & 0.21 & 0.26 \\
\hline $12 q$ & 1.99 & 0.42 & 3.50 & 5.70 & 4.66 & 4.05 & 0.27 & 0.20 \\
\hline $\operatorname{VAR}(2)$ & \multicolumn{8}{|c|}{ Percentage gains (+) or losses (-) relative to VAR(1) model } \\
\hline $1 \mathrm{q}$ & 13.49 & -22.43 & 6.08 & 2.88 & 17.90 & 12.55 & -14.31 & 23.33 \\
\hline $2 q$ & 4.52 & -19.63 & 13.88 & -17.24 & 9.53 & -8.15 & -25.98 & 11.33 \\
\hline $4 q$ & -18.69 & -8.94 & 1.95 & -32.81 & -19.79 & -31.70 & -24.73 & -4.08 \\
\hline $8 \mathrm{q}$ & -73.06 & 1.01 & -21.06 & -80.30 & -63.65 & -37.52 & 1.28 & -52.75 \\
\hline $12 q$ & -63.87 & -15.00 & -42.88 & -38.93 & -40.66 & -20.66 & -9.47 & -76.95 \\
\hline $\operatorname{VAR}(3)$ & \multicolumn{8}{|c|}{ Percentage gains $(+)$ or losses $(-)$ relative to $\operatorname{VAR}(1)$ model } \\
\hline $1 \mathrm{q}$ & -24.75 & -50.31 & -17.19 & -6.98 & 3.94 & -29.27 & -27.56 & 23.44 \\
\hline $2 q$ & -57.16 & -37.58 & -8.63 & -62.82 & -19.07 & -46.03 & -58.50 & 7.95 \\
\hline $4 q$ & -92.17 & -11.76 & -16.99 & -135.18 & -87.62 & -81.28 & -58.11 & -34.27 \\
\hline $8 q$ & -128.47 & -19.30 & -57.48 & -136.17 & -103.14 & -68.83 & -25.85 & -100.11 \\
\hline $12 q$ & -92.23 & -41.34 & -100.56 & -76.09 & -72.88 & -53.00 & -49.69 & -94.44 \\
\hline $\mathrm{ABM}$ & \multicolumn{8}{|c|}{ Percentage gains (+) or losses $(-)$ relative to $\operatorname{VAR}(1)$ model } \\
\hline $1 \mathrm{q}$ & 4.30 & 4.33 & 30.19 & 13.37 & 26.96 & 28.10 & 27.14 & -89.54 \\
\hline $2 q$ & -1.01 & 2.21 & 59.54 & 9.85 & 22.16 & 21.15 & -21.42 & -18.77 \\
\hline $4 \mathrm{q}$ & -2.58 & 5.31 & 61.62 & -12.80 & -4.24 & 20.27 & 7.88 & 22.24 \\
\hline $8 q$ & 10.28 & -0.58 & 60.24 & -10.36 & -14.09 & 35.34 & 27.30 & 65.33 \\
\hline $12 q$ & 37.32 & 20.84 & 44.48 & 34.49 & 5.11 & 41.32 & 29.87 & 74.12 \\
\hline
\end{tabular}

Notes: All models are estimated starting in 1997:Q1. The forecast period is 2010:Q2 to 2016:Q4. All models are re-estimated each quarter. ABM results are obtained as an average over 500 Monte Carlo simulations.

the AR(1) overall turns out to perform better than the AR models of lag orders two and three. Regarding forecasts of GDP growth and inflation, the performance of the ABM, DSGE, and AR(1) model is relatively similar, with the DSGE model applying more filtering than the other models. Both the ABM and the DSGE models show their strengths in terms of forecasts of household consumption, and especially investment, as theory-driven economic models. Both these models explicitly incorporate the behavior of different agents in the economy, as well as constraints due to the consistency requirements of national accounting - for example, they take into consideration that household consumption and investment are major components of GDP. While the improvement for household consumption is clearly noticeable-especially for the DSGE model, whose sophisticated assumptions about agents' behavior seem to make the greatest difference for this variable - there is also quite a pronounced improvement for investment. For investment forecasts, both the ABM and the DSGE model clearly do better than the AR(1) model, especially for longer horizons.

\subsection{Conditional forecasts}

As a further validation exercise, we test the conditional forecast performance of the different model classes (ABM, DSGE, and AR models). In this exercise, we generate forecasts from the three models conditional on the paths realized for the following three variables: real exports, real imports, and real government consumption (as government consumption is an exogenous shock in the DSGE model, conditional forecasts in the DSGE models are subject to exogenous paths for exports and imports). The exogenous predictors can be included in the AR model and the ABM in a straightforward way; for details, see Appendix D. Conditional forecasts in the DSGE model are achieved by controlling certain shocks to match the predetermined paths of the exogenous predictors. In particular, we control the 
Table 3: Out-of-sample forecast performance in comparison to DSGE model

\begin{tabular}{|c|c|c|c|c|}
\hline & GDP growth & Inflation & Household consumption & Investment \\
\hline $\operatorname{AR}(1)$ & \multicolumn{4}{|c|}{ RMSE-statistic for different forecast horizons } \\
\hline $1 \mathrm{q}$ & 0.62 & 0.37 & 0.66 & 1.40 \\
\hline $2 q$ & 0.51 & 0.36 & 0.93 & 2.21 \\
\hline $4 q$ & 0.48 & 0.34 & 1.32 & 3.50 \\
\hline $8 \mathrm{q}$ & 0.36 & 0.37 & 1.57 & 4.34 \\
\hline $12 q$ & 0.29 & 0.33 & 2.00 & 6.09 \\
\hline $\operatorname{AR}(2)$ & \multicolumn{4}{|c|}{ Percentage gains (+) or losses $(-)$ relative to $A R(1)$ model } \\
\hline $1 \mathrm{q}$ & -15.78 & 0.40 & -1.07 & -3.41 \\
\hline $2 q$ & -4.89 & 2.11 & -0.47 & 0.00 \\
\hline $4 q$ & -3.62 & 0.30 & 1.08 & 2.24 \\
\hline $8 \mathrm{q}$ & -1.47 & -0.18 & -3.25 & 7.21 \\
\hline $12 q$ & -5.03 & -0.08 & -3.49 & 7.78 \\
\hline $\operatorname{AR}(3)$ & \multicolumn{4}{|c|}{ Percentage gains (+) or losses (-) relative to $A R(1)$ model } \\
\hline $1 \mathrm{q}$ & -13.25 & 0.74 & -5.25 & -5.42 \\
\hline $2 q$ & -3.74 & 1.29 & -3.87 & -1.80 \\
\hline $4 \mathrm{q}$ & -5.87 & -2.11 & 1.63 & 2.45 \\
\hline $8 \mathrm{q}$ & -4.22 & 0.55 & -5.44 & 8.10 \\
\hline $12 q$ & -13.01 & 0.19 & -6.88 & 8.83 \\
\hline DSGE & \multicolumn{4}{|c|}{ Percentage gains $(+)$ or losses $(-)$ relative to $A R(1)$ model } \\
\hline $1 \mathrm{q}$ & -8.24 & 5.32 & 7.88 & 22.07 \\
\hline $2 q$ & -0.14 & -19.97 & 7.23 & 31.40 \\
\hline $4 q$ & 17.66 & -8.18 & 25.25 & 37.88 \\
\hline $8 \mathrm{q}$ & 12.23 & 1.66 & 10.88 & 36.12 \\
\hline $12 q$ & -14.36 & -4.30 & 7.12 & 50.78 \\
\hline $\mathrm{ABM}$ & \multicolumn{4}{|c|}{ Percentage gains $(+)$ or losses $(-)$ relative to $A R(1)$ model } \\
\hline $1 q$ & -4.79 & 0.04 & 0.47 & 8.89 \\
\hline $2 q$ & -4.16 & -1.20 & 0.49 & 10.16 \\
\hline $4 \mathrm{q}$ & -1.44 & 1.13 & 7.08 & 9.23 \\
\hline $8 \mathrm{q}$ & 4.66 & 0.42 & 21.61 & 29.77 \\
\hline $12 q$ & -5.56 & -0.30 & 29.79 & 39.59 \\
\hline
\end{tabular}

Notes: All models are estimated starting in 1997:Q1. The forecast period is 2010:Q2 to 2016:Q4. All models are re-estimated each quarter. ABM results are obtained as an average over 500 Monte Carlo simulations.

consumption preference shocks for Austria and the EA, which are the major drivers for Austrian exports and imports in the two-country setting of the DSGE model; see Appendix F.12 for details. Again, we use the period 1997:Q12010:Q1 to initially estimate our models. We then forecast real GDP growth, inflation, and nominal household consumption and investment from 2010:Q2 to 2016:Q4, with the models being re-estimated every quarter. Thus, together with the real exports, real imports, and real government consumption, we account for all main components of GDP.

Table 4 shows that the forecast performance of the ABM and AR models improves pronouncedly for GDP growth and household consumption and investment when exogenous predictors are included. Similar to the forecast exercise above, the ARX(1) turns out overall to perform better than the ARX models of lag orders two and three. Again, the performance of the ABM (conditional forecasts) and ARX(1) model is relatively similar for GDP growth and inflation. However, compared to the unconditional case, the ABM as a theory-driven model does not better in forecasting household consumption and investment. The forecast performance of the DSGE model (conditional forecasts) clearly deteriorates for all variables for longer horizons. This is for methodological reasons, that is, the need to control exogenous shocks such that the exogenous paths of the predictors are matched in the DSGE model. This clearly has the most pronounced implications for the forecast of household consumption in the DSGE model, where forecast 
Table 4: Conditional forecast performance

\begin{tabular}{|c|c|c|c|c|}
\hline & GDP growth & Inflation & Household consumption & Investment \\
\hline $\operatorname{ARX}(1)$ & \multicolumn{4}{|c|}{ RMSE-statistic for different forecast horizons } \\
\hline $1 \mathrm{q}$ & 0.34 & 0.38 & 0.58 & 1.11 \\
\hline $2 q$ & 0.39 & 0.34 & 0.75 & 1.49 \\
\hline $4 \mathrm{q}$ & 0.38 & 0.35 & 0.96 & 1.25 \\
\hline $8 \mathrm{q}$ & 0.32 & 0.35 & 1.22 & 1.07 \\
\hline $12 q$ & 0.23 & 0.41 & 1.43 & 1.35 \\
\hline $\operatorname{ARX}(2)$ & \multicolumn{4}{|c|}{ Percentage gains (+) or losses (-) relative to $A R X(1)$ model } \\
\hline $1 \mathrm{q}$ & -12.89 & -0.35 & -1.26 & 3.55 \\
\hline $2 q$ & -3.65 & 1.93 & -1.20 & 3.19 \\
\hline $4 q$ & 3.50 & -0.28 & -1.99 & -7.12 \\
\hline $8 \mathrm{q}$ & 4.71 & 0.83 & -3.30 & 1.16 \\
\hline $12 \mathrm{q}$ & 3.33 & 2.24 & -3.14 & -2.07 \\
\hline $\operatorname{ARX}(3)$ & \multicolumn{4}{|c|}{ Percentage gains (+) or losses (-) relative to $A R X(1)$ model } \\
\hline $1 \mathrm{q}$ & -12.39 & -2.37 & -5.92 & 3.23 \\
\hline $2 q$ & -5.16 & 1.11 & -5.68 & 2.35 \\
\hline $4 \mathrm{q}$ & 3.41 & -0.32 & -4.99 & -16.52 \\
\hline $8 \mathrm{q}$ & 2.18 & 0.76 & -7.55 & -0.06 \\
\hline $12 \mathrm{q}$ & 0.93 & 2.39 & -8.47 & -7.14 \\
\hline DSGE (conditional forecasts) & \multicolumn{4}{|c|}{ Percentage gains $(+)$ or losses $(-)$ relative to $A R X(1)$ model } \\
\hline $1 \mathrm{q}$ & -57.40 & 1.38 & -200.30 & -1.07 \\
\hline $2 q$ & -5.42 & -17.13 & -196.65 & -3.48 \\
\hline $4 \mathrm{q}$ & 0.79 & -12.44 & -242.16 & -86.18 \\
\hline $8 \mathrm{q}$ & -73.70 & -7.67 & -287.57 & -117.54 \\
\hline $12 q$ & -132.96 & -33.89 & -354.04 & -71.94 \\
\hline ABM (conditional forecasts) & \multicolumn{4}{|c|}{ Percentage gains (+) or losses $(-)$ relative to ARX(1) model } \\
\hline $1 \mathrm{q}$ & 0.57 & -0.95 & -22.13 & -1.80 \\
\hline $2 q$ & 8.40 & -1.06 & -8.41 & -11.77 \\
\hline $4 q$ & 2.44 & 0.78 & -12.79 & -107.13 \\
\hline $8 q$ & 12.38 & -0.97 & 18.80 & -142.31 \\
\hline $12 q$ & 5.65 & -1.56 & 6.64 & -120.54 \\
\hline
\end{tabular}

Notes: All models are estimated starting in 1997:Q1. The forecast period is 2010:Q2 to 2016:Q4. All models are re-estimated each quarter. ABM results are obtained as an average over 500 Monte Carlo simulations.

errors increase to a large extent when compared to the ARX(1) model.

Figures 1, 2 and 3 provide a graphical comparison between conditional forecasts with the ABM and results from an ARX(1) model, and between conditional forecasts with the DSGE model and actual time series data reported by Eurostat. Figure 1 shows aggregate GDP growth and inflation (measured by GDP deflator) rates-annually (top) and quarterly (bottom). One can see at first glance that the ABM tracks the data very well for GDP growth (left panels). For annualized (top left) and quarterly (bottom left) model results, almost all data points are within the 90 percent confidence interval (gray shaded area) — except for two outliers (2011:Q1,2012:Q2), where the Austrian growth rate either picked up quite sharply (2011:Q1) or decreased considerably, despite an upward trend before (2012:Q2). It is especially interesting to note how the ABM catches trends in the data somewhat better than the ARX(1) model. In particular, the ABM reacts directly to a fall in exports in 2013:Q1 (see Figure 3)—which reflects a slowdown in economic growth for some of Austria's European trading partners during the European debt crisis- that drags down GDP growth in the ABM. In contrast to this, the ARX(1) model simply extrapolates the past trend into the future. Similar to the ABM, the DSGE in a conditional forecasting setup seems to catch upward and downward trends in the data quite well, but tends to "overreact" by taking the trend too far. This certainly deteriorates the forecast performance of the DSGE, and is most probably connected to the way in which controlling the shocks for the conditional forecasting 

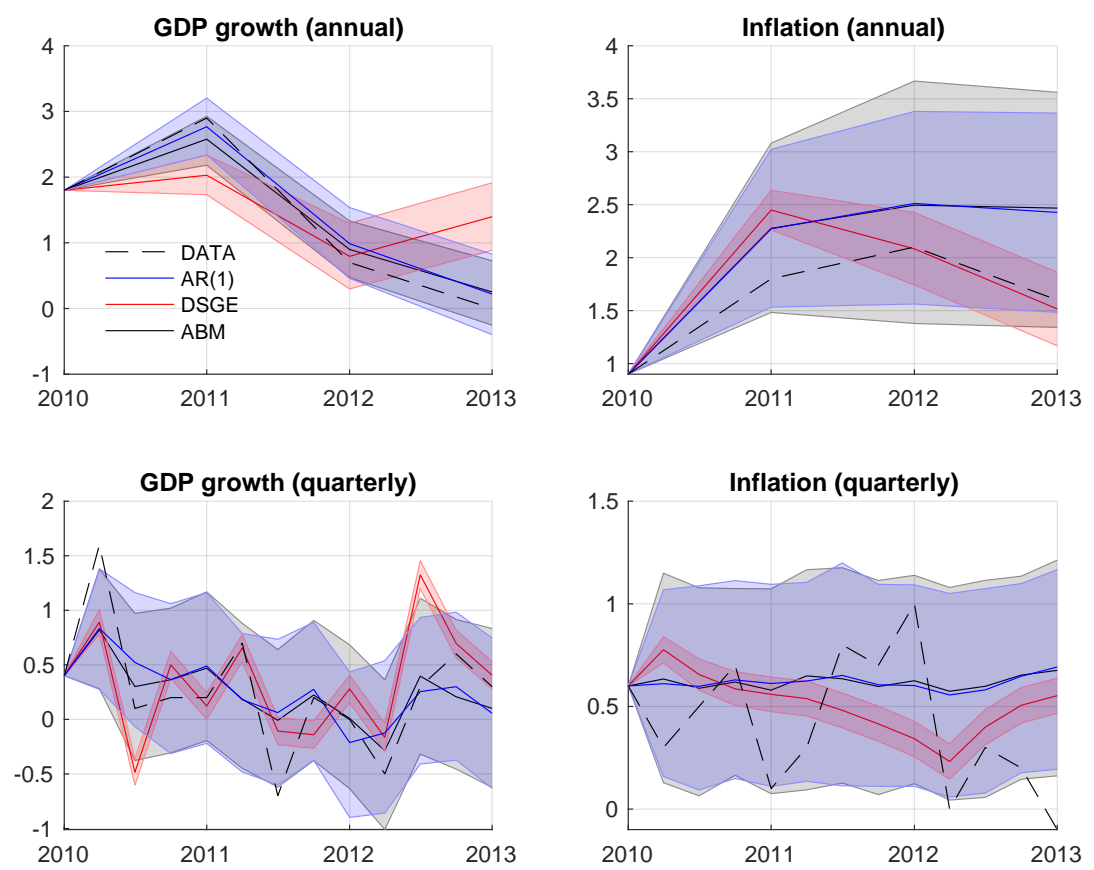

Figure 1: Forecast performance from 2011:Q1-2013:Q4. ABM conditional forecasts (black line), DSGE conditional forecasts (red line), ARX(1) forecasts (blue line) and observed Eurostat data for Austria (dashed line). Top figures show growth and inflation on an annualized basis; bottom figures depict quarterly growth and inflation rates. A 90 percent confidence interval is plotted around the mean trajectory. Model results are obtained as an average over 500 Monte Carlo simulations.

procedure influences the mechanics of the DSGE model.

A similar picture arises when the conditional forecasts for the main macroeconomic aggregates in levels (GDP, household consumption, investment) of the ABM are compared to the other models; see Figures 2 (annual) and 3 (quarterly). Looking at GDP at annual levels (top left in Figure 2) and quarterly levels (top left in Figure 3), it is evident that the ABM closely follows the data, as do the growth rates in Figure 1, and that all data points, except for the two outliers referred to above, are within the confidence interval. The ARX(1) model delivers a comparable forecasting performance, but smooths the trends more than the ABM does. The DSGE model at first consistently underestimates both annual and quarterly GDP levels, and then overestimates the upward trend starting in 2013:Q2. Again, the influence on quarterly GDP of the drop in exports in 2013:Q1, due to overall economic developments in Europe during the European debt crisis (Figure 3, bottom middle panel), remains visible, and the ABM captures this trend quite well. Both the ABM and the ARX(1) model seem to smooth out the changes in household consumption to approximately match the average trend, with the ABM being somewhat closer to the data. Again, the DSGE model seems to follow the trends in the data quite accurately, but consistently overestimates the level, which might be responsible for the overall poor forecasting performance of the DSGE model for household consumption. As to be expected, the volatility of investment in the data is the highest of all these variables. The ARX(1) smoothes this volatility out on average, and is thus very successful in tracking both annual and quarterly investment data (Figures 2 and 3, top right). The DSGE model, while catching the initial trend in the data, overshoots in its forecast at the end, whereas the ABM consistently underestimates investment levels.

\subsection{Components of GDP}

The previous section has demonstrated that the size and detailed structure of the ABM tend to improve its forecasting performance compared to standard models. Another important advantage of our approach is the possibility of breaking down simulation results in a stock-flow consistent way according to national accounting (ESA). In particular, we are able to report results for all economic activities depicted in this model consistent with national accounting rules, in addition to relating them to the main macroeconomic aggregates. Most importantly, for all simulations and fore- 

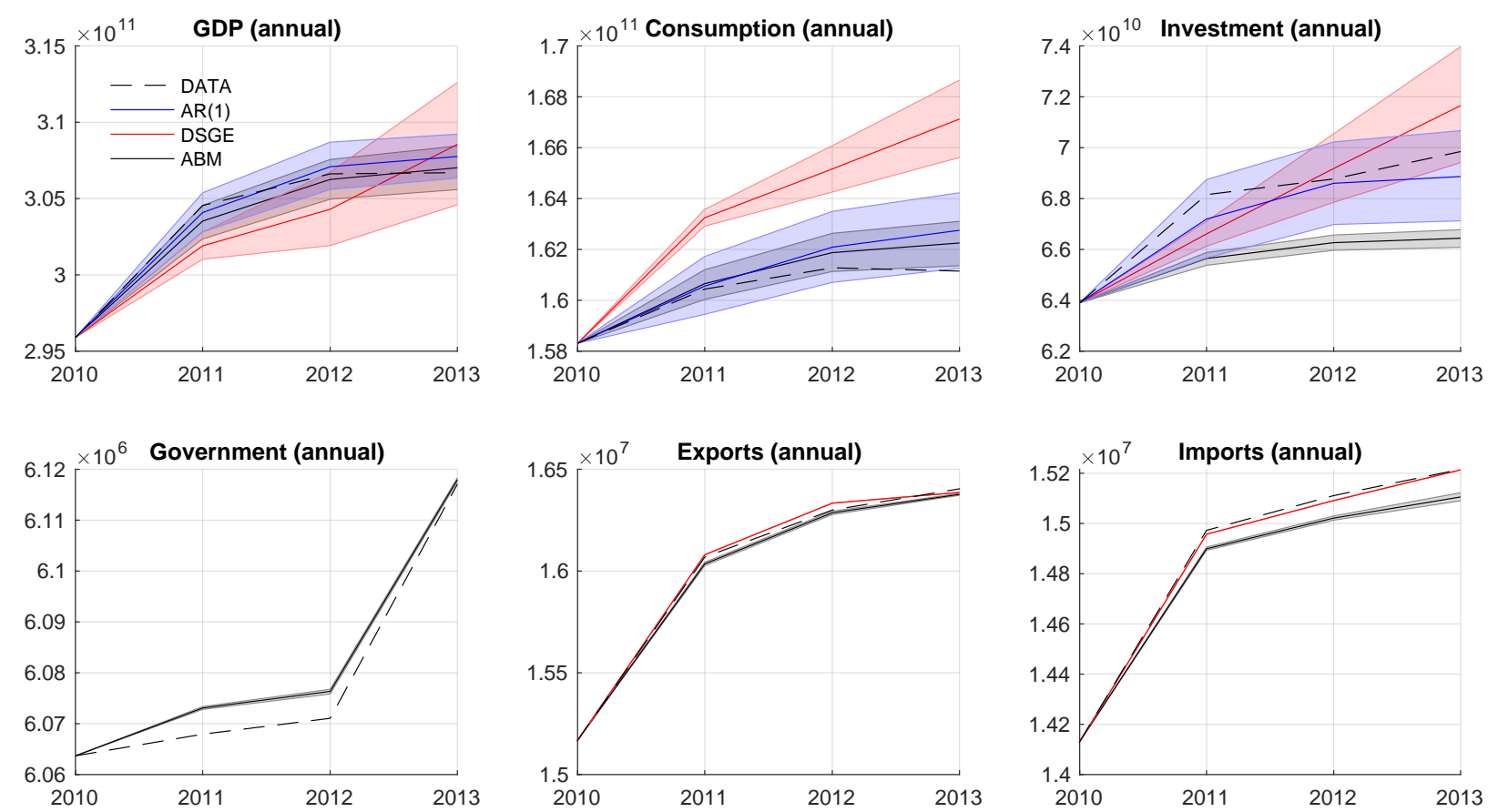

Figure 2: Forecast performance from 2011:Q1-2013:Q4. GDP (annually, in euro and in real terms with base year 2010), household consumption (annually, in euro and in real terms with base year 2010), fixed investment (annually, in euro and in real terms with base year 2010), government consumption (annually, in euro and in real terms with base year 2010), exports (annually, in euro and in real terms with base year 2010), and imports (annually, in euro and in real terms with base year 2010). ABM conditional forecasts (black line), DSGE conditional forecasts (red line), $\operatorname{ARX}(1)$ forecasts (blue line), and observed Eurostat data for Austria (dashed line). A 90 percent confidence interval is plotted around the mean trajectory. Model results are obtained as an average over 500 Monte Carlo simulations.

casts, our model preserves the principle of double-entry bookkeeping. This implies that all financial flows within the model are made explicit and are recorded as an outflow of money (use of funds) for one agent in the model in relation to a certain economic activity, and as an inflow of money (source of funds) for another agent. In principle, we can thus consistently report on the economic activity of every single agent at the micro-level. A more informative aggregation is on a meso-level according to the NACE/CPA classification into 64 industries, which encompasses many variables. This multitude of results consists of all components of GDP on a sectoral level: among others, wages, operating surplus, investment, taxes and subsidies of different kinds, intermediate inputs, exports, imports, final consumption of different agents (household, government), employment, and also economic indicators such as productivity coefficients for capital, labor, and intermediate inputs. Probably the simplest example indicative of this model structure is that it breaks down simulation results into the larger components of GDP.

Figure 4 is a graphical representation of the conditional ABM forecasts from Section 3.3 decomposed for these larger components of GDP. The components are shown according to the production, income, and expenditure approaches to determining GDP, which are defined within the framework of our model along ESA lines, as laid out in equation (Appendix E.1). With the fine-grained detail incorporated into our model, we can demonstrate how the development of macroeconomic aggregates such as GDP relates to trends in different industry sectors (production approach), the distribution of national income (income approach), and the composition of final uses in the economy (expenditure approach). Here, the colored fields indicate ABM simulation results for the different components of GDP, while the dashed line refers to the values reported in the data. Our results show that ABM forecasts of these components of GDP, where the ABM does not predict major structural changes for the Austrian economy, correspond closely to the developments in the data. 

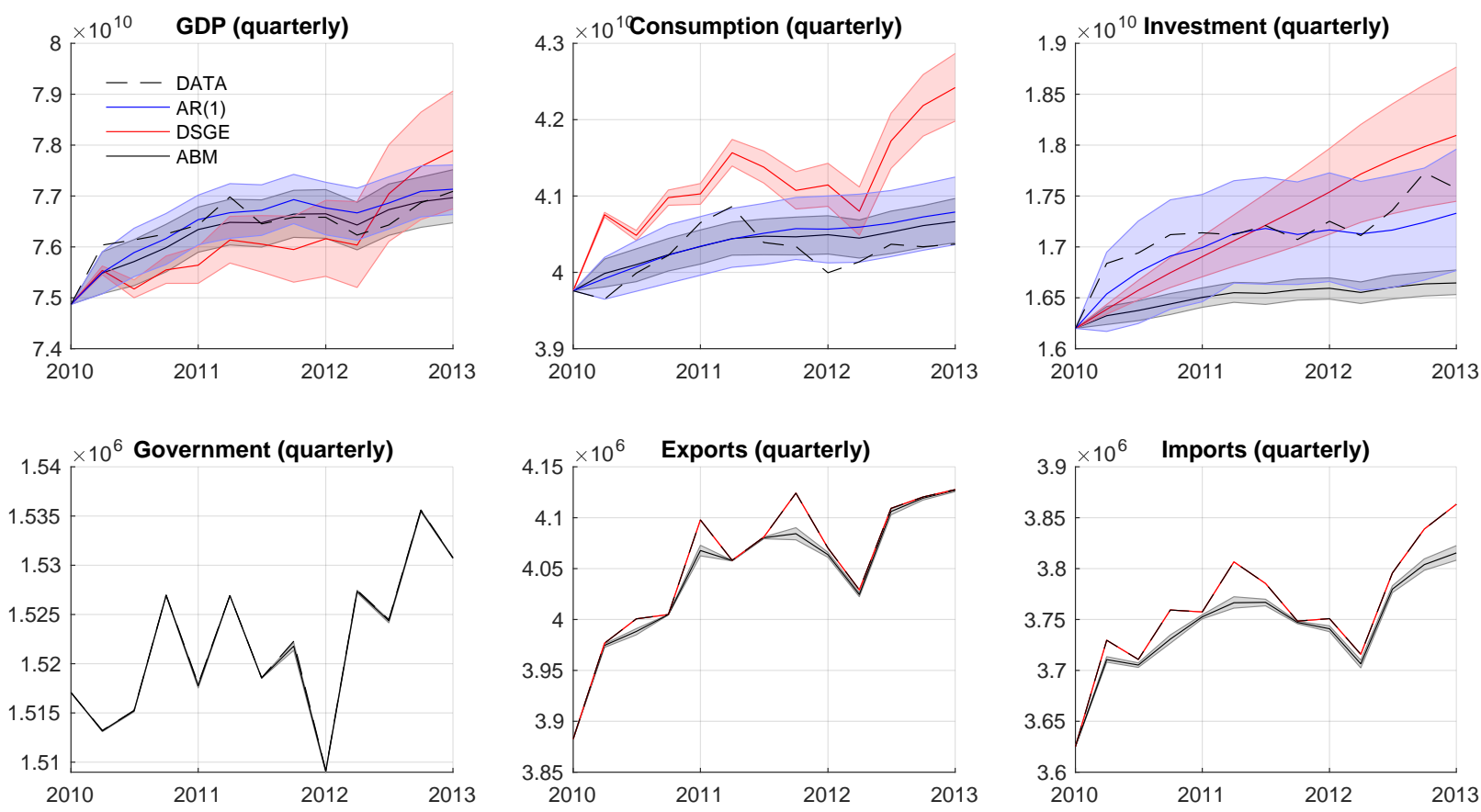

Figure 3: Forecast performance from 2011:Q1-2013:Q4. GDP (quarterly, in euro and in real terms with base year 2010), household consumption (quarterly, in euro and in real terms with base year 2010), fixed investment (quarterly, in euro and in real terms with base year 2010), government consumption (quarterly, in euro and in real terms with base year 2010), exports (quarterly, in euro and in real terms with base year 2010), and imports (quarterly, in euro and in real terms with base year 2010). ABM conditional forecasts (black line), DSGE conditional forecasts (red line), ARX(1) forecasts (blue line), and observed Eurostat data for Austria (dashed line). A 90 percent confidence interval is plotted around the mean trajectory. Model results are obtained as an average over 500 Monte Carlo simulations.

\subsection{Sectoral decomposition}

The detailed structure of the ABM allows macroeconomic forecasts to be broken down into varying levels of detail, offering insights into the composition of overall macroeconomic trends. Figure 5 shows ABM forecasts for gross value added (GVA) generated within the industry sectors in comparison with the data for the conditional forecasting setup (see Table B.8 for a detailed list of industry sectors). ${ }^{15}$ The projections of the ABM capture the trends in larger sectors particularly well. Most notably, trends in major sectors such as construction and construction works (F), retail trade (G47), accommodation and food services (I), or land transport services (H49) are matched by the ABM in close relation to the data. These sectors tend to follow overall trends in GDP to a large degree, which is one explanation for the good forecasting performance of the ABM for these sectors.

Some of the more pronounced differences are due to sector-specific features such as sizeable export-induced exogenous shocks or an unusually low number of firms in the sector, which can cause sectors to deviate from aggregate macroeconomic trends. This is especially true for smaller sectors, where deviations of ABM forecasts are higher in relative terms. This is especially relevant to products of agriculture, hunting and related services (A01), mining and quarrying (B), air transport services (H51), motion picture, video, and television program services (J59), and telecommunication services (J61), among others. For manufacturing sectors, which are potentially influenced more by trends exogenous to the ABM, such as the structure of Austrian exports, the forecasts are within an acceptable range, which is often also the case for larger sectors. Indicative examples for such sectors are wood and products of wood (C16), fabricated metal products (C25), and machinery and equipment (C28).

\footnotetext{
${ }^{15}$ Note the varying scales for the sectors of different sizes.
} 

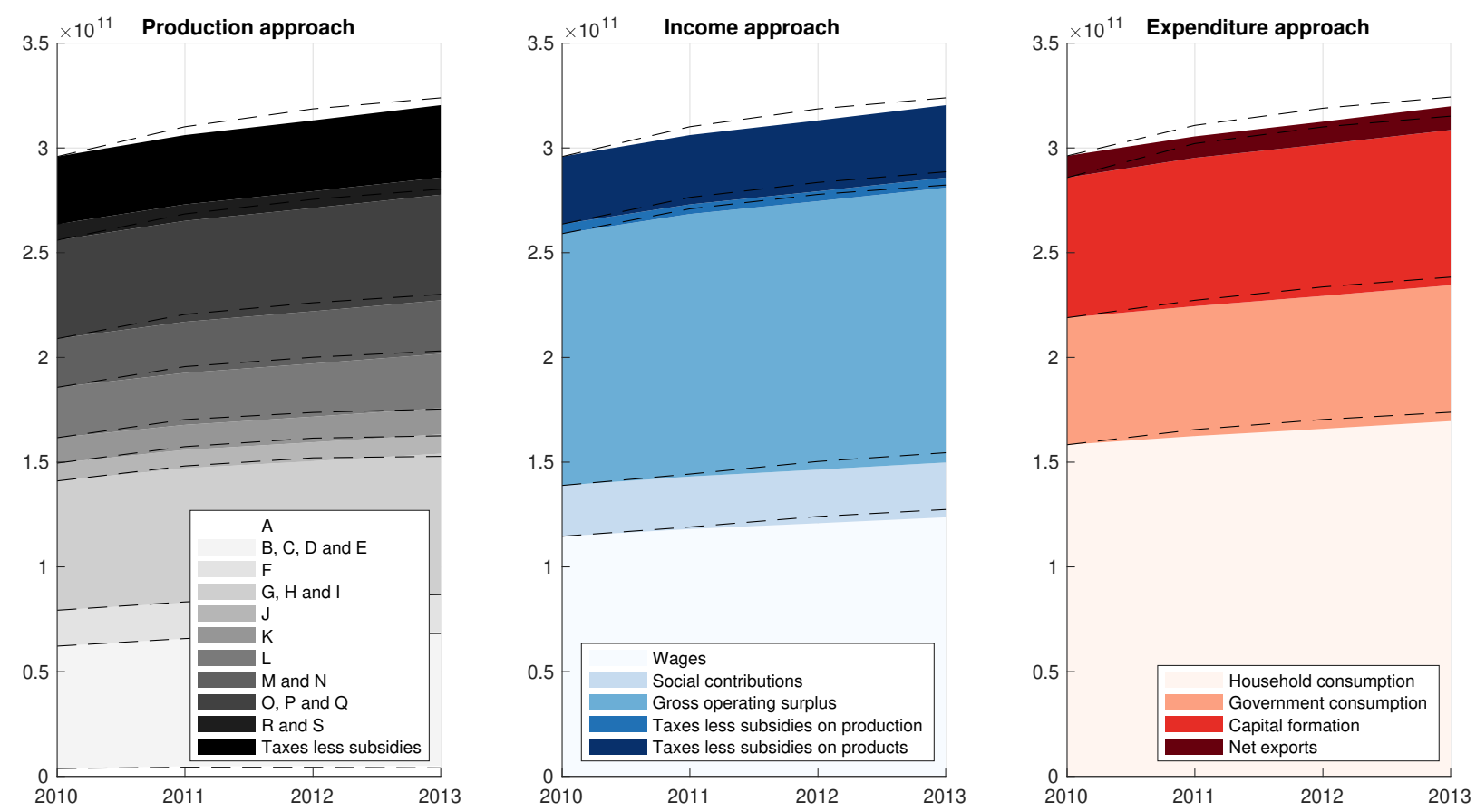

Figure 4: Composition of GDP according to production, income and expenditure approaches. The colored areas indicate ABM simulation results for one selected time period (2011:Q1-2013:Q4), again as an average over 500 Monte Carlo simulations. The dashed line shows the corresponding values obtained from the data.

\section{Conclusion}

We have developed an ABM of a small open economy that fits micro and macro data from national accounts, sector accounts, input-output tables, government statistics, census data, and business demography data. Although the model is very detailed, it is able to compete with standard VAR, AR, and DSGE models in out-of-sample forecasting. An advantage of our detailed ABM is that it allows for a breakdown of the forecasts of aggregate variables in a stock-flow consistent manner to generate forecasts of disaggregated sectoral variables and the main components of GDP.

The ABM is tailor-made for the small open economy of Austria, but the model can easily be adapted to other economies of larger countries such as the UK and the US or to larger regions such as the EU. Such extensions and applications are currently being explored. Our detailed ABM can also be used for stress-testing exercises or for predicting the effect of changes in monetary, fiscal, and other macroeconomic policies.

Our model is the first ABM that can compete in out-of-sample forecasting of macro variables. A grand challenge for future work would be a "big data ABM" research program to develop ABMs for larger economies and regions based on available micro and macro data to eventually monitor the macro economy in real time on supercomputers. Such detailed "big data ABMs" have the potential for improved macro forecasting and more reliable policy scenario analysis.

\section{Acknowledgments}

This project builds upon the results of the EU FP7 project CRISIS and we are grateful for the inspiration and vision from J. Doyne Farmer, who was the scientific coordinator of that project. We would like to thank the following people: Jakob Grazzini for providing us with the code of the model developed in Assenza et al. (2015); Katrin Rabitsch for providing us with the codes of an improved version of the DSGE model developed in Breuss and Rabitsch (2009), and for her advice and assistance; Tolga Özden for his help with the estimation of the DSGE model; Stefan Thurner for his contribution to early discussions in the initiation of the ideas incorporated and reported in the paper manuscript; 

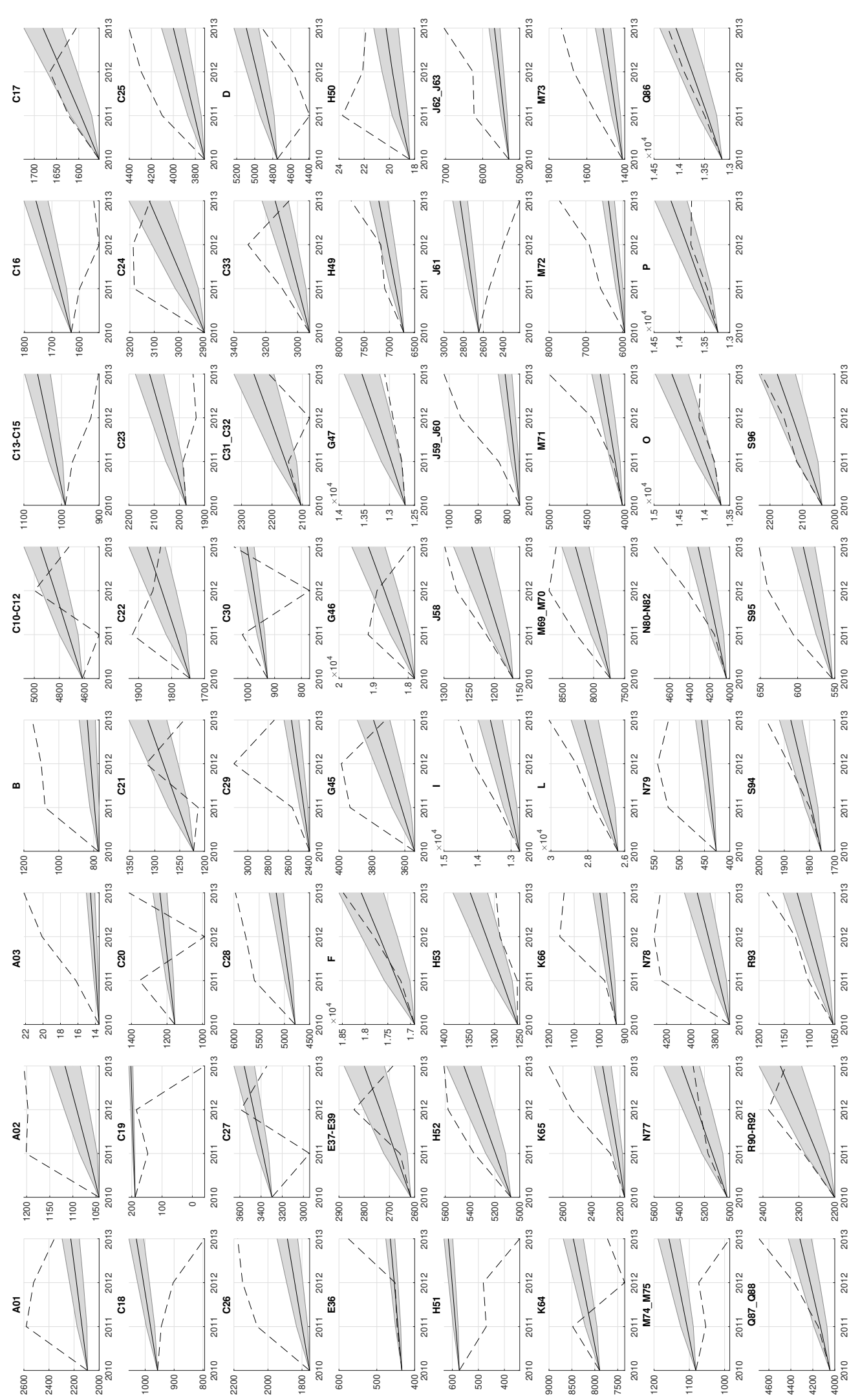
researchers at the Institute for Advanced Studies Vienna and at CeNDEF; as well as conference and seminar participants and discussants at the International Conference on Computing in Economics and Finance (CEF) 2017 and 2018 , the Second Conference on Network Models and stress testing for financial stability at Banco de México 2017, the 11 ${ }^{\text {th }}$ Workshop on Economic Complexity at the SKEMA Business 2017, the $1^{\text {st }}$ Vienna Workshop on Economic Forecasting 2018 at IHS, the March 2018 DNB Lunchseminar at the De Nederlandsche Bank; and, in particular, Jesus Crespo Cuaresma, Cees Diks, Marco van der Leij, Mauro Napoletano, Helmut Hofer, Michael Reiter, and Leopold Sögner for stimulating discussions and valuable comments. Michael Miess acknowledges funding from IIASA through the Systems Analysis Forum Project "A big-data approach to systemic risk in very large financial networks", the Austrian Research Promotion Agency FFG under grant number 857136, and from the Austrian Central Bank (Österreichische Nationalbank, OeNB) Anniversary Fund (Jubiläumsfonds) under grant number 17400. Sebastian Poledna acknowledges funding from IIASA through the Cross-cutting Project "Systemic Risk and Network Dynamics" and a research fellowship at the Institute for Advanced Study of the University of Amsterdam.

\section{Author contributions}

SP developed the model. SP implemented and estimated the model, and performed the simulations. SP and MM gathered and processed the data for the model. SP, MM, and $\mathrm{CH}$ analyzed simulation results and wrote the manuscript. SP and MM wrote the Appendix on the ABM. MM wrote the Appendix on the DSGE model.

\section{References}

An, S., Schorfheide, F., 2007. Baysian analysis of dsge models. Econometric Reviews Vol. 26, Iss. 2-4, $113-172$.

Arthur, W. B., Holland, J. H., LeBaron, B., Palmer, R., Tayler, P., 1997. Asset pricing under endogenous expectations in an artificial stock market. In: Arthur, W. B., Durlauf, S., Lane, D. (Eds.), The Economy as an Evolving Complex System II. Addison-Wesley, Reading, MA, U.S.A.

Ashraf, Q., Gershman, B., Howitt, P., 2017. Banks, market organization, and macroeconomic performance: an agent-based computational analysis. Journal of Economic Behavior \& Organization 135, 143-180.

Assenza, T., Delli Gatti, D., Grazzini, J., 2015. Emergent dynamics of a macroeconomic agent based model with capital and credit. Journal of Economic Dynamics and Control 50, 5-28.

Axtell, R. L., 2001. Zipf distribution of us firm sizes. Science 293 (5536), 1818-1820.

Axtell, R. L., 2018. Endogenous firm dynamics and labor flows via heterogeneous agents. In: Hommes, C., LeBaron, B. (Eds.), Handbook of Computational Economics. Vol. 4 of Handbook of Computational Economics. Elsevier, pp. $157-213$.

URL http://www.sciencedirect.com/science/article/pii/S1574002118300133

Baptista, R., Farmer, J. D., Hinterschweiger, M., Low, K., Tang, D., Uluc, A., 2016. Macroprudential policy in an agent-based model of the uk housing market. Staff Working Paper 619, Bank of England.

Blanchard, O., 2016. Do dsge models have a future? PIIE Policy Brief PB 16-11.

Blattner, T. S., Margaritov, E., 2010. Towards a robust monetary policy rule for the euro area. ECB Working Paper No. 1210.

Brayton, F., Mauskopf, E., Reifschneider, D., Tinsley, P., Williams, J., Doyle, B., Sumner, S., 1997. The role of expectations in the frb/us macroeconomic model. Federal Reserve Bulletin April 1997.

Breuss, F., Rabitsch, K., 2009. An estimated two-country dsge model auf austria and the euro area. Empirica 36, $123-158$.

Brunnermeier, M. K., Eisenbach, T. M., Sannikov, Y., 2013. Macroeconomics with financial frictions: A survey. In: Advances in Economics and Econometrics, Tenth World Congress of the Econometric Society. New York: Cambridge University Press.

Calvo, G. A., 1983. Staggered prices in a utility-maximizing framework. Journal of monetary Economics 12 (3), 383-398.

Canova, F., Sala, L., 2009. Back to square one: Identification issues in dsge models. Journal of Monetary Economics 56, $431-449$.

Christiano, L. J., Eichenbaum, M. S., Trabandt, M., 2018. On DSGE models. Journal of Economic Perspectives 32 (3), $113-40$.

Christiano, L. J., Trabandt, M., Walentin, K., 2010. Dsge models for monetary policy analysis. NBER Working Paper 16074.

Cincotti, S., Raberto, M., Teglio, A., 2010. Credit money and macroeconomic instability in the agent-based model and simulator eurace. Economics: The Open-Access, Open-Assessment E-Journal 4.

Colander, D., Goldberg, M., Haas, A., Juselius, K., Kirman, A., Lux, T., Sloth, B., 2009. The financial crisis and the systemic failure of the economics profession. Critical Review 21:2-3, 249 - 267.

Colander, D., Howitt, P., Kirman, A., Leijonhufvud, A., Mehrling, P. G., 2008. Beyond dsge models: Toward an empirically based macroeconomics. American Economic Review, Papers and Proceedings Vol. 98 No. 2, 236-240.

Dawid, H., Delli Gatti, D., 2018. Agent-based macroeconomics. In: Hommes, C., LeBaron, B. (Eds.), Handbook of Computational Economics. Vol. 4 of Handbook of Computational Economics. Elsevier, pp. 63 - 156.

URL http://www.sciencedirect.com/science/article/pii/S1574002118300066

Dawid, H., Harting, P., van der Hoog, S., Neugart, M., Nov 2018. Macroeconomics with heterogeneous agent models: fostering transparency, reproducibility and replication. Journal of Evolutionary Economics. URL https : //doi .org/10.1007/s00191-018-0594-0

Delli Gatti, D., Desiderio, S., Gaffeo, E., Cirillo, P., Gallegati, M., 2011. Macroeconomics from the Bottom-up. Springer Milan.

Dosi, G., Napoletano, M., Roventini, A., Treibich, T., 2017. Micro and macro policies in the keynes+schumpeter evolutionary models. Journal of Evolutionary Economics 27, 63 - 90. 
Eurostat, 2013. European System of Accounts: ESA 2010. EDC collection. Publications Office of the European Union.

Evans, G. W., Honkapohja, S., 2001. Learning and expectations in macroeconomics. Princeton University Press.

Fagiolo, G., Roventini, A., 2017. Macroeconomic policy in dsge and agent-based models redux: New developments and challenges ahead. Journal of Artificial Societies and Social Simulation 20(1).

Farmer, J. D., Foley, D., 2009. The economy needs agent-based modelling. Nature 460, 685 - 686.

Fernandez-Villaverde, J., 2010. The econometrics of dsge models. J. SERIEs Volume 1, Issue 1, 3-49.

Freeman, R. B., 1998. War of the models: Which labour market institutions for the 21st century? Labour Economics 5, 1-24.

Geanakoplos, J., Axtell, R. L., Farmer, J. D., Howitt, P., Conlee, B., Goldstein, J., Hendrey, M., Palmer, N. M., Yang, C.-Y., 2012. Measuring system risk: Getting at systemic risk via an agent-based model of the housing market. American Economic Review: Papers and Proceedings 102(3), 53-58.

Gintis, H., 2007. The dynamics of general equilibrium. The Economic Journal 117 (October), 1280 - 1309.

Haldane, A. G., Turrell, A. E., 2018. An interdisciplinary model for macroeconomics. Oxford Review of Economic Policy 34 (1-2), $219-251$. URL http://dx.doi.org/10.1093/oxrep/grx051

Hommes, C., 2018. Behavioral \& experimental macroeconomics and policy analysis: a complex systems approach. Journal of Economic LiteratureForthcoming.

URL https : //ideas.repec.org/p/ecb/ecbwps/20182201.html

Hommes, C., Mavromatis, K., Özden, T., Zhu, M., 2019. Behavioral learning equilibria in the new keynesian model. Working Paper Dutch Central Bank.

Hommes, C., Zhu, M., 2014. Behavioral learning equilibria. Journal of Economic Theory 150, 778-814.

Ijiri, Y., Simon, H. A., 1977. Skew distributions and the sizes of business firms. North-Holland.

Kirman, A., 2010. The economic crisis is a crisis for economic theory. CESifo Economic Studies 56 (4), $498-535$.

Klimek, P., Poledna, S., Farmer, J. D., Thurner, S., 2015. To bail-out or to bail-in? answers from an agent-based model. Journal of Economic Dynamics and Control 50, 144-154.

Krugman, P., 2011. The profession and the crisis. Eastern Economic Journal 37, 307 - 312.

LeBaron, B., Tesfatsion, L., 2008. Modeling macroeconomies as open-ended dynamic systems of interacting agents. AER Papers and Proceedings Vol. 98, No. 2, $246-250$.

Leeper, E. M., Zha, T., 2003. Modest policy interventions. Journal of Monetary Economics 50 (8), 1673-1700.

Linde, J., Smets, F., Wouters, R., 2016. Challenges for central banks' macro models. Sveriges Riksbank Working Paper Series 323.

Lux, T., Zwinkels, R. C. J., 2018. Empirical validation of agent-based models. In: Hommes, C., LeBaron, B. (Eds.), Handbook of Computational Economics. Vol. 4 of Handbook of Computational Economics. Elsevier, pp. 437 - 488. URL http://www.sciencedirect.com/science/article/pii/S1574002118300030

Orcutt, G. H., 1957. A new type of socio-economic system. Review of Economics and Statistics 39(2), $116-123$.

Poledna, S., Hochrainer-Stigler, S., Miess, M. G., Klimek, P., Schmelzer, S., Sorger, J., Shchekinova, E., Rovenskaya, E., Linnerooth-Bayer, J., Dieckmann, U., Thurner, S., 2018. When does a disaster become a systemic event? estimating indirect economic losses from natural disasters. arXiv preprint arXiv:1801.09740.

Romer, P., 2016. The trouble with macroeconomcs. The American Economist, Forthcoming.

Schelling, T. C., 1969. Models of segregation. The American Economic Review Vol. 59, No. 2, 488 - 493.

Schmedders, K., Judd, K. L., 2013. Handbook of Computational Economics. Vol. 3 of Handbook of Computational Economics. Elsevier. URL https : //books . google.nl/books?id=xDh06L_Psp8C

Schorfheide, F., 2011. Estimation and evaluation of dsge models: Progress and challenges. NBER Working Paper No. 16781.

Seppecher, P., Salle, I. L., Lavoie, M., 2018. What drives markups? evolutionary pricing in an agent-based stock-flow consistent macroeconomic model. Industrial and Corporate Change, dty011.

URL http://dx.doi.org/10.1093/icc/dty011

Sims, C. A., 1980. Macroeconomics and reality. Econometrica: Journal of the Econometric Society, 1-48.

Slobodyan, S., Wouters, R., 2012. Learning in a medium-scale DSGE model with expectations based on small forecasting models. American Economic Journal: Macroeconomics 4 (2), 65-101.

Smets, F., Wouters, R., 2003. An estimated dynamic stochastic general equilibium model of the euro area. Journal of the European Economic Association 1(5), 1123-1175.

Smets, F., Wouters, R., 2004. Forecasting with a bayesian dsge model: an application to the euro area. JCMS: Journal of Common Market Studies $42(4), 841-867$

Smets, F., Wouters, R., 2007. Shocks and frictions in us business cycles: A bayesian dsge approach. American Economic Review Vol. 97, No. 3, $586-606$.

Stiglitz, J. E., 2011. Rethinking macroeconomics: What failed, and how to repair it. Journal of the European Economic Association 9(4), 591-645.

Stiglitz, J. E., 2018. Where modern macroeconomics went wrong. Oxford Review of Economic Policy 34 (1-2), $70-106$.

Stiglitz, J. E., Gallegati, M., 2011. Heterogeneous interacting agent models for understanding monetary economies. Eastern Economic Journal 37 , $6-12$.

Taylor, J., 1993. Discretion versus policy rules in practice. Carnegie-Rochester Conference Series on Public Policy 39, 195 -214.

Trichet, J.-C., 2010. Reflections on the nature of monetary policy non-standard measures and finance theory. Speech for the Opening address at the ECB Central Banking Conference, Frankfurt, 18 November 2010Available at: https://www.ecb.europa.eu/press/key/date/2010/ html/sp101118.en.html [Last accessed Dec. 7, 2018].

Vines, D., Wills, S., 2018. The rebuilding macroeconomic theory project: an analytical assessment. Oxford Review of Economic Policy 34 (1-2), $1-42$.

URL http://dx.doi.org/10.1093/oxrep/grx062

Wolf, S., Fürst, S., Mandel, A., Lass, W., Lincke, D., Pablo-Marti, F., Jaeger, C., 2013. A multi-agent model of several economic regions. Environmental modelling \& software 44, 25-43. 


\section{Appendix A. Details of the agent-based model}

\section{Appendix A.1. Firms}

Each firm $i\left(i=1,2, \ldots, I=\sum_{S} I_{s}\right)$ produces a principal product $g(g=1,2, \ldots, G)$ using labor, capital and intermediate inputs from other firms, and is part of an industry or sector $s(s=1,2, \ldots, S)$, ${ }^{16}$ with a number of $I_{s}$ firms in each industry. Demand for products of firm $i$ is formed on markets for final consumption goods, capital goods as well as material or intermediate input goods.

Firms face fundamental uncertainty regarding the main determinants of their individual success on the market: future sales, market prices, the availability of inputs for the production process (labor, capital, intermediate inputs), wages, cash flow, and their access to external finance, among others, are unknown. This implies that in each period $t,(t=1, \ldots, T)$, the firm has no knowledge about its equilibrium position $\left(\hat{P}_{i}(t), \hat{Q}_{i}^{\mathrm{d}}(t)\right)^{17}$ — given by the equilibrium price $\hat{P}_{i}(t)$ and equilibrium demand $\hat{Q}_{i}^{\mathrm{d}}(t)$-at which all its products would be sold and all consumer demand for its products would be satisfied. Therefore, the firm's future input costs, its capacity to produce given input constraints, as well as the corresponding implications for its cash flow and balance sheet are fundamentally uncertain. Firms only have access to partial information: their current status quo-sales, prices, labor, capital and material input costs, cash flow, etc. - and its past development, as well as selected macro time series such as growth, inflation, or index prices. Consequently, each firm has to form expectations about the future that may not correspond to actual realizations.

\section{Appendix A.1.1. Sales}

Every agent active on a market as a consumer-be it a household $h$ or a government entity $j$ intending to consume, or a firm demanding capital or intermediate input goods - searches for the best bargain, i.e., the lowest price, to satisfy its demand for each of products $g$ it requires. The consumption and supply networks in the model are formed in every period of the model according to a search-and-matching process: in each period, consumers visit a number of randomly chosen firms $i$ that sell the good $g$ in order to ascertain the selling prices. The probability of a firm $i$ being chosen is determined by weighted sampling without replacement. This probability is given (1) by the price charged by firm $i$ according to an exponential distribution, where firms charging a lower price are more likely of being picked, and (2) by the relative size of the firm compared to other firms, so that bigger firms have a higher probability to be picked. The total probability of firm $i$ of being selected in this process is then the average of the latter two probabilities:

$$
\begin{aligned}
p r_{i}^{\text {price }}(t) & =\frac{e^{-P_{i}(t)}}{\sum_{i \in I_{s=g}} e^{-P_{i}(t)}} \\
p r_{i}^{\text {size }}(t) & =\frac{Y_{i}(t)}{\sum_{i \in I_{s=g}} Y_{i}(t)} \\
p r_{i}^{\text {cum }}(t) & =\frac{p r_{i}^{\text {price }}(t)+p r_{i}^{\text {size }}(t)}{2}
\end{aligned}
$$

where $p r_{i}^{\text {price }}(t)$ is the probability of firm $i$ of being selected by a consumer due to its offering price, $p r_{i}^{\text {size }}(t)$ the probability of being chosen due to its size, $p r_{i}^{\mathrm{cum}}(t)$ the cumulative average probability to be picked according to both of these factors, and $Y_{i}(t)$ is the production of goods by firm $i$, see equation (A.12). If the most preferred firm is in short supply, the consumer resorts to the remaining firms, otherwise it satisfies all its demand with the first firm. If an agent does not succeed in satisfying its demand for a specific product $g$, it saves involuntarily. Thus realized demand is the endogenous outcome of the model algorithm, which depends mainly on the random-visiting element, that is, whether the agent acting as a customer finds firms to fulfill its demands.

\footnotetext{
${ }^{16}$ We suppose a one-to-one correspondence between the sets of industries $s$ and products $g$, meaning that the $n$-th sector produces only the $n$-th good, and $S=G$; formally, the correspondence between goods $g$ being produced in sector $s$ would be represented by a unity matrix.

${ }^{17}$ In this manuscript subscripts are used for indices referring to an agent in the model, while superscripts generally indicate a behavioral relation for a variable. For example, a quantity $X$ referring to a firm is denoted by $X_{i}$, expectations for a quantity $X$ are written as $X^{\mathrm{e}}$, or demand for a quantity $X$ is indicated by $X^{\mathrm{d}}$. Additionally, superscripts in capital letters are used to further distinguish related variables, e.g., $\bar{P}^{\mathrm{HH}}(t)$ denotes the consumer price index while $\bar{P}^{\mathrm{CF}}(t)$ is capital formation price index.
} 
Demand $Q_{i}^{\mathrm{d}}(t)$ will be determined by consumers only after the firm has set its price and carried out production $Y_{i}(t)$. It is subject to the search-and-matching mechanism specifying the visiting consumers of firm $i$ :

$$
Q_{i}^{\mathrm{d}}(t) \begin{cases}<S_{i}(t-1)+Y_{i}(t) & \text { if demand from visiting consumers is smaller than supply from firm } i, \text { and } \\ =S_{i}(t-1)+Y_{i}(t) & \text { if demand from visiting consumers exactly matches supply from firm } i, \text { and } \\ >S_{i}(t-1)+Y_{i}(t) & \text { if demand from visiting consumers is larger than supply from firm } i,\end{cases}
$$

where $S_{i}(t-1)$ is the inventory of finished goods. Sales are then the realized demand dependent on the supply available from firm $i$ after the production process has taken place:

$$
Q_{i}(t)=\min \left(S_{i}(t-1)+Y_{i}(t), Q_{i}^{\mathrm{d}}(t)\right) .
$$

The difference between production and sales is excess supply

$$
\Delta S_{i}(t)=Y_{i}(t)-Q_{i}(t),
$$

which is a reflection of firms' expectation error concerning demand. This difference is stored as inventories,

$$
S_{i}(t)=S_{i}(t-1)+\Delta S_{i}(t),
$$

until the next period, where they are supplied on the goods market together with newly produced goods. We do not assume any depreciation of this inventory of finished goods.

\section{Appendix A.1.2. Price Setting and Supply}

Given the importance of accurate forecasts, fundamental uncertainty and imperfect information, firms' have the option of choosing forecasting methods that may closely reflect their economic environment, but that fail to be a complete model of the economy inclusive of every detail. One such forecasting model that meets these requirements is an AR model: this is a simple procedure for projecting past trends into the future, while its forecasting capabilities are comparably high. We therefore assume that an individual firm $i$ in our model uses an autoregressive model to form expectations of demand for its products $\left(Q_{i}^{\mathrm{e}}(t)\right)$ and to determine the selling price $P_{i}(t)$ it will charge. According to these expectations, the firm will set its desired production $\left(Q_{i}^{\mathrm{S}}(t)\right)$ as well as its selling price. The information set that the firm uses for these two decisions consists of the previous period's demand for its product, the expected rate of real economic growth, the expected rate of inflation, its expected future input costs based on past prices and expected inflation, and a unit target for attaining an operating surplus.

The supply choice of firm $i$ is thus made based on the expected rate of real economic growth $\left(\gamma^{\mathrm{e}}(t)\right)$ and the previous period's demand for its product $Q_{i}^{\mathrm{d}}(t-1)$ :

$$
Q_{i}^{\mathrm{s}}(t)=Q_{i}^{\mathrm{e}}(t)=Q_{i}^{\mathrm{d}}(t-1)\left(1+\gamma^{\mathrm{e}}(t)\right) .
$$

Expectations regarding economic growth are formed using an autoregressive model with lag one (AR(1)): ${ }^{18}$

$$
\log \left(Y^{\mathrm{e}}(t)\right)=\alpha^{\mathrm{Y}}(t) \log \left(\sum_{i} Y_{i}(t-1)\right)+\beta^{\mathrm{Y}}(t)+\epsilon^{\mathrm{Y}}(t),
$$

where $\alpha^{\mathrm{Y}}(t), \beta^{\mathrm{Y}}(t)$, and $\epsilon^{\mathrm{Y}}(t)$ are re-estimated every period on the time series of aggregate output of firms $\sum_{i} Y_{i}\left(t^{\prime}\right)$ where $t^{\prime}=-T^{\prime},-T^{\prime}+1,-T^{\prime}+2, \ldots, 0,1,2, \ldots, t-1$. To allow the data to decide on the degree of persistence and cointegration, output is entered in log levels and the growth rate is calculated from the percentage change to the previous period:

$$
\gamma^{\mathrm{e}}(t)=\frac{Y^{\mathrm{e}}(t)}{\sum_{i} Y_{i}(t-1)}-1 .
$$

\footnotetext{
${ }^{18}$ This is comparable to other adaptive mechanisms such as VAR expectations as used in the US Federal Reserve's FRB/US macroeconomic model (Brayton et al., 1997), or expectations according to an exponential moving average (EMA) model as in Assenza et al. (2015).
} 
Price setting by the firm evolves according to the expected rate of inflation $\left(\pi^{\mathrm{e}}(t)\right)$, the cost-structure faced by the firm ("cost-push inflation"), and the unit target for attaining an operating surplus (where again firm $i$ is part of sector $\left.s\left(i \in I_{S}\right)\right)$ :

$$
\begin{aligned}
& P_{i}(t)=\underbrace{\frac{\bar{w}_{i}\left(1+\tau^{\mathrm{SIF}}\right) \bar{P}^{\mathrm{HH}}(t-1)\left(1+\pi^{\mathrm{e}}(t)\right)}{\bar{\alpha}_{i}}}_{\text {Unit labour costs }}+\underbrace{\frac{1}{\beta_{i}} \sum_{g} a_{s g} \bar{P}_{g}(t-1)\left(1+\pi^{\mathrm{e}}(t)\right)}_{\text {Unit Material costs }}+\underbrace{\frac{\delta_{i}}{\kappa_{i}} \bar{P}^{\mathrm{CF}}(t-1)\left(1+\pi^{\mathrm{e}}(t)\right)}_{\text {Unit capital costs }} \\
& +\underbrace{\tau_{i}^{\mathrm{Y}} P_{i}(t-1)\left(1+\pi^{\mathrm{e}}(t)\right)}_{\text {Unit net taxes/subsidies products }}+\underbrace{\tau_{i}^{\mathrm{K}} P_{i}(t-1)\left(1+\pi^{\mathrm{e}}(t)\right)}_{\text {Unit net taxes/subsidies production }}+\underbrace{\bar{\pi}_{i} P_{i}(t-1)\left(1+\pi^{\mathrm{e}}(t)\right)}_{\text {Target unit operating surplus }} \quad \forall i \in I_{s}
\end{aligned}
$$

where $\bar{\alpha}_{i}$ indicates the average productivity of labor, $w_{i}$ are gross wages indexed by the consumer price index $\bar{P}^{\mathrm{HH}}(t)$, see equation (A.30), and including employers' contribution to social insurance charged at a rate $\tau^{\mathrm{SIF}} ; \frac{1}{\beta_{i}} \sum_{g} a_{s g}$ are unit real expenditures on intermediate input by industry $s$ on good $g$ weighted by the average product price index for good $g\left(\bar{P}_{g}(t)\right)$, see equation (A.28), $\delta_{i} / \kappa_{i}$ are unit real capital costs due to depreciation $\left(\delta_{i}\right.$ is the firm's capital depreciation rate and $\kappa_{i}$ is the productivity coefficient for capital); $\bar{P}^{\mathrm{CF}}(t)$ is the average price of capital goods as in equation (A.29), $\tau_{i}^{\mathrm{Y}}$ and $\tau_{i}^{\mathrm{K}}$ are net tax rates on products and production, respectively, and $\bar{\pi}_{i}=\left(1-\left(\left(1+\tau^{\mathrm{SIF}}\right) \frac{\bar{w}_{i}}{\bar{\alpha}_{i}}+\frac{\delta_{i}}{\kappa_{i}}+\frac{1}{\beta_{i}}\right)\right)-\tau_{i}^{\mathrm{K}}-\tau_{i}^{\mathrm{Y}}$ is the operating margin. Expectations on inflation are formed using an autoregressive model of lag order one (AR(1)):

$$
\log \left(1+\pi^{\mathrm{e}}(t)\right)=\alpha^{\pi}(t) \pi(t-1)+\beta^{\pi}(t)+\epsilon^{\pi}(t)
$$

where $\alpha^{\pi}(t), \beta^{\pi}(t)$, and $\epsilon^{\pi}(t)$ are re-estimated every period on the time series of inflation $\pi\left(t^{\prime}\right)$ where $t^{\prime}=-T^{\prime},-T^{\prime}+$ $1,-T^{\prime}+2, \ldots, 0,1,2, \ldots, t-1$. The inflation rate is calculated from the log difference of the producer price index

$$
\pi(t)=\log \left(\frac{\bar{P}(t)}{\bar{P}(t-1)}\right),
$$

where the producer price index is defined as

$$
\bar{P}(t)=\frac{\sum_{i} P_{i}(t) Y_{i}(t)}{\sum_{i} Y_{i}(t)}
$$

With our assumption for firm price setting, we simultaneously incorporate firms' current input cost structure as well as their expectations about future cost, inflation and profit developments.

\section{Appendix A.1.3. Production}

In each period $t$ firm $i$ (which is part of industry $s$ ) produces output $\left(Y_{i}(t)\right.$, in real terms) in form of the principal product $g$ by means of inputs of labor $\left(N_{i}(t)\right.$, the number of persons employed), intermediate goods/services and raw materials $\left(M_{i}(t)\right.$, in real terms), as well as capital $\left(K_{i}(t-1)\right.$, in real terms). We assume a production function with Leontief technology and separate nests for intermediate goods, labour and capital, respectively—all of which represent upper limits to production:

$$
Y_{i}(t)=\min \left(Q_{i}^{\mathrm{s}}(t), \beta_{i} M_{i}(t-1), \alpha_{i}(t) N_{i}(t), \kappa_{i} K_{i}(t-1)\right),
$$

where $\alpha_{i}(t)$ is the productivity of labor of firm $i \in I_{S}$, see equation (A.22), and $\beta_{i}$ and $\kappa_{i}$ are productivity coefficients for intermediate inputs and capital, respectively. Production by firm $i$ may not equal desired scale of activity $\left(Q_{i}^{\mathrm{s}}(t)\right)$. Output could be limited by the amount of available labor force, the quantity of intermediate goods, or the availability of capital needed in the production process. In these cases, the firm has to scale down activity.

\section{Appendix A.1.4. Investment}

In each period the $i$-th firm has to decide how much to invest $\left(I_{i}^{\mathrm{d}}(t)\right.$, in real terms). Investment allows the firm to adjust the real capital stock $K_{i}(t)$. Capital adjustment, however, is not immediate and time consuming. New capital 
goods ${ }^{19}$ bought at the time $t$ will be part of the capital stock only in the next period $t+1$. This makes capital a durable and sticky input.

The desired investment in capital stock in period $t$ is

$$
I_{i}^{\mathrm{d}}(t)=\frac{\delta_{i}}{\kappa_{i}} Q_{i}^{\mathrm{s}}(t)=\frac{\delta_{i}}{\kappa_{i}} Q_{i}^{\mathrm{e}}(t)=\frac{\delta_{i}}{\kappa_{i}} Q_{i}^{\mathrm{d}}(t-1)\left(1+\gamma^{\mathrm{e}}(t)\right),
$$

where $\delta_{i}$ is the firm's capital depreciation rate. The economic rationale behind this equation is that firms adjust their investment demand to expected wear and tear of capital, and that only capital planned to be used in the production process is expected to depreciate and needs to be replaced by new investment. The latter in turn depends on the future demand estimated by the firm according to past demand and the expected rate of economic growth.

We assume a homogenous capital stock for all firms and thus fixed weights $b_{g}^{\mathrm{CF}}$, namely, each firm $i$-irrespective of the sector $s$ firm $i$ is part of-demands $b_{g}^{\mathrm{CF}} I_{i}^{\mathrm{d}}(t)$ as its real investment from firms producing good $g$ :

$$
I_{i g}^{\mathrm{d}}(t)=b_{g}^{\mathrm{CF}} I_{i}^{\mathrm{d}}(t) .
$$

It may be the case that firms cannot obtain the requested investments goods on the capital goods market, or at an unexpectedly high price. The amount of realized investment therefore depends on the search-and-matching process on the capital goods market, see Appendix A.1.1:

$$
I_{i}(t) \begin{cases}=\sum_{g} I_{i g}^{\mathrm{d}}(t) & \text { if the firm successfully realized the investment plan, and } \\ <\sum_{g} I_{i g}^{\mathrm{d}}(t) & \text { if all firms visited could not satisfy its demand }\end{cases}
$$

In the case where firm $i$ cannot realize its investment plan, it will have to scale down future activity, see equation (A.12).

The capital stock, as an aggregate over all goods $g$, evolves according to a depreciation and investment law of motion, where only the amount of capital actually used in the production process depreciates:

$$
K_{i}(t)=K_{i}(t-1)-\frac{\delta_{i}}{\kappa_{i}} Y_{i}(t)+I_{i}(t) .
$$

\section{Appendix A.1.5. Intermediate Inputs}

Each firm needs intermediate input of goods for production. We assume that firm $i$ holds a stock of input goods $M_{i}(t)$ (in real terms) for each type of good $g$. From this stock of intermediate input goods, firm $i$ takes out materials for production as needed, and it keeps these goods in positive supply to avoid shortfalls of material input impeding production. Each period the $i$-th firm has to decide on the desired amount of intermediate goods and raw materials $\left(\Delta M_{i g}^{\mathrm{d}}(t)\right)$ that it intends to purchase in order to keep its stock in positive supply. Here also, similar to equation (A.12), firm $i$ is part of industry $s$ and consumes an intermediate input $g$ according to sector-specific technology coefficients $\left(a_{s g}\right)$. We assume a steady use by the firm of its raw materials in production, and hence that the material stock does not depreciate. This is given by

$$
\Delta M_{i g}^{\mathrm{d}}(t)=a_{s g} \frac{Q_{i}^{\mathrm{s}}(t)}{\beta_{i}} \quad \forall i \in I_{s} .
$$

Firms thus try to keep their stock of material input goods within a certain relationship to $Q_{i}^{\text {s }}(t)$ by accounting for planned material input use in this period. In the intermediate goods market, too, the amount of realized purchases of intermediate goods depends on a search-and-matching process, see Appendix A.1.1:

$$
\Delta M_{i}(t) \begin{cases}=\sum_{g} \Delta M_{i g}^{\mathrm{d}}(t) & \text { if the firm successfully realized its plan, and } \\ <\sum_{g} \Delta M_{i g}^{\mathrm{d}}(t) & \text { if all firms visited could not satisfy its demand. }\end{cases}
$$

If firm $i$ does not succeed in acquiring the materials it intended to purchase, it will be limited in its production possibilities. The stock of good $g$ held by firm $i$ evolves according to the material use in the production process necessary to achieve actual production $\left(Y_{i}(t)\right)$ and realized new acquisitions of intermediate goods:

$$
M_{i}(t)=M_{i}(t-1)-\frac{Y_{i}(t)}{\beta_{i}}+\Delta M_{i}(t) .
$$

\footnotetext{
${ }^{19}$ We assume no difference between investment (or capital) goods, consumption and intermediate-input goods in our model, but rather that each product $g$ is used for all these demand components, according to production needs and consumer preferences.
} 


\section{Appendix A.1.6. Employment}

Each firm $i$ uses employment $N_{i}(t)$ as labor input for production, which is the number of persons employed. The firm decides on the planned amount of employment $N_{i}^{\mathrm{d}}(t)$ in each period according to its desired scale of activity $\left(Q_{i}^{\mathrm{s}}(t)\right)$ and its average labor productivity $\left(\bar{\alpha}_{i}\right)$ :

$$
N_{i}^{\mathrm{d}}(t)=\max \left(1, \text { round }\left(\frac{Q_{i}^{\mathrm{s}}(t)}{\bar{\alpha}_{i}}\right)\right) .
$$

Rounding to the nearest integer translates as follows: if the additional labor demand of firm $i$ is less than a half-time position, labor demand is left unchanged. If the additional production needs of firm $i$ exceed a half-time occupation, a new employee is hired.

If the operating workforce at the beginning of period $t\left(N_{i}(t-1)\right)$, i.e., the number of persons employed in $t-1$, is higher than the desired work force, the firm fires $N_{i}(t-1)-N_{i}^{\mathrm{d}}(t)$ randomly chosen employees (accounting for production constraints due possibly to a shortage of capital). If demand for labor to reach the desired scale of activity is greater than the operating workforce, the firm posts labor vacancies, $V_{i}(t)=\max \left(N_{i}^{\mathrm{d}}(t)-N_{i}(t-1), 0\right)$, which represent a demand for new labor. Whether vacancies are filled or not depends on the search-and-matching mechanism in the labor market (see Appendix A.2.1), thus

$$
N_{i}(t) \begin{cases}=N_{i}^{\mathrm{d}}(t) & \text { if the firm successfully fills all vacancies, and } \\ <N_{i}^{\mathrm{d}}(t) & \text { if there are unfilled vacancies. }\end{cases}
$$

As employees are either employed full-time, part-time, or work overtime, the actual productivity of labor $\alpha_{i}(t)$ of firm $i$ reflects overtime or part-time employment:

$$
\alpha_{i}(t)=\bar{\alpha}_{i} \min \left(1.5, \frac{\min \left(Q_{i}^{\mathrm{s}}(t), \beta_{i} M_{i}(t-1), \kappa_{i} K_{i}(t-1)\right)}{N_{i}(t) \bar{\alpha}_{i}}\right),
$$

where the maximum work effort is 150 percent of a full position. To remunerate increased or decreased work effort as compared to a full-time position, the average wage $\bar{w}_{i}$ of firm $i$ is adapted accordingly:

$$
w_{i}(t)=\bar{w}_{i} \min \left(1.5, \frac{\min \left(Q_{i}^{\mathrm{s}}(t), \beta_{i} M_{i}(t-1), \kappa_{i} K_{i}(t-1)\right)}{N_{i}(t) \bar{\alpha}_{i}}\right),
$$

where $w_{i}(t)$ is the real wage paid by firm $i$. Nominal wage increases accounting for inflation are considered when money wages are paid out to households as part of their disposable income, see Appendix A.2.4.

\section{Appendix A.1.7. External Finance}

Firms may need external financial resources to finance current or future expenditures. Thus, each firm $i$ forms an expectation on its future cash flow $\Delta D_{i}^{\mathrm{e}}(t)$, that is, the expected change of deposits $D_{i}(t)$ :

$$
\Delta D_{i}^{\mathrm{e}}(t)=\underbrace{\Pi_{i}^{\mathrm{e}}(t)}_{\text {Exp. profit }}-\underbrace{\theta L_{i}(t-1)}_{\text {Debt installment }}-\underbrace{\tau^{\mathrm{FIRM}} \max \left(0, \Pi_{i}^{\mathrm{e}}(t)\right)}_{\text {Corporate taxes }}-\underbrace{\theta^{\operatorname{DIV}}\left(1-\tau^{\mathrm{FIRM}}\right) \max \left(0, \Pi_{i}^{\mathrm{e}}(t)\right)}_{\text {Dividend payout }},
$$

where

$$
\Pi_{i}^{\mathrm{e}}(t)=\Pi_{i}(t-1)\left(1+\gamma^{\mathrm{e}}(t)\right)\left(1+\pi^{\mathrm{e}}(t)\right)
$$

is the profit expected by firm $i$ based on the profit in the previous period; $\theta$ is the rate of debt installment on firm $i$ 's outstanding loans $L_{i}(t-1), \tau^{\mathrm{FIRM}}$ is the corporate tax rate, and $\theta^{\mathrm{DIV}}$ is the dividend payout ratio.

If the internal financial resources of a firm are not adequate to finance its expenditures, the firm will ask for a bank loan, i.e., new credit $\Delta L_{i}^{\mathrm{d}}(t)$, to cover its financing gap

$$
\Delta L_{i}^{\mathrm{d}}(t)=\max \left(0, \Delta D_{i}^{\mathrm{e}}(t)-D_{i}(t-1)\right) .
$$

The availability of credit depends on the capitalization of the banking sector and the arrival of firms to ask for a loan, see Appendix A.4.1 for details. If the firm cannot obtain a loan on the credit market, it might become credit constrained, see equation (A.64). If the firm does not obtain the desired loan, it may become insolvent, see Appendix A.1.9. 


\section{Appendix A.1.8. Accounting}

Firm profits $\Pi_{i}(t)$ are an accounting measure that are defined as revenues from sales plus change in inventories minus expenditures on labor, material, depreciation, interest payments and taxes (all accounted for mark-to-market):

$$
\begin{aligned}
\Pi_{i}(t)= & \underbrace{P_{i}(t) Q_{i}(t)}_{\text {Sales }}+\underbrace{P_{i}(t) \Delta S_{i}(t)}_{\text {Inventory change }}-\underbrace{w_{i}(t)\left(1+\tau^{\mathrm{SIF}}\right) N_{i}(t) \bar{P}^{\mathrm{HH}}(t)}_{\text {Labor costs }}-\underbrace{\sum_{g} a_{s g} \bar{P}_{g}(t) \frac{Y_{i}(t)}{\beta_{i}}}_{\text {Material costs }}-\underbrace{\underbrace{\frac{Y_{i}(t)}{\kappa_{i}}}_{i} \bar{P}^{\mathrm{CF}}(t)}_{\text {Depreciation }} \\
& -\underbrace{\tau_{i}^{\mathrm{Y}} P_{i}(t) Y_{i}(t)-\tau_{i}^{\mathrm{K}} P_{i}(t) Y_{i}(t)}_{\text {Net taxes/subsidies on products/production }}-\underbrace{r(t)\left(L_{i}(t-1)-\min \left(0, D_{i}(t-1)\right)\right)}_{\text {Interest payments }}+\underbrace{\bar{r}(t) \max \left(0, D_{i}(t-1)\right)}_{\text {Interest received }} \quad \forall i \in I_{s}
\end{aligned}
$$

where $r(t)$ is the interest rate paid on outstanding loans, see equation (A.66). $\bar{P}_{g}(t)$ is the price index for the principal good $g$ :

$$
\bar{P}_{g}(t)=\frac{\sum_{i \in I_{s=g}} P_{i}(t) Y_{i}(t)}{\sum_{i \in I_{s=g}} Y_{i}(t)},
$$

$\bar{P}^{\mathrm{CF}}(t)$ is the economy-wide capital formation price index defined as

$$
\bar{P}^{\mathrm{CF}}(t)=\sum_{g} b_{g}^{\mathrm{CF}} \bar{P}_{g}(t),
$$

where $b_{g}^{\mathrm{CF}}$ is the capital formation coefficient for product $g$, and $\bar{P}^{\mathrm{HH}}(t)$ is the consumer price index:

$$
\bar{P}^{\mathrm{HH}}(t)=\sum_{g} b_{g}^{\mathrm{HH}} \bar{P}_{g}(t),
$$

where $b_{g}^{\mathrm{HH}}$ is the household consumption coefficient for product $g$.

Firm net cash flow reflects the amount of liquidity moving in or out of its deposit account:

$$
\begin{aligned}
\Delta D_{i}(t)= & \underbrace{P_{i}(t) Q_{i}(t)}_{\text {Sales }}-\underbrace{w_{i}(t)\left(1+\tau^{\mathrm{SIF}}\right) N_{i}(t) \bar{P}^{\mathrm{HH}}(t)}_{\text {Labor costs }}-\underbrace{\sum_{g} a_{s g} P_{i g}(t) \Delta M_{i}(t)}_{\text {Material costs }}-\underbrace{\tau_{i}^{\mathrm{Y}} P_{i}(t) Y_{i}(t)-\tau_{i}^{\mathrm{K}} P_{i}(t) Y_{i}(t)}_{\text {Net taxes/subsidies on products and production }} \\
& -\underbrace{\tau^{\mathrm{FIRM}} \max \left(0, \Pi_{i}(t)\right)}_{\text {Corporate tax payments }}-\underbrace{\theta^{\mathrm{DIV}}\left(1-\tau^{\mathrm{FIRM}}\right) \max \left(0, \Pi_{i}(t)\right)}_{\text {Dividend payments }}-\underbrace{r(t)\left(L_{i}(t-1)-\min \left(0, D_{i}(t-1)\right)\right)}_{\text {Interest payments }} \\
& +\underbrace{\bar{r}(t) \max \left(0, D_{i}(t-1)\right)}_{\text {Interest received }}-\underbrace{P_{i}^{\mathrm{CF}}(t) I_{i}(t)}_{\text {Investment costs }}+\underbrace{\Delta L_{i}(t)}_{\text {New credit }}-\underbrace{\theta L_{i}(t-1)}_{\text {Debt installment }} \quad \forall i \in I_{s},
\end{aligned}
$$

where $P_{i g}(t)$ and $P_{i}^{\mathrm{CF}}(t)$ are the actual prices paid by firm $i$ for intermediate goods of type $g$ and investment in capital goods, respectively, which both are an outcome of the search an matching process. Furthermore, firm $i$ pays interest on outstanding loans and overdrafts on firm $i$ 's deposit account (in case $D_{i}(t)<0$ ) at the same rate $r$, which includes the bank's markup rate. In the opposite case when the firm holds (positive) deposits with the bank, i.e., $D_{i}(t)>0$, the interest rate received is lower and corresponds to the policy rate set by the central bank, see Appendix A.4.

Firm deposits are then previous deposits plus net cash flow:

$$
D_{i}(t)=D_{i}(t-1)+\Delta D_{i}(t) .
$$

Similarly, overall debt is updated as follows:

$$
L_{i}(t)=(1-\theta) L_{i}(t-1)+\Delta L_{i}(t) .
$$

Finally, firm equity $E_{i}(t)$ evolves as the balancing item on the firm's balance sheet, where all stocks are again accounted for mark-to-market:

$$
E_{i}(t)=D_{i}(t)+\sum_{g} a_{s g} \bar{P}_{g}(t) M_{i}(t)+P_{i}(t) S_{i}(t)+\bar{P}^{\mathrm{CF}}(t) K_{i}(t)-L_{i}(t) \quad \forall i \in I_{s} .
$$




\section{Appendix A.1.9. Insolvency}

If a firm is cash-flow insolvent, i.e., $D_{i}(t)<0$, and balance-sheet insolvent, i.e., $E_{i}(t)<0$, at the same time, it goes bankrupt and is replaced by a firm that newly enters the market. We assume that the real capital stock of the bankrupt firm is left to the entrant firm at zero costs, but that the new firm has to take over a part of the bankrupt firm's liabilities. Therefore, a part of loans taken out by the bankrupt firm is written off so that the remaining liabilities of firm $i$ amount to a fraction $\zeta^{\mathrm{b}}$ of its real capital stock. After this partial debt cancellation, the remaining liabilities of the bankrupt firm are transferred to the balance sheet of the entrant firm. In the next period $(t+1)$ liabilities of firm $i$ are initialized with

$$
L_{i}(t+1)=\zeta^{\mathrm{b}} \bar{P}_{i}^{\mathrm{CF}}(t) K_{i}(t)
$$

and firm deposits with

$$
D_{i}(t+1)=0 .
$$

Correspondingly, in the next period $(t+1)$ equity of the new firm $i$ is initialized according to equation (A.34).

\section{Appendix A.2. Households}

The household sector consists of a total number of $H(h=1,2, \ldots, H)$ persons. Every person in the household sector has an activity status, that is, a type of economic activity from which she receives an income. Each person also participates in the consumption market as a consumer with a certain consumption budget. The activity status is categorized into $H^{\text {act }}$ economically active and $H^{\text {inact }}$ economically inactive persons. Economically active persons are $H^{W}$ workers, and $I$ investors (the number of investors equals the number of firms and is constant, see below). The set of workers consists of $H^{\mathrm{E}}(t)$ employed persons and $H^{\mathrm{U}}(t)$ unemployed persons that are actively looking for a job. $H^{\mathrm{E}}(t)$ and $H^{\mathrm{U}}(t)$ are endogenous since we assume that agents may switch between these two sets by being dismissed from their current job or by being hired for a new position. Economically inactive persons include, among others, persons below the age of 15 , students, and retirees.

\section{Appendix A.2.1. Activity Status}

The $h$-th worker $\left(h=1,2, \ldots, H^{\mathrm{W}}\right)$ supplies labor to the extent of employment (part-time, full, or including overtime). If worker $h$ works for firm $i$ in period $t$, she receives wage $w_{h}(t)=w_{i}(t)$.

If unemployed, the person looks for a job on the labor market by visiting firms with open vacancies in random order and applies for a job (the search-and-matching process on the labor market). The unemployed person will accept a job from the first firm with open vacancies that she has the chance to visit. If she does not find a vacancy to fill, that is, when there are no open vacancies left in the economy, she remains unemployed. For simplicity's sake, we do not consider hiring or firing costs for firms, and fired employees become unemployed and start searching for a job in the same period. All unemployed persons receive unemployment benefits, which are a fraction of the labor income that was last received in the period when unemployment starts. In the event that an unemployed person finds a new job, she is remunerated with the wage of firm $i$ that provides the new employment:

$$
w_{h}(t)= \begin{cases}\theta^{\mathrm{UB}} w_{h}(t-1) & \text { if newly unemployed } \\ w_{i}(t) & \text { if newly employed by firm } i \\ w_{h}(t-1) & \text { otherwise, i.e., unemployment continues. }\end{cases}
$$

For simplicity's sake, we assume that each firm is owned by one investor, i.e., the number of investors matches that the number of firms overall. Each investor receives income in the form of dividends in the event that the firm she owns makes profits after interest and tax payments. We assume limited liability, i.e., in the case of bankruptcy, the associated losses are borne by the creditor and not the investor household, see Appendix A.1.9.

An economically inactive person $h$ receives social benefits $s b^{\text {inact }}(t)$ and does not look for a job:

$$
s b^{\text {inact }}(t)=s b^{\text {inact }}(t-1)\left(1+\gamma^{\mathrm{e}}(t)\right) .
$$

Additionally, each household receives additional social transfers $s b^{\text {other }}(t)$ (related to family and children, sickness, etc.) from the government, which we assume to be constant and the same size for all households:

$$
s b^{\text {other }}(t)=s b^{\text {other }}(t-1)\left(1+\gamma^{\mathrm{e}}(t)\right) .
$$




\section{Appendix A.2.2. Consumption}

In a bounded rationality setting, consumers' behavior follows a rule of thumb (heuristic) where they plan to consume a fraction of their expected disposable net income including social benefits $\left(Y_{h}^{\mathrm{e}}(t)\right)$. The consumption budget (net of VAT) of household $h\left(C_{h}^{\mathrm{d}}(t)\right)$ is thus given by:

$$
C_{h}^{\mathrm{d}}(t)=\frac{\psi Y_{h}^{\mathrm{e}}(t)}{1+\tau^{\mathrm{VAT}}},
$$

where $\psi \in(0,1)$ is the propensity to consume out of expected income and $\tau^{\mathrm{VAT}}$ is a value added tax rate on consumption.

Expected disposable net income inclusive of social transfers is determined according to the household's activity status and the associated income from labor, expected profits or social benefits, as well as tax payments, the consumer index price index of the last period, and expectations of the rate of inflation $\pi^{\mathrm{e}}(t)$ formed using an AR(1) model (see equation (A.9)):

$$
Y_{h}^{\mathrm{e}}(t)= \begin{cases}\left(w_{h}(t)\left(1-\tau^{\mathrm{SIW}}-\tau^{\mathrm{INC}}\left(1-\tau^{\mathrm{SIW}}\right)\right)+s b^{\text {other }}(t)\right) \bar{P}^{\mathrm{HH}}(t-1)\left(1+\pi^{\mathrm{e}}(t)\right) & \text { if employed } \\ \left.w_{h}(t)+s b^{\text {other }}(t)\right) \bar{P}^{\mathrm{HH}}(t-1)\left(1+\pi^{\mathrm{e}}(t)\right) & \text { if unemployed } \\ \left.s b^{\text {inact }}(t)+s b^{\text {oher }}(t)\right) \bar{P}^{\mathrm{HH}}(t-1)\left(1+\pi^{\mathrm{e}}(t)\right) & \text { if not economically active }, \\ \theta^{\mathrm{DIV}}\left(1-\tau^{\mathrm{INC}}\right)\left(1-\tau^{\mathrm{FIRM}}\right) \max \left(0, \Pi_{i}^{\mathrm{e}}(t)\right)+s b^{\text {other }}(t) \bar{P}^{\mathrm{HH}}(t-1)\left(1+\pi^{\mathrm{e}}(t)\right) & \text { if an investor } \\ \theta^{\mathrm{DIV}}\left(1-\tau^{\mathrm{INC}}\right)\left(1-\tau^{\mathrm{FIRM}}\right) \max \left(0, \Pi_{k}^{\mathrm{e}}(t)\right)+s b^{\text {other }}(t) \bar{P}^{\mathrm{HH}}(t-1)\left(1+\pi^{\mathrm{e}}(t)\right) & \text { if a bank investor }\end{cases}
$$

where $\Pi_{i}^{\mathrm{e}}(t)$ (see equation (A.25)) and

$$
\Pi_{k}^{\mathrm{e}}(t)=\Pi_{k}(t-1)\left(1+\gamma^{\mathrm{e}}(t)\right)\left(1+\pi^{\mathrm{e}}(t)\right)
$$

is the expected profit based on the profit of the previous period of firm $i$ and of the banking sector, respectively; $\tau^{\mathrm{INC}}$ is the income tax rate, $\tau^{\mathrm{SIW}}$ is the rate of social insurance contributions to be paid by the employee, $\theta^{\mathrm{DIV}}$ is the dividend payout ratio, and $\tau^{\mathrm{FIRM}}$ the corporate tax rate.

Consumers then allocate their consumption budget to purchase different goods from firms. The consumption budget of the $h$-th household to purchase the $g$-th good is

$$
C_{h g}^{\mathrm{d}}(t)=b_{g}^{\mathrm{HH}} C_{h}^{\mathrm{d}}(t),
$$

where $b_{g}^{\mathrm{HH}}$ is the consumption coefficient for the $g^{\text {th }}$ product of households. ${ }^{20}$

Once they have determined their consumption budget, consumers visit firms in order to purchase goods according to the search-and-matching mechanism, see Appendix A.1.1 above. Whether the individual firm can accommodate demand depends (apart from aggregate economic conditions) on its production and inventory stock. Thus realized consumption of household $h$ is another outcome of the search-and-matching process:

$$
C_{h}(t) \begin{cases}=\sum_{g} C_{h g}^{\mathrm{d}}(t) & \text { if the consumer successfully realized the consumption plan, and } \\ <\sum_{g} C_{h g}^{\mathrm{d}}(t) & \text { if all firms visited could not satisfy the consumer's demand. }\end{cases}
$$

\section{Appendix A.2.3. Household Investment}

To depict a simple housing market, households use part of their income to invest in dwellings and other durable investment goods. Similar to equation (A.40) above, we assume household investment occurs according to a fixed rate $\psi^{\mathrm{H}}$ on expected disposable net income:

$$
I_{h}^{\mathrm{d}}(t)=\frac{\psi^{\mathrm{H}} Y_{h}^{\mathrm{e}}(t)}{1+\tau^{\mathrm{CF}}},
$$

\footnotetext{
${ }^{20}$ At this stage we assume all households to buy the same set of goods, independent of the amount they spend on consumption. We also assume that this set of goods is invariant to price changes.
} 
where $\tau^{\mathrm{CF}}$ is the tax rate on investment goods.

Investment demand by household $h$ for product $g$ net of taxes $\left(I_{h g}^{\mathrm{d}}(t)\right)$ is then determined by fixed weights $b_{g}^{\mathrm{CFH}}$ :

$$
I_{h g}^{\mathrm{d}}(t)=b_{g}^{\mathrm{CFH}} I_{h}^{\mathrm{d}}(t) .
$$

Again, realized sales of investment goods purchased by households are an outcome of the search-and-matching process on the capital goods market:

$$
I_{h}(t) \begin{cases}=\sum_{g} I_{h g}^{\mathrm{d}}(t) & \text { if the household successfully realized the investment plan, and } \\ <\sum_{g} I_{h g}^{\mathrm{d}}(t) & \text { if all firms visited could not satisfy its demand. }\end{cases}
$$

The capital stock of household $h$ then follows:

$$
K_{h}(t)=K_{h}(t-1)+I_{h}(t) .
$$

\section{Appendix A.2.4. Income}

In each period $t$, all households receive income according to their activity status. Nominal disposable net income $Y_{h}(t)$ (i.e., realized income after taxes but including unemployment benefits and other social transfers) of the $h$-th household is different from expected income by the realized inflation in period $t$, which is represented by the current consumer price index, as well as the realized profits by firms and the bank:

$$
Y_{h}(t)= \begin{cases}\left(w_{h}(t)\left(1-\tau^{\mathrm{SIW}}-\tau^{\mathrm{INC}}\left(1-\tau^{\mathrm{SIW}}\right)\right)+s b^{\text {other }}(t)\right) \bar{P}^{\mathrm{HH}}(t) & \text { if employed } \\ \left(w_{h}(t)+s b^{\text {other }}(t)\right) \bar{P}^{\mathrm{HH}}(t) & \text { if unemployed } \\ \left(s b^{\text {inact }}(t)+s b^{\text {other }}(t)\right) \bar{P}^{\mathrm{HH}}(t) & \text { if not economically active } \\ \theta^{\mathrm{DIV}}\left(1-\tau^{\mathrm{INC}}\right)\left(1-\tau^{\mathrm{FIRM}}\right) \max \left(0, \Pi_{i}(t)\right)+s b^{\text {other }}(t) \bar{P}^{\mathrm{HH}}(t) & \text { if an investor } \\ \theta^{\mathrm{DIV}}\left(1-\tau^{\mathrm{INC}}\right)\left(1-\tau^{\mathrm{FIM}}\right) \max \left(0, \Pi_{k}(t)\right)+s b^{\text {other }}(t) \bar{P}^{\mathrm{HH}}(t) & \text { if a bank investor }\end{cases}
$$

\section{Appendix A.2.5. Savings}

Savings is the difference between current disposable income $Y_{h}(t)$ and realized consumption expenditure $C_{h}(t)$ plus realized investment in housing $I_{h}(t)$, and is used to accumulate financial wealth: ${ }^{21}$

$D_{h}(t)=D_{h}(t-1)+\underbrace{Y_{h}(t)-\left(\left(1+\tau^{\mathrm{VAT}}\right) C_{h}(t)+\left(1+\tau^{\mathrm{CF}}\right) I_{h}(t)\right)}_{\text {Savings }}+\underbrace{r(t) \min \left(0, D_{h}(t-1)\right)}_{\text {Interest payments }}+\underbrace{\bar{r}(t) \max \left(0, D_{h}(t-1)\right)}_{\text {Interest received }}$.

Additionally, the stock of deposits is corrected for interest payments on overdrafts of the household's deposit account $\left(D_{h}(t-1)<0\right)$, and interest received on deposits held with the bank $\left(D_{h}(t-1)>0\right){ }^{22}$

\section{Appendix A.3. The general government}

In our model, the government takes two functions: as a consumer on the retail market (government consumption), and as a redistributive entity that levies taxes and social contributions to provide social services and benefits to its citizens. We assume that government consumption is exogenous and attributed to individual government entities. Government expenditures, revenues, deficit and public debt, however, are accounted for at the aggregate level (i.e., for the general government).

\footnotetext{
${ }^{21}$ Savings can also be negative in our model, in which case the respective person $h$ would decumulate her financial wealth to finance her consumption needs.

${ }^{22}$ Here, we assume that these interest payments or receipts do not enter the household's consumption decision, and thus we abstract from wealth effects on consumption.
} 


\section{Appendix A.3.1. Government Consumption}

Individual government entities $j(j=1,2, \ldots, J)$ participate in the goods market as consumers. These entities represent the central government, state government, local governments and social security funds. Analogous to imports and exports, the real final consumption expenditure of the general government $\left(C^{\mathrm{G}}(t)\right)$ is assumed to follow an autoregressive process of lag order one (AR(1)):

$$
\log \left(C^{\mathrm{G}}(t)\right)=\alpha^{\mathrm{G}} \log \left(C^{\mathrm{G}}(t-1)\right)+\beta^{\mathrm{G}} .
$$

Total nominal government consumption demand is attributed to goods $g$ and is uniformly distributed to the $J$ government entities; the consumption budget of the $j$-th government entity to purchase the $g$-th good is thus given as

$$
C_{j g}^{\mathrm{d}}(t)=\frac{C^{\mathrm{G}}(t) \bar{P}_{g}(t-1)\left(1+\pi^{\mathrm{e}}(t)\right) c_{g}^{\mathrm{G}}}{J},
$$

where $c_{g}^{\mathrm{G}}$ is the fraction of goods of type $g$ demanded by the government.

Realized government consumption is then another outcome of the search-and-matching process on the consumption goods market:

$$
C_{j}(t) \begin{cases}=\sum_{g} C_{j g}^{\mathrm{d}}(t) & \text { if the government successfully realized the consumption plan, and } \\ <\sum_{g} C_{j g}^{\mathrm{d}}(t) & \text { if all firms visited could not satisfy its demand. }\end{cases}
$$

Other expenditures of the general government include interest payments, social benefits other than social transfers in kind, and subsidies. Interest payments by the general government are made with a fixed average interest rate $r^{\mathrm{G}}$ on loans taken out by the government $L^{\mathrm{G}}(t-1)$. Social transfers by the government consist of social benefits for inactive households $\left(\sum_{h \in H^{\text {inact }}} s b^{\text {inact }}(t)\right)$ such as pension payments or social exclusion benefits, social benefits for any household $h\left(\sum_{h} s b^{\text {other }}(t)\right)$ such as relating to family, sickness or housing, and unemployment benefits for unemployed households $\left(\sum_{h \in H^{\mathrm{U}}(t)} w_{h}(t)\right)$. Subsidies are paid to firms with subsidy rates (uniform for each industry, but different across industries) on products and production, and are in incorporated in the net tax rates on products $\left(\tau_{i}^{\mathrm{Y}}\right)$ and production $\left(\tau_{i}^{\mathrm{K}}\right)$, respectively. ${ }^{23}$

\section{Appendix A.3.2. Government Revenues}

Revenues of the general government are generated through taxes, social contributions and other transfers from all sectors.

$$
\begin{aligned}
& Y^{\mathrm{G}}(t)=\underbrace{\left(\tau^{\mathrm{SIF}}+\tau^{\mathrm{SIW}}\right) \bar{P}^{\mathrm{HH}}(t) \sum_{h \in H^{\mathrm{E}}(t)} w_{h}(t)}_{\text {Social security contributions }}+\underbrace{\tau^{\mathrm{INC}}\left(1-\tau^{\mathrm{SIW}}\right) \bar{P}^{\mathrm{HH}}(t) \sum_{h \in H^{\mathrm{E}}(t)} w_{h}(t)}_{\text {Labour income taxes }}+\underbrace{\tau^{\mathrm{VAT}} \sum_{h} C_{h}(t)}_{\text {Value added taxes }} \\
& +\underbrace{\tau^{\mathrm{INC}}\left(1-\tau^{\mathrm{FIRM}}\right) \theta^{\mathrm{DIV}}\left(\sum_{i} \max \left(0, \Pi_{i}(t)\right)+\max \left(0, \Pi_{k}(t)\right)\right)}_{\text {Cani }}+\underbrace{\tau^{\mathrm{FIRM}}\left(\sum_{i} \max \left(0, \Pi_{i}(t)\right)+\max \left(0, \Pi_{k}(t)\right)\right)} \\
& +\underbrace{\tau^{\mathrm{CF}} \sum_{h} I_{h}(t)}_{\text {Taxes on capital formation }}+\underbrace{\sum_{i} \tau_{i}^{\mathrm{Y}} P_{i}(t) Y_{i}(t)}_{\text {Net taxes/subsidies on products }}+\underbrace{\sum_{i} \tau_{i}^{\mathrm{K}} P_{i}(t) Y_{i}(t)}_{\text {Net taxes/subsidies on production }}+\underbrace{\tau^{\mathrm{EXPORT}} \sum_{l} C_{l}(t)}_{\text {Export taxes }} .
\end{aligned}
$$

\footnotetext{
${ }^{23}$ The latter can therefore also have negative values if a sector receives more subsidies on products or production than it has to pay in taxes.
} 


\section{Appendix A.3.3. Government Deficit}

The government deficit (or surplus) resulting from its redistributive activities is

$$
\begin{aligned}
\Pi^{\mathrm{G}}(t)= & \underbrace{Y^{\mathrm{G}}(t)}_{\text {Government revenues }}-\underbrace{\sum_{j} C_{j}(t)}_{\text {Government consumption }}-\underbrace{r^{\mathrm{G}} L^{\mathrm{G}}(t-1)}_{\text {Interest payments }} \\
& -\underbrace{\sum_{h \in H^{\text {inact }}} \bar{P}^{\mathrm{HH}}(t) s b^{\text {inact }}(t)+\sum_{h \in H^{\mathrm{U}}(t)} \bar{P}^{\mathrm{HH}}(t) w_{h}(t)+\sum_{h} \bar{P}^{\mathrm{HH}}(t) s b^{\text {other }}(t)}_{\text {Social benefits and transfers }} .
\end{aligned}
$$

\section{Appendix A.3.4. Government Debt}

The government debt as a stock variable is determined by the year-to-year deficits/surpluses of the government sector:

$$
L^{\mathrm{G}}(t)=L^{\mathrm{G}}(t-1)+\Pi^{\mathrm{G}}(t) .
$$

For reasons of model parsimony, we assume that the government sells its debt contracts to the central bank, which we model as a "clearing house" for capital flows between the national economy and the Rest of the World. Thus, we implicitly assume that the purchase of government bonds is financed by inflows of foreign capital recorded on the liability side of the central bank's balance sheet.

\section{Appendix A.4. The bank}

For the sake of simplicity we assume that there is one representative bank. ${ }^{24}$ The bank takes deposits from firms and households, extends loans to firms, and receives advances from (or deposits reserves at) the central bank.

\section{Appendix A.4.1. Provision of Loans}

We assume that government regulation imposes a minimum capital requirement on the bank. Thus, the bank can extend loans up to a multiple of its equity base or net worth:

$$
\frac{E_{k}(t)}{\sum_{i=1}^{I} L_{i}(t)} \geq \zeta
$$

where $E_{k}(t)$ is the equity capital (common equity) of the bank, and $0<\zeta<1$ can be interpreted as a minimum capital requirement coefficient. Hence, $1 / \zeta$ is the maximum allowable leverage for the bank. However, the bank-like any other agent-has no knowledge of the realized value of either its equity capital or loans extended to the individual firm $i$, due to fundamental uncertainty prevailing in the model economy. Therefore, the bank has to form expectations both for its equity capital $\left(E_{k}^{\mathrm{e}}(t)\right)$ and for the sum of all loans extended to firms in the economy $\left(\sum_{i=1}^{I} L_{i}^{\mathrm{e}}(t)\right)$ :

$$
\frac{E_{k}^{\mathrm{e}}(t)}{\sum_{i=1}^{I} L_{i}^{\mathrm{e}}(t)}=\frac{E_{k}(t-1)}{\sum_{i=1}^{I}\left(L_{i}(t-1)+\Delta L_{i}(t)\right)} \geq \zeta .
$$

Here, $\Delta L_{i}(t)$ is the realized amount of new loans to firm $i$ in period $t$ as given in equation (A.64), which is either the full amount of new credit demanded by firms $\left(\Delta L_{i}^{\mathrm{d}}(t)\right.$, see equation (A.26)) if the capital requirements for the banks

\footnotetext{
${ }^{24}$ This assumption of one representative bank is above all due to national accounting conventions. From national annual sector accounts, which determine the logic of financial flows between the aggregate sectors for our model (households, non-financial corporations, financial corporations, government and rest of the world), we obtain balance sheet positions (credit and debts), as well as interest payment flows between firms and the financial sector (banks) on an aggregate level. Since we do not have information on financial relations between individual firms (or industry sectors) and banks for this model, we have no empirically based method to determine credit and debt relations, acquisition and provision of credit, as well as interest payments, between individual firms (or industry sectors) and individual banks. Therefore, we account for credit relations and financial flows between individual firms and banks on an aggregate level for the banking sector, i.e., we assume a representative bank extending credit to individual firms according to the amount of firms' real capital stock, see Appendix $\mathrm{C}$ for details, while we account for the value added generated by financial corporations in the real economy according to the logic of IOTs as separate industries within the firm sector.
} 
have not been surpassed. However, it is equal to zero if the bank does not have enough equity capital to provide the loan asked for by firm $i$ :

$$
\Delta L_{i}(t) \leq \max \left(0, \frac{E_{k}(t-1)}{\zeta}-\sum_{i^{\prime}=1}^{I}\left(L_{i^{\prime}}(t-1)+\Delta L_{i^{\prime}}(t)\right)\right) .
$$

Furthermore, the bank forms a risk assessment of a potential default on the part of firm $i$ before extending a loan to it. This risk assessment is based on the borrower's leverage as measured by its loan-to-value ratio, i.e., the amount of loans over the market value of its capital stock. Thus, the bank will grant a loan to firm $i$ only up to the point where the borrower's leverage (or loan-to-value) ratio after the loan (including overdrafts on deposit accounts),

$$
\frac{L_{i}(t)}{\bar{P}^{\mathrm{CF}}(t) K_{i}(t)} \leq \zeta^{\mathrm{LTV}}
$$

is below $\zeta^{\mathrm{LTV}}$, which is a constant. However, due to fundamental uncertainty, also in this case the bank has to form expectations on both the loans to be provided to firm $i\left(L_{i}^{\mathrm{e}}(t)\right)$, as well as on the value of firm $i$ 's capital stock $\left(K_{i}^{\mathrm{e}}(t)\right)$ :

$$
\frac{L_{i}^{\mathrm{e}}(t)}{\bar{P}^{\mathrm{CF}}(t-1)\left(1+\pi^{\mathrm{e}}(t)\right) K_{i}^{\mathrm{e}}(t)} \leq \zeta^{\mathrm{LTV}},
$$

where

$$
L_{i}^{\mathrm{e}}(t)=(1-\theta) L_{i}(t-1)+\Delta L_{i}(t)
$$

and

$$
K_{i}^{\mathrm{e}}(t)=K_{i}(t-1)-\frac{\delta_{i}}{\kappa_{i}} Q_{i}^{\mathrm{s}}(t)+I_{i}^{\mathrm{d}}(t)
$$

Altogether, therefore, the amount of new credit extended to firm $i$ by the bank $\left(\Delta L_{i}(t)\right)$ is limited by the credit demanded by the firm, the bank's risk assessment regarding the default of its potential borrower, and the minimum capital requirements imposed by the regulator:

$$
\begin{aligned}
\Delta L_{i}(t) & =\max \left(0, \min \left(\Delta L_{i}^{\mathrm{d}}(t), \zeta^{\mathrm{LTV}} \bar{P}^{\mathrm{CF}}(t-1)\left(1+\pi^{\mathrm{e}}(t)\right) K_{i}^{\mathrm{e}}(t)-(1-\theta) L_{i}(t-1),\right.\right. \\
& \left.\left.\frac{E_{k}(t-1)}{\zeta}-\sum_{i=1}^{I}\left(L_{i}(t-1)+\Delta L_{i}(t)\right)\right)\right) .
\end{aligned}
$$

The order of arrival of firms at the bank is assumed to be random. A financially robust (low leverage) firm, which in principle deserves a large chunk of bank loans, may be denied credit if it arrives "too late" (i.e., after other less robust firms).

Appendix A.4.2. Accounting for Profits and Losses

The bank's profits are computed as the difference between revenues from interest payments payable on outstanding loans to firms, including overdrafts on deposit accounts incurred by firms and households $\left(D_{i, h}(t-1)<0\right)$, and costs due to interest payments on deposits held with the bank by firms and households $\left(D_{i, h}(t-1)>0\right)$ :

$$
\begin{aligned}
\Pi_{k}(t)= & \underbrace{\bar{r}(t) \max \left(0, D_{k}(t-1)\right)+r(t)\left(\sum_{i=1}^{I} L_{i}(t-1)-\sum_{i=1}^{I} \min \left(0, D_{i}(t-1)\right)-\sum_{h=1}^{H} \min \left(0, D_{h}(t-1)\right)\right)}_{\text {Interest received }} \\
& +\underbrace{\bar{r}(t) \min \left(0, D_{k}(t-1)\right)-\bar{r}(t)\left(\sum_{i=1}^{I} \max \left(0, D_{i}(t-1)\right)+\sum_{h=1}^{H} \max \left(0, D_{h}(t-1)\right)\right)} .
\end{aligned}
$$


Deposits are remunerated at the policy rate $\bar{r}(t)$, which we assume to be set exogenously by the central bank. The interest rate $r$ for bank credit to firms is then determined by a fixed markup $\mu$ over the policy rate $\bar{r}(t)$ :

$$
r(t)=\bar{r}(t)+\mu \text {. }
$$

Bank equity grows or shrinks according to bank profits or losses, and is given by

$$
E_{k}(t)=E_{k}(t-1)+\Pi_{k}(t)-\underbrace{\theta^{\mathrm{DIV}}\left(1-\tau^{\mathrm{FIRM}}\right) \max \left(0, \Pi_{k}(t)\right)}_{\text {Dividend payments }}-\underbrace{\tau^{\mathrm{FIRM}} \max \left(0, \Pi_{k}(t)\right)}_{\text {Corporate taxes }}-\underbrace{\sum_{i \in I^{\prime}}\left(L_{i}(t)-D_{i}(t)-\zeta^{\mathrm{b}} \bar{P}_{i}^{\mathrm{CF}}(t) K_{i}(t)\right)}_{\text {Write-off of bad debt }},
$$

where $I^{\prime}$ is the set of insolvent borrowers, and we assume that outstanding overdraft of firm $i$ 's deposit account as well as a fraction $\left(1-\zeta^{\mathrm{b}}\right) \bar{P}_{i}^{\mathrm{CF}}(t) K_{i}(t)$ of loans extended to firm $i$ have to be written off from the bank's balance sheet. The residual and balancing item on the bank's balance sheet $\left(D_{k}(t)\right),{ }^{25}$ after accounting for loans extended, deposits taken in and its equity capital, are (net) central bank reserves held $\left(D_{k}(t)>0\right)$ or advances obtained by the bank from the central bank $\left(D_{k}(t)<0\right){ }^{26}$

$$
D_{k}(t)=\sum_{i=1}^{I} D_{i}(t)+\sum_{h=1}^{H} D_{h}(t)+E_{k}(t)-\sum_{i=1}^{I} L_{i}(t)
$$

\section{Appendix A.5. The Central Bank}

The central bank (CB) sets the policy rate $\bar{r}(t)$ based on implicit inflation and growth targets, provides liquidity to the banking system (advances to the bank), and takes deposits from the bank in the form of reserves deposited at the central bank. Furthermore, the central bank purchases external assets (government bonds) and thus acts as a creditor to the government.

\section{Appendix A.5.1. Determination of Interest Rates}

The policy rate is determined by a generalized Taylor rule (Taylor, 1993). Following Blattner and Margaritov (2010), we use a "growth" rule specification where the output gap does not enter the equation: ${ }^{27}$

$$
\bar{r}(t)=\max \left(0, \rho \bar{r}(t-1)+(1-\rho)\left(r^{*}+\pi^{*}+\xi^{\pi}\left(\pi^{\mathrm{EA}}(t)-\pi^{*}\right)+\xi^{\gamma} \gamma^{\mathrm{EA}}(t)\right)\right),
$$

where $\rho$ is a measure for gradual adjustment of the policy rate, $r^{*}$ is the real equilibrium interest rate, $\pi^{*}$ is the inflation target by $\mathrm{CB}, \xi^{\pi}$ is the weight the $\mathrm{CB}$ puts on inflation targeting, and $\xi^{\gamma}$ the weight placed on economic growth, respectively. Inflation $\left(\pi^{\mathrm{EA}}(t)\right)$ and economic growth $\left(\gamma^{\mathrm{EA}}(t)\right)$ of the monetary union are assumed to follow an autoregressive process of lag order one $(\operatorname{AR}(1))$ :

$$
\log \left(1+\pi^{\mathrm{EA}}(t)\right)=\alpha^{\pi^{\mathrm{EA}}}(t) \pi^{\mathrm{EA}}(t-1)+\beta^{\pi^{\mathrm{EA}}}(t)
$$

and

$$
\gamma^{\mathrm{EA}}(t)=\frac{Y^{\mathrm{EA}}(t)}{Y^{\mathrm{EA}}(t-1)}-1
$$

where

$$
\log \left(Y^{\mathrm{EA}}(t)\right)=\alpha^{\mathrm{YAA}}(t) \log \left(\sum_{i} Y^{\mathrm{EA}}(t-1)\right)+\beta^{\mathrm{Y}^{\mathrm{EA}}}(t) .
$$

Note that we assuming here a SoE as part of a monetary union with no influence on interest rates. ${ }^{28}$

\footnotetext{
${ }^{25}$ Which also includes currency held by the bank.

${ }^{26}$ Note that this variable, if it takes a positive value $\left(D_{k}(t)>0\right)$, signifies that the bank holds positive net reserves, i.e., it holds more reserves than advances and is thus a net creditor to the central bank. On the other hand, in the opposite case of $D_{k}(t)<0$, this means that the bank has taken out more central bank advances than it holds central bank reserves, i.e., it is a net debtor to the central bank. The possibility of an inequality of advances and reserves, or, for that matter, an inequality of loans and deposits, is due to the fact that we do not explicitly distinguish between deposits and reserves for reasons of model parsimony. Rather, we use the central bank as a "clearing house" for flows of reserves and deposits between the national economic and the RoW, see equation (A.76).

${ }^{27}$ Here, we rely on empirical evidence and statements by leading central bankers reported in Blattner and Margaritov (2010) implying that the concept of an output gap does not seem to influence the behavior of the European Central Bank (ECB) to a large extent.

${ }^{28}$ For example, Austria as part of the EA contributes only about 3 percent of total GDP of the monetary union.
} 


\section{Appendix A.5.2. Accounting for Profits and Losses}

The central bank's profits $\Pi^{\mathrm{CB}}(t)$ are computed as the difference between revenues from interest payments on government debt, as well as revenues $\left(D_{k}(t)<0\right)$ or costs $\left(D_{k}(t)>0\right)$ due to the net position in advances/reserves vis-à-vis the banking system:

$$
\Pi^{\mathrm{CB}}(t)=r^{\mathrm{G}} L^{\mathrm{G}}(t-1)-\bar{r}(t) D_{k}(t-1) .
$$

The central bank's equity $E^{\mathrm{CB}}(t)$ evolves according to its profits or losses and its past equity, and is given by

$$
E^{\mathrm{CB}}(t)=E^{\mathrm{CB}}(t-1)+\Pi^{\mathrm{CB}}(t) .
$$

The net creditor/debtor position of the national economy to the rest of the world $\left(D^{\mathrm{Row}}(t)\right)^{29}$ evolves according to the following law of motion

$$
D^{\mathrm{RoW}}(t)=D^{\mathrm{RoW}}(t-1)-\underbrace{\left(1+\tau^{\mathrm{EXPORT}}\right) \sum_{l} C_{l}(t)}_{\text {Exports }}+\underbrace{\sum_{m} P_{m}(t) Q_{m}(t)}_{\text {Imports }} .
$$

Here, for example, a balance of trade surplus (deficit) enters with a negative (positive) sign, since $D^{\mathrm{RoW}}(t)$ is on the liability side of the CB's balance sheet. Thus a trade surplus (deficit), i.e., an inflow (outflow) money into (out of) the national economy, would reduce (increase) national liabilities versus the RoW.

Inherent stock-flow consistency relating to the accounting principles incorporated in our model implies that our financial system is closed via the accounting identity that connects the change in the amount of deposits in the banking system $^{30}$ to the government deficit (surplus) ${ }^{31}$ and to the balance of trade: ${ }^{32}$

$$
\begin{aligned}
E^{\mathrm{CB}}(t)+D^{\mathrm{RoW}}(t) & =L^{\mathrm{G}}(t)-D_{k}(t) \\
& =L^{\mathrm{G}}(t)-\sum_{i=1}^{I} D_{i}(t)-\sum_{h=1}^{H} D_{h}(t)-E_{k}(t)+\sum_{i=1}^{I} L_{i}(t) .
\end{aligned}
$$

\section{Appendix A.6. Imports and Exports}

To depict trade with the RoW, we include a set of agents that are based abroad and trade with the domestic economy. For simplicity's sake, a representative foreign firm for each sector supplies goods on domestic markets for intermediate, capital and consumption goods (imports), while foreign consumers demand products on these domestic markets (exports). As we assume a small open economy (SoE) setting, we suppose exports and imports to be exogenously given.

\section{Appendix A.6.1. Imports}

Following this approach, the total amount of imports $Y^{\mathrm{I}}(t)$ (in real terms) is assumed to follow an autoregressive process of lag order one $(\operatorname{AR}(1)):{ }^{33}$

$$
\log \left(Y^{\mathrm{I}}(t)\right)=\alpha^{\mathrm{I}} \log \left(Y^{\mathrm{I}}(t-1)\right)+\beta^{\mathrm{I}}
$$

and a representative foreign firm for each sector imports goods from the RoW and supplies them to domestic markets. Thus the $m$-th, $(m=1,2, \ldots, S)$, foreign firm representing an industry $s$ imports the principal product $g:{ }^{34}$

$$
Y_{m}(t)=c_{g=s}^{\mathrm{I}} Y^{\mathrm{I}}(t),
$$

\footnotetext{
${ }^{29}$ If $D^{\mathrm{RoW}}(t)<0$, the national economy is a net creditor of the RoW, if $D^{\mathrm{RoW}}(t)>0$, the national economy is a net debtor to the RoW.

${ }^{30}$ These changes in the amount of deposits in the banking system directly correspond to changes in net central bank reserves $D_{k}(t)$, which in turn depend the private sector's surplus or deficit in relation to both the government and the RoW.

${ }^{31}$ Financial flows relating to a deficit (surplus) on the part of the government sector either accrue to (are paid by) the private sector (households and firms), or have to flow to (in from) the RoW, in the first case increasing (decreasing) deposits, in the second case increasing (decreasing) $D^{R O W}$.

${ }^{32}$ A positive (negative) balance of trade will either increase (decrease) deposits held by the private sector, or reduce (increase) the amount of government debt by e.g. reducing (increasing) the amount of government deficit.

${ }^{33}$ As a simplifying assumption, this implies that imports to the domestic economy are not demand-driven, but rather subject to a supply constraint.

${ }^{34} \mathrm{As}$ for domestic firms, we assume that there is a one-to-one correspondence between the sets of industries $s$ and products $g$, meaning that the $n$-th sector produces only the $n$-th good, and $S=G$.
} 
where $c_{g}^{\mathrm{I}}$ is the fraction of imported goods of type $g$ as part of total imports.

The prices for these import goods are assumed to develop in line with the average sectoral domestic price level. The foreign firm thus sells its products at the inflation-adjusted average sectoral domestic price level. Consequently,

$$
P_{m}(t)=\bar{P}_{g}(t-1)\left(1+\pi^{\mathrm{e}}(t)\right),
$$

where $m$ produces the principal product $g$. This corresponds to the assumption of a fixed relation between the domestic and international price level, i.e., the same inflation rate at home and abroad.

Sales of imports are then the realized demand as an outcome of the search-and-matching process on the goods markets (see Appendix A.1.1):

$$
Q_{m}(t)=\min \left(Y_{m}(t), Q_{m}^{\mathrm{d}}(t)\right),
$$

where $Q_{m}^{\mathrm{d}}(t)$ is the demand by consumers from foreign firm $m$.

\section{Appendix A.6.2. Exports}

The $l$-th $(l=1,2, \ldots, L)$ foreign consumer, be it a foreign firm, household, or government entity, participates in the domestic goods market as a consumer. Total sales to these foreign consumers on domestic markets represent exports to the rest of the world. Analogous to imports, real exports $\left(C^{\mathrm{E}}(t)\right)$ are assumed to follow an autoregressive process of lag order one $(\operatorname{AR}(1))$ :

$$
\log \left(C^{\mathrm{E}}(t)\right)=\alpha^{\mathrm{E}} \log \left(C^{\mathrm{E}}(t-1)\right)+\beta^{\mathrm{E}} .
$$

Total exports are then attributed to goods $g$ and are uniformly distributed to the $L$ foreign consumers; the demand for exported goods by the $l$-th foreign consumer to purchase the $g$-th good is thus given by

$$
C_{l g}^{\mathrm{d}}(t)=\frac{c_{g}^{\mathrm{E}} C^{\mathrm{E}}(t) \bar{P}_{g}(t-1)\left(1+\pi^{\mathrm{e}}(t)\right)}{L},
$$

where $c_{g}^{\mathrm{E}}$ is the fraction of exports of goods of type $g$.

Realized consumption by foreign consumers is then an outcome of the search-and-matching process on goods markets (see Appendix A.1.1):

$$
C_{l}(t) \begin{cases}=\sum_{g} C_{l g}^{\mathrm{d}}(t) & \text { if the foreign consumer successfully realized the consumption plan, and } \\ <\sum_{g} C_{l g}^{\mathrm{d}}(t) & \text { if all firms visited could not satisfy its demand. }\end{cases}
$$




\section{Appendix B. Parameters for the Austrian economy}

Parameters for the model presented in Appendix A are set for the Austrian economy, so that each agent in the model represents a natural person or legal entity, such as a corporation, a government entity or any other institution, in Austria. Austria is a typical example of an advanced small open economy with about 8.8 million inhabitants and more than half a million registered businesses ${ }^{35}$ : it is closely integrated into the European economy by extensive trade (the export quota, i.e. the share of exports in GDP, is slightly more than 52 percent, the import quota about 48 percent). Austria's well-developed service sector constitutes about 71 percent of total GDP, while the industry sector takes a smaller share with about 28 percent in GDP and the agricultural sector contributes much less (about 1.5 percent of GDP). Austria has a well-developed social and welfare system, primarily based on social security contributions, as well as taxation of income and consumption. Correspondingly, the ratio of public spending to GDP is about 52 percent, while the overall tax burden, that is, the ratio of total taxes and social security contributions to GDP, reaches 43 percent.

The parameters of the model are summarized in Table B.5. For the forecasting exercise in Section 3, parameters were initially calculated and estimated over the sample 1997:Q1 to 2010:Q1 and then, respectively, re-estimated and recalculated, every quarter until 2013:Q4. Here we show and discuss, as an example, parameter values for 2010:Q4. Data sources include macroeconomic and sectoral data from national accounts, sector accounts, input-output tables, government statistics, census data, and business demography data and are obtained from the Eurostat bulk download facility where it is freely available. ${ }^{36}$ The codes under which the respective datasets are available from Eurostat (such as, e.g., naio_10_cp1700) at this download facility are given in brackets in the description below. Eurostat data tables are collected in Table B.6. Model parameters are either taken directly from data or calculated from national accounting identities. For exogenous processes such as government consumption, imports and exports of Austria, as well as real GDP and inflation of the EA, parameters are estimated from quarterly time series from national accounts (main aggregates).

\section{Appendix B.1. Firms}

Parameters that specify the number of firms are taken directly (or derived from) business demography data. Specifically we use data from business demography by legal form (from 2004 onwards, NACE Rev. 2) (bd_9ac_l_form_r2) to set the number of firms in industries $\left(I_{s}\right)$ according to the population of active enterprises in $\mathrm{t}$ (V.11910). Business demography tables do not include the agriculture, forestry and fishing sector (A01-A03), or the public administration, defense, and compulsory social security sector (O64). The number of firms in industries A01-A03 is set according to the "Grüner Bericht", ${ }^{37}$ and the number of firms in industry $\mathrm{O} 64$ (i.e. generic administrative government units) is set at 10,000 . The amount $L$ of foreign firms that import and export goods is not available from business demography data. As a first simplifying assumption, this number is assumed to be 50 percent of domestically producing firms, which approximately corresponds to the share of exports in total value added. For the classification of industries $(s)$ we use the statistical classification of economic activities in the European Community (NACE). Products $(g)$ are classified according to the classification of products by activity (CPA), which is fully aligned with NACE. Several consolidated tables including input-output tables, demographic data and cross-classification tables are compiled for the EA and European Union with a breakdown of 64 activities/products (NACE*64, CPA*64). We, therefore, set the number of industries $(S)$ and the number of products $(G)$ at $64(S=64, G=64)$.

Several model parameters concerning the firm agents are directly taken from input-output tables (IOTs), or are derived from them. The input-output framework of the ESA consists of supply and use tables in current prices and the prices of the previous year. Supply and use tables are matrices describing the values of transactions in products for the national economy categorized by product type and industry; see (Eurostat, 2013). We use the symmetric input-output

\footnotetext{
${ }^{35}$ For facts and figures about the Austrian economy see e.g. the Austrian Statistical Agency, http://statistik.at/web_en/statistics/ index.html (Last accessed November 30 ${ }^{\text {th }}$, 2018). All data for the Austrian economy is provided for the year 2016.

${ }^{36}$ see http://ec.europa.eu/eurostat/estat-navtree-portlet-prod/BulkDownloadListing?sort=1\&dir=data (Last accessed November $30^{\text {th }}, 2018$ )

${ }^{37}$ In English the Green report, which is a yearly report on agricultural development in Austria, as well as on the social and economic situation of Austrian farmers and forest workers. For further reference, see http://www . awi.bmlfuw.gv . at/index.php?id=gruenerbericht (Last accessed November $30^{\text {th }}, 2018$ ).
} 
Table B.5: Model parameters

\begin{tabular}{|c|c|c|}
\hline Parameter & Description & Value \\
\hline$G / S$ & Number of products/industries & 62 \\
\hline$H^{\text {act }}$ & Number of economically active persons & 4729215 \\
\hline$H^{\text {inact }}$ & Number of economically inactive persons & 4130385 \\
\hline$J$ & Number of government entities & 152820 \\
\hline$L$ & Number of foreign consumers & 305639 \\
\hline$I_{s}$ & Number of firms/investors in the $s^{\text {th }}$ industry & see Table B.7 \\
\hline $\bar{\alpha}_{i}$ & Average productivity of labor of the $i^{\text {th }}$ firm & see Appendix B.1 \\
\hline$\kappa_{i}$ & Productivity of capital of the $i^{\text {th }}$ firm & see Appendix B.1 \\
\hline$\beta_{i}$ & Productivity of intermediate consumption of the $i^{\text {th }}$ firm & see Appendix B.1 \\
\hline$\delta_{i}$ & Depreciation rate for capital of the $i^{\text {th }}$ firm & see Appendix B.1 \\
\hline $\bar{w}_{i}$ & Average wage rate of firm $i$ & see Appendix B.1 \\
\hline$a_{s g}$ & Technology coefficient of the $g^{\text {th }}$ product in the $s^{\text {th }}$ industry & see Appendix B.1 \\
\hline$b_{g}^{\mathrm{CF}}$ & Capital formation coefficient of the $g^{\text {th }}$ product (firm investment) & see Table B.7 \\
\hline$b_{g}^{\mathrm{CFH}}$ & Household investment coefficient of the $g^{\text {th }}$ product & see Table B.7 \\
\hline$b_{g}^{\mathrm{HH}}$ & Consumption coefficient of the $g^{\text {th }}$ product of households & see Table B.7 \\
\hline$c_{g}^{g}$ & Consumption of the $g^{\text {th }}$ product of the government in mln. Euro & see Table B.7 \\
\hline$c_{g}^{g}$ & Exports of the $g^{\text {th }}$ product in $\mathrm{mln}$. Euro & see Table B.7 \\
\hline$c_{g}^{g}$ & Imports of the $g^{\text {th }}$ product in mln. Euro & see Table B.7 \\
\hline$\tau_{i}^{\mathrm{Y}}$ & Net tax rate on products of the $i^{\text {th }}$ firm & see Appendix B.3 \\
\hline$\tau_{i}^{\mathrm{K}}$ & Net tax rate on production of the $i^{\text {th }}$ firm & see Appendix B. 3 \\
\hline$\tau^{\mathrm{INC}}$ & Income tax rate & 0.2134 \\
\hline$\tau^{\mathrm{FIRM}}$ & Corporate tax rate & 0.0779 \\
\hline$\tau^{\mathrm{VAT}}$ & Value-added tax rate & 0.1529 \\
\hline$\tau^{\mathrm{SIF}}$ & Social insurance rate (employers' contributions) & 0.2122 \\
\hline$\tau^{\mathrm{SIW}}$ & Social insurance rate (employees' contributions) & 0.1711 \\
\hline$\tau^{\text {EXPORT }}$ & Export tax rate & 0.003 \\
\hline$\tau^{\mathrm{CF}}$ & Tax rate on capital formation & 0.2521 \\
\hline$\tau^{\mathrm{G}}$ & Tax rate on government consumption & 0.0091 \\
\hline$r^{\mathrm{G}}$ & Interest rate on government bonds & 0.0087 \\
\hline$\mu$ & Risk premium on policy rate & 0.0256 \\
\hline$\psi$ & Fraction of income devoted to consumption & 0.9079 \\
\hline$\psi^{\mathrm{H}}$ & Fraction of income devoted to investment in housing & 0.0819 \\
\hline$\theta^{\mathrm{UB}}$ & Unemployment benefit replacement rate & 0.3586 \\
\hline$\theta^{\mathrm{DIV}}$ & Dividend payout ratio & 0.7953 \\
\hline$\theta$ & Rate of installment on debt & 0.05 \\
\hline$\zeta$ & Banks' capital requirement coefficient & 0.03 \\
\hline$\zeta^{\mathrm{LTV}}$ & Loan-to-value (LTV) ratio & 0.6 \\
\hline$\zeta^{\mathrm{b}}$ & Loan-to-capital ratio for new firms after bankruptcy & 0.5 \\
\hline$\pi^{*}$ & Inflation target of the monetary authority & 0.02 \\
\hline$\alpha^{\mathrm{G}}$ & Autoregressive coefficient for government consumption & 0.9832 \\
\hline$\beta^{\mathrm{G}}$ & Scalar constant for government consumption & 0.1644 \\
\hline$\alpha^{\mathrm{E}}$ & Autoregressive coefficient for exports & 0.9679 \\
\hline$\beta^{\mathrm{E}}$ & Scalar constant for exports & 0.3436 \\
\hline$\alpha^{\mathrm{I}}$ & Autoregressive coefficient for imports & 0.9736 \\
\hline$\beta^{\mathrm{I}}$ & Scalar constant for imports & 0.2813 \\
\hline$\alpha^{\mathrm{Y}^{\mathrm{EA}}}$ & Autoregressive coefficient for euro area GDP & 0.9681 \\
\hline$\beta^{\mathrm{Y}^{\mathrm{EA}}}$ & Scalar constant for euro area GDP & 0.4706 \\
\hline$\alpha^{\pi^{\mathrm{EA}}}$ & Autoregressive coefficient for euro area inflation & 0.3198 \\
\hline$\beta^{\mathrm{n}^{\mathrm{EA}}}$ & Scalar constant for euro area inflation & 0.0028 \\
\hline$\rho$ & Adjustment coefficient of the policy rate & 1.0028 \\
\hline$r^{*}$ & Real equilibrium interest rate & -0.0617 \\
\hline$\xi^{\pi}$ & Weight of the inflation target & -17.7004 \\
\hline$\xi^{\gamma}$ & Weight of economic growth & -40.9463 \\
\hline
\end{tabular}

Notes: Model parameters are calculated for 2010:Q4. Exogenous autoregressive parameters are estimated starting in 1997:Q1. 


\begin{tabular}{ll}
\hline Name & Code \\
\hline GDP and main components - output, expenditure and income (quarterly time series) & namq_10_gdp \\
Symmetric input-output table (IOT) at basic prices (product by product) & naio_10_cp1700 \\
Cross-classification of fixed assets by industry and by asset (stocks) & nama_10_nfa_st \\
Balance sheets for financial assets & nasa_10_f_bs \\
Non-financial transactions & nasa_10_nf_tr \\
Business demography by legal form (from 2004 onwards, NACE Rev. 2) & bd_9ac_1_form_r2 \\
Government revenue, expenditure and main aggregates & gov_10a_main \\
Government deficit/surplus, debt and associated data & gov_10dd_edpt1 \\
Government expenditure by function - COFOG & gov_10a_exp \\
Population by current activity status, NACE Rev. 2 activity and NUTS 2 region & cens_11an_r2 \\
Money market interest rates - annual data & irt_st_a \\
Money market interest rates - quarterly data & irt_st_q \\
\hline
\end{tabular}

table at basic prices (product by product) (naio_10_cp1700) to set the technology, consumption and capital formation coefficients $\left(a_{s g}, b_{g}^{\mathrm{HH}}, b_{g}^{\mathrm{CF}}, c_{g}^{\mathrm{G}}, c_{g}^{\mathrm{E}}\right.$ and $\left.c_{g}^{\mathrm{I}}\right)$. Specifically, we use intermediate consumption (P.2) $)^{38}$ of 64 (CPA*64) products for the technology coefficient of the $g^{\text {th }}$ product in the $s^{\text {th }}$ industry $a_{s g}$. To obtain the technology coefficient, the entries are normalized column-wise. Real estate services (CPA_L68) also include imputed rents. Entries of "services of households as employers, undifferentiated goods and services produced by households for own use" (CPA_T) and "Services provided by extraterritorial organizations and bodies" (CPA_U) contain zeros only and are excluded. The capital formation coefficient of the $g^{\text {th }}$ product $b_{g}^{\mathrm{CF}}$ is set according to the gross fixed capital formation (P.51G) as given in the symmetric input-output table. The consumption coefficient of the $g^{\text {th }}$ product of households $b_{g}^{\mathrm{HH}}$ is set according to final consumption expenditure by households (P.3) plus final consumption expenditure by non-profit organizations serving households (NPISH). Again, entries are normalized to obtain capital formation and consumption coefficients. The consumption of the $g^{\text {th }}$ product of the government $c_{g}^{\mathrm{G}}$, imports of the $g^{\text {th }}$ product $c_{g}^{\mathrm{I}}$ and exports of the $g^{\text {th }}$ product $\left(c_{g}^{\mathrm{E}}\right)$ are taken directly from the symmetric input-output table by using the final consumption expenditure by government (P.3), as well as total exports (P.6) and imports (P.7).

For some parameters we need to combine the logic of annual sectoral accounts and IOTs. The information by institutional sector in the sector accounts and the information by industry or product in the supply and use tables can be linked by cross-classification tables. We use the cross-classification tables and structural business statistics (business demography) to complement symmetric IOTs. Specifically we are using statistics on population by current activity status, NACE Rev. 2 activity and NUTS 2 region (cens_11an_r2) to set the average productivity of labor for firm $i$ $\left(\bar{\alpha}_{i}\right)$, which is assumed to be equal across firms in each industry $s$, but different between industries $\left(\bar{\alpha}_{i}=\alpha_{s} \quad \forall i \in I_{s}\right)$. It is defined by output (P.1) in the industry divided by the number of persons employed in the population of active enterprises in $\mathrm{t}$ (V.16910) in the industry. ${ }^{39}$ The average wage that employees receive from firm $i\left(\bar{w}_{i}=\frac{w_{s}}{N_{s}} \quad \forall i \in I_{s}\right)$ (which is industry-specific) is defined by wages and salaries (D.11) in the industry divided by the number of persons employed in the population of active enterprises in $\mathrm{t}$ (V.16910) in the industry. The average productivity of capital

\footnotetext{
${ }^{38}$ The accounting code of the European System of Accounts (ESA) data source is given in brackets. In this coding system, the capital letter D represents a figure from the distributive transactions account, while a $\mathrm{P}$ indicates data from the transactions in products and non-produced asset account. The letter B generally stands for a balancing item, i.e. the subtraction of one side of an account from the other. Balancing items carry much of the most vital information in these data. For example, operating surplus/mixed income (B.2A3N) is obtained by subtracting the cost factors compensation of employees and taxes on products from value added. The capital letter $\mathrm{F}$ indicates a financial asset/liability for financial balance sheets, e.g. F.2 indicates currency and deposits. The numbers after the letters indicate the type of transaction/balancing item/asset class, in a similar coding system as IO classification with increasing amount of detail in the classification as the amount of digits increases. This means that e.g. D.41 (interest payments) is a sub-category of D4 (property income).

${ }^{39}$ In the context of the Labour Force Survey (LFS), an employed person is a person aged 15 and over (or 16 and over in Iceland and Norway) who during the reference week performed work-even if just for one hour a week-for pay, profit or family gain. For further information, see http://ec.europa.eu/eurostat/statistics-explained/index.php/Glossary:Employed_person_-_LFS (Last accessed November $\left.30^{\text {th }}, 2018\right)$.
} 
Table B.7: Sectoral parameters

\begin{tabular}{|c|c|c|c|c|c|c|c|c|c|c|c|c|c|c|c|}
\hline & $I_{s}$ & $N_{s}$ & $\alpha_{s}$ & $\beta_{s}$ & $\kappa_{s}$ & $\delta_{s}$ & $w_{s}$ & $\tau_{s}^{\mathrm{Y}}$ & $\tau_{s}^{\mathrm{K}}$ & $b_{g}^{\mathrm{CF}}$ & $b_{g}^{\mathrm{CFH}}$ & $b_{g}^{\mathrm{HH}}$ & $c_{g}^{\mathrm{G}}$ & $c_{g}^{\mathrm{E}}$ & \\
\hline A01 & 47901 & 123068 & 0.0111 & 1.6632 & 0.044 & 0.0114 & 0.0003 & 0.0095 & -0.2611 & 0.0033 & 0.0006 & 0.0113 & 0 & $0.0051^{\circ}$ & $0.0174^{\circ}$ \\
\hline A02 & 1867 & 18107 & 0.0307 & 1.9507 & 0.2048 & 0.0131 & 0.0023 & 0.0088 & -0.0398 & 0 & 0 & 0.002 & 0 & 0.0006 & 0.0047 \\
\hline A03 & 234 & 283 & 0.0379 & 1.5267 & 0.0335 & 0.0076 & 0.0018 & 0.023 & 0.0036 & 0 & 0 & 0.0003 & 0 & 0 & 0.0004 \\
\hline B & 448 & 6395 & 0.0701 & 1.8244 & 0.1908 & 0.0279 & 0.0078 & 0.0124 & -0.0073 & 0.0008 & 0.0044 & 0.0003 & 0 & 0.0073 & 0.0569 \\
\hline C10-12 & 4842 & 79431 & 0.0527 & 1.3946 & 0.498 & 0.025 & 0.0059 & 0.002 & -0.0112 & 0 & 0 & 0.0631 & 0 & 0.0544 & 0.0495 \\
\hline C13-15 & 2254 & 21660 & 0.0336 & 1.5409 & 0.3738 & 0.0201 & 0.0058 & 0.0042 & -0.0035 & 0.0033 & 0 & 0.0307 & 0 & 0.0214 & 0.0469 \\
\hline $\mathrm{C} 16$ & 3802 & 34971 & 0.0496 & 1.3227 & 0.4361 & 0.017 & 0.0058 & 0.0047 & 0.0033 & 0.0031 & 0.0671 & 0.0004 & 0 & 0.0239 & 0.0104 \\
\hline $\mathrm{C} 17$ & 1019 & 18789 & 0.0772 & 1.3819 & 0.4108 & 0.0246 & 0.0088 & 0.0035 & -0.0017 & 0 & 0 & 0.002 & 0 & 0.0281 & 0.0172 \\
\hline $\mathrm{C} 18$ & 463 & 12444 & 0.053 & 1.5943 & 0.3205 & 0.0266 & 0.0091 & 0.003 & 0.0056 & 0 & 0 & 0 & 0 & 0.0059 & 0.0005 \\
\hline C19 & 7 & 1544 & 0.6413 & 1.0612 & 0.8256 & 0.0328 & 0.0143 & 0.0091 & -0.0027 & 0 & 0 & 0.0191 & 0 & 0.0119 & 0.0405 \\
\hline $\mathrm{C} 20$ & 459 & 16812 & 0.1828 & 1.1085 & 0.7932 & 0.019 & 0.0075 & 0.0021 & 0.0005 & 0 & 0.0017 & 0.0077 & 0 & 0.0765 & 0.0909 \\
\hline $\mathrm{C} 21$ & 104 & 10505 & 0.0666 & 1.8145 & 0.2156 & 0.0241 & 0.0073 & 0.0033 & 0.0054 & 0 & 0 & 0.0054 & .0236 & 0.0212 & 0.03 \\
\hline $\mathrm{C} 22$ & 679 & 27163 & 0.046 & 1.5616 & 0.4311 & 0.0262 & 0.0081 & 0.004 & 0.0085 & 0.0028 & 0.0103 & 0.0034 & 0 & 0.0269 & 0.0306 \\
\hline $\mathrm{C} 23$ & 1697 & 33127 & 0.041 & 1.6122 & 0.2614 & 0.0213 & 0.0079 & 0.0091 & 0.0087 & 0.0026 & 0.026 & 0.0011 & 0 & 0.015 & 0.0132 \\
\hline $\mathrm{C} 24$ & 2639 & 37414 & 0.0862 & 1.3083 & 0.5286 & 0.0262 & 0.008 & 0.0071 & 0.0042 & 0.0053 & 0 & 0 & 0 & 0.0686 & 0.0602 \\
\hline $\mathrm{C} 25$ & 2127 & 65597 & 0.0396 & 1.5823 & 0.4002 & 0.0236 & 0.0081 & 0.0037 & 0.0054 & 0.0132 & 0.0116 & 0.0021 & 0 & 0.0381 & 0.0332 \\
\hline $\mathrm{C} 26$ & 461 & 21164 & 0.049 & 1.7646 & 0.19 & 0.0374 & 0.0075 & 0.0023 & 0.0013 & 0.046 & 0 & 0.0106 & 05 & 384 & 0.0608 \\
\hline $\mathrm{C} 27$ & 838 & 41492 & 0.0454 & 1.8096 & 0.3523 & 0.0293 & 0.0072 & 0.0014 & 0.002 & 0.0209 & 0 & 0.0068 & 0 & 0.0507 & 0.042 \\
\hline $\mathrm{C} 28$ & 1519 & 69049 & 0.0539 & 1.4923 & 0.5642 & 0.0287 & 0.0086 & 0.002 & 0.0076 & 0.1155 & 0.0022 & 0.0008 & 0 & 0.0995 & 0.0848 \\
\hline $\mathrm{C} 29$ & 365 & 26418 & 0.1012 & 1.2977 & 0.4055 & 0.0294 & 0.0088 & 0.0016 & 0.0029 & 0.071 & 0 & 0.0193 & 0 & 0.079 & 0.0809 \\
\hline $\mathrm{C} 30$ & 115 & 9932 & 0.0848 & 1.3929 & 0.9523 & 0.0495 & 0.0086 & 0.0019 & 0.0058 & 0.0155 & 0 & 0.0018 & 02 & 0.0197 & 0.0131 \\
\hline C31_32 & 6147 & 48442 & 0.0321 & 1.5459 & 0.479 & 0.0199 & 0.0058 & 0.0081 & 0.0109 & 0.031 & 0 & 0.0205 & & 0.0294 & 0.0341 \\
\hline $\mathrm{C} 33$ & 2219 & 24758 & 0.0729 & 1.7116 & 1.9659 & 0.001 & 0.017 & 0.0027 & 0.0125 & 0.042 & 0 & 0 & 0 & 0.0069 & 0.0046 \\
\hline D & 2923 & 29577 & 0.1908 & 1.2803 & 0.2477 & 0.0193 & 0.0103 & 0.0044 & 0.0076 & 0 & 0 & 0.0265 & 0 & 0.013 & 0.0064 \\
\hline E36 & 319 & 1860 & 0.0988 & 2.5567 & 0.0399 & 0.0095 & 0.0134 & 0.0071 & 0.0266 & 0 & 0 & 0 & 0 & 0 & 0 \\
\hline E37-39 & 2660 & 13748 & 0.1116 & 1.8111 & 0.0698 & 0.0125 & 0.0131 & 0.0133 & 0.0082 & 0 & 0 & 0.0005 & 0 & 0.0065 & 0.0118 \\
\hline $\mathrm{F}$ & 40541 & 289349 & 0.0388 & 1.6356 & 0.4075 & 0.0131 & 0.0074 & 0.0045 & 0.0117 & 0.2993 & 63 & 0.0096 & 0 & 0.0046 & 0.0037 \\
\hline G45 & 12773 & 79935 & 0.0225 & 2.0223 & 0.4369 & 0.0131 & 0.006 & 0.0048 & 0.0182 & 0.0135 & 0 & 0.0257 & 0 & 0.0039 & 0.0002 \\
\hline G46 & 35476 & 211081 & 0.037 & 2.4179 & 0.4586 & 0.0224 & 0.0086 & 0.0051 & 0.013 & 0.0391 & 127 & 0.0405 & & 0.0676 & 0.0035 \\
\hline G47 & 54533 & 367771 & 0.0135 & 2.9497 & 0.3531 & 0.0159 & 0.0041 & 0.0085 & 0.0188 & 0.0041 & 0.0458 & 0.1216 & 0.009 & 0 & 0 \\
\hline H49 & 15527 & 130956 & 0.0272 & 2.0273 & 0.1591 & 0.0188 & 0.0061 & 0.0255 & 0.019 & 0.0015 & 0.0017 & 0.0261 & 0.0307 & 0.0353 & 0.0273 \\
\hline $\mathrm{H} 50$ & 194 & 650 & 0.0356 & 1.2557 & 0.165 & 0.0524 & 0.004 & 0.0018 & 0.006 & 0 & 0.0001 & 0.0002 & 0 & 0.0029 & 0.0083 \\
\hline H51 & 315 & 8345 & 0.0939 & 1.2358 & 0.4242 & 0.0549 & 0.0106 & 0.0043 & 0.0084 & 0 & 0 & 0.0089 & 0 & 0.007 & 0.0069 \\
\hline H52 & 1681 & 51360 & 0.0403 & 2.7059 & 0.0467 & 0.0112 & 0.0091 & 0.0054 & 0.0206 & 0.0008 & 0.0006 & 0.0049 & 259 & 0.0133 & 0.0121 \\
\hline H53 & 681 & 27422 & 0.022 & 2.1974 & 1.0186 & 0.026 & 0.0077 & 0.014 & 0.0255 & 0 & 0 & 0.0019 & 0 & 0.0027 & 0.0015 \\
\hline I & 58156 & 297890 & 0.0177 & 2.7159 & 0.2627 & 0.0103 & 0.0042 & 0.0161 & 0.0049 & 0 & 0 & 0.1177 & .0002 & 0.0164 & 0.0121 \\
\hline $\mathrm{J} 58$ & 1635 & 13604 & 0.0601 & 1.5738 & 1.5796 & 0.0591 & 0.0107 & 0.0017 & 0.0009 & 0.0074 & 0 & 0.0076 & 0.0009 & 0.0064 & 0.0115 \\
\hline J59_60 & 3754 & 13894 & 0.0384 & 1.5732 & 0.5471 & 0.0521 & 0.0074 & 0.0033 & -0.0297 & 0.0027 & 0 & 0.0063 & 0 & 0.0019 & 0.0047 \\
\hline J61 & 407 & 11480 & 0.1414 & 1.7194 & 0.1377 & 0.0319 & 0.0158 & 0.003 & 0.0087 & 0 & 0 & 0.017 & 0 & 0.0051 & 0.0046 \\
\hline J62_63 & 20232 & 61985 & 0.0429 & 2.0445 & 1.1036 & 0.0912 & 0.0117 & 0.0031 & 0.0183 & 65 & 0 & 0 & 0 & 0.014 & 0.0106 \\
\hline K64 & 2242 & 80368 & 0.0442 & 2.5271 & 0.2425 & 0.0186 & 0.0125 & & 0.0165 & 0 & 0 & 0.0172 & 01 & 0.0131 & 0.0075 \\
\hline K65 & 451 & 30324 & 0.0474 & 1.7555 & 0.3369 & 0.0105 & 0.0121 & 0.0464 & 0.0216 & 0 & 0 & 0.024 & 0 & 0.0065 & 0.0036 \\
\hline K66 & 11338 & 24314 & 0.0296 & 1.551 & 2.1919 & 0.0428 & 0.0049 & 0.0252 & 0.0121 & 0 & 0 & 0.002 & 0 & 0.0007 & 0.0007 \\
\hline L68A & 12043 & 29579 & 0.3389 & 3.1659 & 0.0808 & 0.0251 & 0.011 & 0.0138 & 0.0111 & 0.0046 & 0053 & 0.1743 & 0.0006 & 0.0009 & 0.0006 \\
\hline M69_70 & 42306 & 127617 & 0.0312 & 1.9971 & 0.9796 & 0.01 & 0.0081 & 0.0051 & 0.0169 & 0.0008 & 0.0013 & 0.0025 & 0 & 0.0112 & 0.0092 \\
\hline M71 & 21944 & 65354 & 0.0301 & 2.1107 & 0.4376 & 0.0253 & 0.0072 & 0.0031 & 0.0165 & 0.0213 & 0.0783 & 0 & & 0.0087 & 0.0033 \\
\hline M72 & 2351 & 14252 & 0.1473 & 3.7771 & 1.4741 & 0.1967 & 0.0544 & 0.0136 & 0.0018 & 0.138 & 0 & 0 & 0.0022 & 0.0116 & 0.0045 \\
\hline M73 & 14055 & 36513 & 0.0368 & 1.3863 & 1.4981 & 0.0327 & 0.0042 & 0.0106 & 0.0076 & 0 & 0 & 0 & 0.0002 & 0.0055 & 0.0065 \\
\hline M74_75 & 14077 & 21981 & 0.0242 & 2.1125 & 0.7877 & 0.0334 & 0.0037 & 0.0082 & 0.0051 & 0 & 0 & 0.0022 & 0.0002 & 0.001 & 0.0004 \\
\hline N77 & 3578 & 12244 & 0.1527 & 3.2182 & 0.0886 & 0.0594 & 0.0064 & 0.0051 & 0.0034 & 0 & 0 & 0.0076 & 0.0014 & 0.0058 & 0.0063 \\
\hline N78 & 1437 & 82828 & 0.0129 & 8.2179 & 5.9181 & 0.0465 & 0.0083 & 0.0009 & 0.0453 & 0 & 0 & 0 & 0 & 0.0005 & 0.0007 \\
\hline N79 & 2692 & 14603 & 0.0375 & 1.2591 & 0.9812 & 0.0207 & 0.0047 & 0.0073 & 0.0073 & 0 & 0 & 0.0126 & 0.0018 & 0.0003 & 0.0004 \\
\hline N80-82 & 14290 & 113132 & 0.0144 & 2.7553 & 0.6078 & 0.0177 & 0.0044 & 0.0059 & 0.0223 & 0.0018 & 0.0042 & 0.0056 & 0.0086 & 0.0015 & 0.0018 \\
\hline $\mathrm{O}$ & 10000 & 251139 & 0.021 & 3.3616 & 0.1005 & 0.0116 & 0.0092 & 0.043 & 0.0182 & 0 & 0 & 0.0004 & 0.3324 & 0.0009 & 0.0004 \\
\hline $\mathrm{P}$ & 12573 & 115507 & 0.0347 & 7.5534 & 0.1459 & 0.0168 & 0.02 & 0.0258 & 0.0267 & 0 & 0 & 0.0144 & 0.2207 & 0.0001 & 0.0003 \\
\hline Q86 & 40749 & 166917 & 0.0301 & 3.484 & 0.2014 & 0.0131 & 0.0116 & 0.0449 & 0.0125 & 0 & 0 & 0.0351 & 0.2371 & 0.001 & 0.0007 \\
\hline Q87_88 & 20452 & 138958 & 0.011 & 3.3889 & 0.2302 & 0.0121 & 0.0057 & 0.0306 & -0.0348 & 0 & 0 & 0.0249 & 0.0478 & 0 & 0.0029 \\
\hline R90-92 & 16239 & & 0.0229 & & & 0.0236 & & 0.0211 & -0.0063 & 0.0023 & 0 & 0.0133 & 0.0129 & 0.0013 & 0.0021 \\
\hline R93 & 6525 & 22679 & 0.019 & 2.7802 & 0.0663 & 0.0089 & 0.0041 & 0.0165 & 0.0022 & 0 & 0 & 0.0097 & 0.0047 & 0.0001 & 0.0001 \\
\hline S94 & 7182 & 57121 & 0.014 & 2.6605 & 0.151 & 0.0088 & 0.0057 & 0.0659 & 0.0316 & 0 & 0 & 0.0111 & 0.0218 & 0 & 0 \\
\hline S95 & 1979 & 4947 & 0.0509 & 2.3756 & 2.3287 & 0.1374 & 0.0116 & 0.0193 & 0.0149 & 0 & 0 & 0.0021 & 0 & 0 & 0 \\
\hline S96 & 18762 & 60330 & 0.0123 & 3.476 & 0.1833 & 0.0128 & 0.0028 & 0.0104 & 0.0134 & 0 & 0 & 0.0172 & 0.002 & 0 & 0.0002 \\
\hline
\end{tabular}

Notes: Sectoral parameters are calculated for 2010:Q4.

in the $i^{\text {th }}$ firm $\left(\kappa_{i}\right)$ is set using cross-classification of fixed assets by industry and by asset (stocks) (nama_10_nfa_st) 
Table B.8: Statistical classification of economic activities in the European Community (NACE Rev. 2)

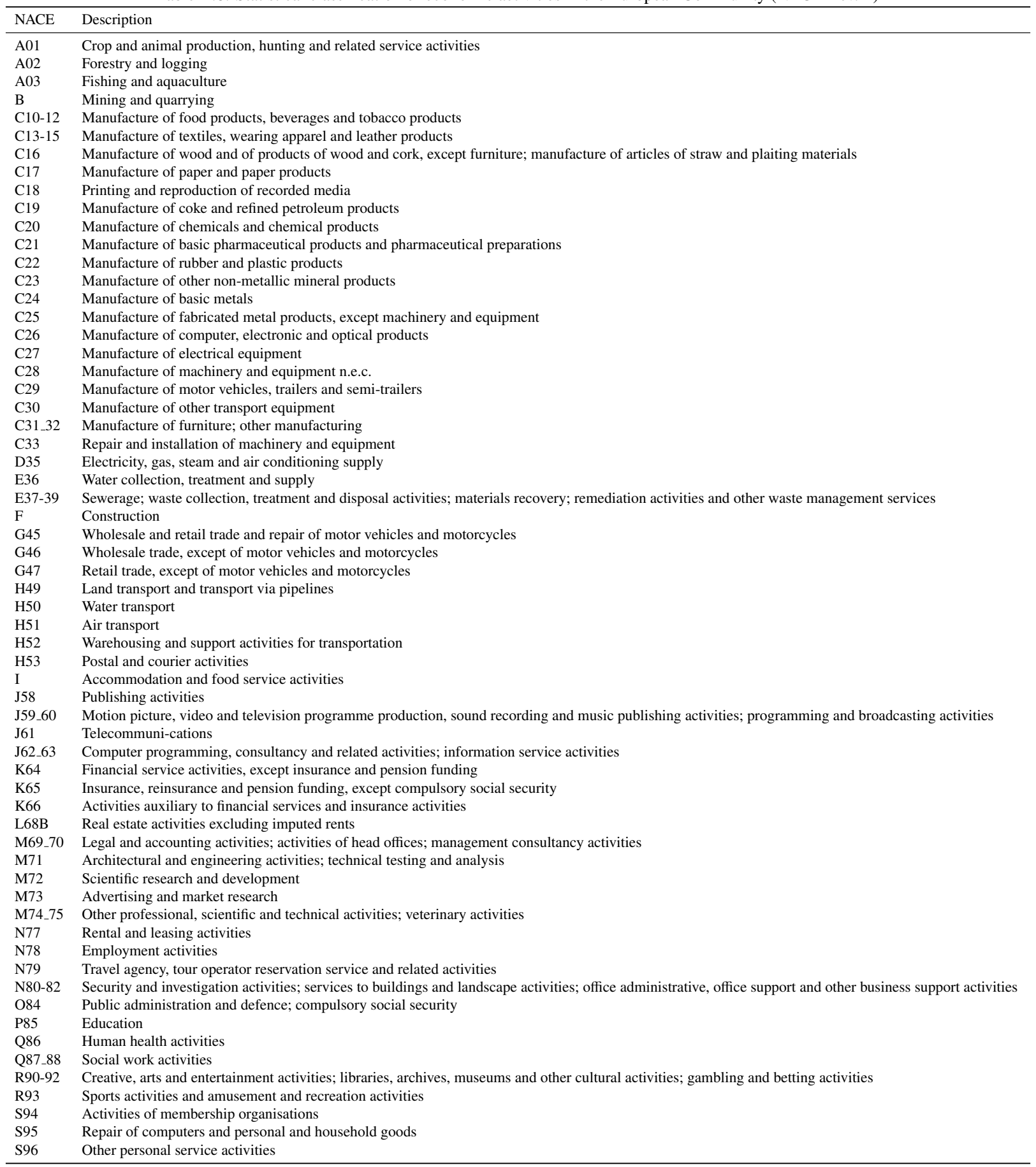

and is again assumed to be equal across firms by industries $\left(\kappa_{i}=\kappa_{s} \quad \forall i \in I_{s}\right)$, and different across industries $s$. It is defined by output (P.1) in the industry divided by total fixed assets (net) $(\mathrm{N} 11 \mathrm{~N})^{40}$ in the industry multiplied by the desired capacity utilization rate ( $\omega$, see the Appendix C.1). An exception is the sector L68 (real estate services),

${ }^{40}$ We use total fixed assets (net) because the gross capital stock includes the values of the accumulated consumption of fixed capital. Most fixed 
where the stock of household dwellings $\left(K_{h}(0)\right)$ is included that has no productive use in the economy regarding the output of goods and services on markets, and thus has to be treated differently. We remove the stock of dwellings from sector L68 and attribute it to the household sector, see Appendix C.2. The productivity of intermediate consumption goods of firm $i\left(\beta_{i}\right)$ is again the same for each firm in industry $s$, but differs across industries $\left(\beta_{i}=\beta_{s} \quad \forall i \in I_{s}\right)$. It is defined by output (P.1) in the industry divided by total intermediate consumption (P.2) of the industry from symmetric input-output tables. The average depreciation of capital in the $i^{\text {th }}$ firm $\left(\delta_{i}\right)$ is again heterogenous across industries and homogenous across firms by industry $\left(\delta_{i}=\delta_{s} \quad \forall i \in I_{s}\right)$. It is defined by consumption of fixed capital (P.51C1) in the industry divided by total fixed assets (net) $(\mathrm{N} 11 \mathrm{~N})$ in the industry multiplied by the desired capacity utilization rate.

Firms' dividend payout ratio $\theta^{\mathrm{DIV}}$ is set to match interest and dividend receipts (D.4 received) plus mixed income $(\text { B. } 2 \mathrm{~A} 3 \mathrm{~N})^{41}$ by the household sector in national accounting data (non-financial transactions (nasa_nf_tr)) in relation to total net operating surplus and mixed income (B.2A3N) as obtained from IOTs. As these payments also include interest payments to the household sector, the dividend payout ratio can be seen as the total return property rights ownership in non-financial and financial firms by the household sector, and is set accordingly for each individual firm.

\section{Appendix B.2. Households}

Parameters that specify the number of households (persons) are taken directly (or derived from) census data. We use the register-based census and the register-based labor market statistics in Austria conducted by Statistik Austria, and supplied via Eurostat. Specifically we are using statistics on population by current activity status, NACE Rev. 2 activity and NUTS 2 region (cens_11an_r2) to set the constant number of inactive persons $\left(H^{\text {inact }}\right)$. The total number of economically active persons $\left(H^{\text {act }}\right)$ is set to the total number of persons employed in the population of active enterprises in $\mathrm{t}$ (V16910) plus the total number of unemployed and one investor for each firm. The total number of unemployed (plus the labor reserve) is taken from the European Labour Force Survey (LFS). ${ }^{42}$

Households' marginal propensity to consume out of initial disposable income $(\psi)$ is chosen such that consumption out of disposable income $\left(\psi Y_{h}(0)\right)$ equals actual household and NPISH consumption in IOTs (P.3 in sectors S.14, S.15). The parameter $\psi^{\mathrm{H}}$ capturing the fraction of household expected disposable income $Y_{h}(0)$ which is invested gross of taxes every period is set according to IOTs. We set $\psi^{\mathrm{H}}$ such that investment by the firm sector (in line with our investment function) plus investment by the household sector equals total gross fixed capital formation (P.51G). The household investment coefficients $b_{g}^{\mathrm{CFH}}$ are set such that investment in dwellings as obtained from IOTs for Austria provided by Statistik Austria ${ }^{43}$ and gross fixed capital by sector from IOTs are mutually consistent. The replacement rate for unemployment benefits $\theta^{\mathrm{UB}}$ is chosen according to the statutory replacement rate of 55 percent of net income, which amounts to a replacement rate on gross income of $\theta^{\mathrm{UB}}=0.55\left(1-\tau^{\mathrm{INC}}\right)\left(1-\tau^{\mathrm{SIW}}\right)$.

\section{Appendix B.3. The general government}

The number of government entities $(J)$ is set to 25 percent of domestically producing firms, which roughly equals the share of government consumption in total value added. This corresponds to a realistic depiction of public entities comprising municipalities, public schools, social insurance carriers, and districts, among others, in Austria according to their participation in the Austrian economy.

\footnotetext{
assets can be recorded in balance sheets at current purchasers' prices reduced for the accumulated consumption of fixed capital; this is known as the written-down replacement cost. The sum of the reduced values of all fixed assets still in use is described as the net capital stock. The gross capital stock includes the values of the accumulated consumption of fixed capital.

${ }^{41}$ In the logic of IOTs, the self-employed are attributed to firm sectors. Thus, operating surplus of IO sectors includes mixed income, which directly flows to households in the depiction of our model and is thus treated as dividend income.

${ }^{42}$ The number of unemployed and employed persons extracted from the Labour Force Survey (LFS) complies with the ILO definition. According to the ILO definition, unemployed persons are defined as persons who are without work during the reference week, are currently available to work and have either actively been seeking work during the past four weeks or have already found a job to start within the next three months. The LFS also provides information on persons who do not meet the ILO criteria for unemployment but who are willing and available to work within short notice (labor reserve).

${ }^{43}$ See https://www.statistik.at/web_en/statistics/Economy/national_accounts/input_output_statistics/index.html (Last accessed November $30^{\text {th }}, 2018$ ) for more information on IOTs provided by Statistik Austria. More detailed IOTs for Austria, which include a breakdown of investment into different investment purposes (dwellings, other buildings and structures, machinery, transport equipment, cultivated assets, and intangible fixed assets), can be purchased. This is the only case where we do not rely on publicly and freely available data from the Eurostat bulk download facility.
} 
Tax and subsidy rates are set such that these rates approximate the actual financial flows observed in national accounting data, i.e. non-financial transactions (nasa_10_nf_tr), as well as government revenue, expenditure and main aggregates (gov_10a_main). In the context of the model, we define an average tax rate as the aggregate tax flow paid by an institutional sector (firms in CPA classification, households, etc.) divided by the corresponding aggregate monetary flow that serves as the base for the tax and that is received by the same institutional sector (such as income, profit, output, fixed assets, etc.). This average tax rate obtained from macroeconomic aggregates is then applied to every individual unit/person in our model in the corresponding economic context. The income tax rate $\tau^{\mathrm{INC}}$ on income from both labor and capital is particularly chosen such that tax payments on wages received by employees and taxes on dividends received by investors add up to total income tax payments by the household sector taken from government expenditure data (gov_10a_main, D.5REC and D.91REC). ${ }^{44}$ For reasons of model parsimony we abstract from the progressivity of the Austrian tax system (e.g. regarding income taxes), and secondly from other tax regulations (deductions, exemptions, etc.) relevant for some agents due to specific features of the Austrian tax code.

Firm profit taxes $\tau^{\mathrm{FIRM}}$ are specified by the ratio of total corporate tax flows (D.51, paid by sectors S.11 and S.12), which are obtained from national accounting data (non-financial transactions (nasa_nf_tr)), to total operating surplus and mixed income (sum over all firm sectors), which we directly take from IOTs (B.2A3N). Value added tax rates $\tau^{\mathrm{VAT}}$ are specified as total value added taxes net of subsidies (D.21X31) from IOTs divided by consumption by households and NPISH (P.3 in sectors S.14 and S.15). Rates for social security contributions both for employers $\left(\tau^{\mathrm{SIF}}\right)$ and employees $\left(\tau^{\mathrm{SIW}}\right)$ are levied on gross wage income of households (D.11) as given in IOTs. Employers' social security contributions are taken from IOTs by subtracting total gross wage income (D.11) from total compensation of employees (D.1). Employees' social contributions include actual social security contributions (D.613) as well as social security supplements to be paid by employees (D.614), and are obtained by subtracting employers' social contributions from total social contributions received by the government according to government statistics (gov_10a_main, D.61REC). Finally, sector-specific net rates for other taxes and subsidies on products $\left(\tau_{i}^{\mathrm{Y}}=\tau_{s}^{\mathrm{Y}} \quad \forall i \in I_{s}\right)$ as well as on production $\left(\tau_{i}^{\mathrm{K}}=\tau_{s}^{\mathrm{K}} \quad \forall i \in I_{s}\right)$ are taken from IOTs: sectoral product tax (D.21X31) and production tax (D.29X39) payments. Tax rates on exports $\left(\tau^{\text {EXPORT }}\right)$, which are levied on total firms' exports as in IOTs (P.6 total) as a uniform tax rate according to total net export tax flows in IOTs (D.21X31 for final use export, P.6). Taxes on capital formation $\left(\tau^{\mathrm{CF}}\right)$ payable on firm investments are determined by dividing tax flows on investments as IOTs (D.21X31) by total investments in dwellings (obtained from IOTs provided by Statistik Austria, see footnote 43).

\section{Appendix B.4. The Bank}

Banks' capital requirement coefficient $(\zeta)$ is set at 3 percent. A capital requirement of 3 percent corresponds to the maximum leverage ratio (tier 1 capital in relation to total exposure) as recommended in the Basel III framework. The rate of debt installment $(\theta)$ is set such that firms repay 5 percent of their total outstanding debt every quarter. The risk premium $\mu$ paid on firms' outstanding debt is obtained from national accounting data. It is set such that total interest payments in our model financial market, where firm debt constitutes the only financial asset held by the banking sector, matches empirically observed interest payments (D.41) paid by non-financial (S.11) and financial corporations (S.12) in national accounting data (non-financial transactions (nasa_nf_tr)). Therefore, the risk premium by the banking sector $\mu$ is calculated by the difference between the 3-month Euribor interest rate obtained from money market interest rates (irt_st_a) and the observed interest payments (D.41) divided by the initial amount of firm debt $L^{\mathrm{I}}$, which is obtained from national accounting data, see Appendix C. In order to obtain a quarterly risk premium, $\mu$ is converted to a quarterly rate. The bank's maximum loan-to-value (LTV) ratio ( $\left.\zeta^{\mathrm{LTV}}\right)$ is set to 60 percent. LTV is one of the most common ratios considered for secured loans, and loans with an LTV ratio below 60 percent are typically considered as low- or medium-risk loans. Finally, the loan-to-value ratio for a new firm replacing a bankrupt firm $\zeta^{\mathrm{b}}$ is set to be equal to 0.5 .

\footnotetext{
${ }^{44}$ From national accounting data alone, it is not possible to distinguish between the amount of income taxes due to incomes from labor and capital, respectively. For this distinction, it would be necessary to resort to the Austrian tax code and household surveys.
} 


\section{Appendix C. Initial conditions for the Austrian economy}

We set initial conditions for the model presented in Appendix A to represent the Austrian economy. All initial conditions in the model are collected in Table C.9. For the forecasting exercise in Section 3, initial conditions were initially calculated and set according to 2010:Q1 and then, respectively, recalculated and reset, every quarter until 2013:Q4. Here we show and discuss, as an example, initial conditions for 2010:Q4.

Table C.9: Initial conditions

\begin{tabular}{llr}
\hline Initial condition & Description & Value \\
\hline$P_{i}(0)$ & Initial price of the $i^{\text {th }}$ firm & see Appendix C.1 \\
$Y_{i}(0) / Q_{i}^{\text {d }}(0)$ & Initial production/demand of the $i^{\text {th }}$ firm (in mln. Euro) & see Appendix C.1 \\
$K_{i}(0)$ & Initial capital of the $i^{\text {th }}$ firm (in mln. Euro) & see Appendix C.1 \\
$M_{i}(0)$ & Initial stocks of raw materials, consumables, supplies of the $i^{\text {th }}$ firm (in mln. Euro) & see Appendix C.1 \\
$S_{i}(0)$ & Initial stocks of finished goods of the $i^{\text {th }}$ firm (in mln. Euro) & see Appendix C.1 \\
$N_{i}(0)$ & Initial number of employees of the $i^{\text {th }}$ firm & see Appendix C.1 \\
$D_{i}(0)$ & Initial liquidity (deposits) of the $i^{\text {th }}$ firm (in mln. Euro) & see Appendix C.1 \\
$L_{i}(0)$ & Initial debt of the $i^{\text {th }}$ firm (in mln. Euro) & see Appendix C.1 \\
$\Pi_{i}(0)$ & Initial profits of the $i^{\text {th }}$ firm (in mln. Euro) & see Appendix C.1 \\
$D_{h}(0)$ & Initial personal assets (deposits) of the $h^{\text {th }}$ household (in mln. Euro) & see Appendix C.2 \\
$K_{h}(0)$ & Initial household capital (in mln. Euro) & see Appendix C.2 \\
$w_{h}(0)$ & Initial wage of the $h^{\text {th }}$ household (in mln. Euro) & see Appendix C.2 \\
$s b^{\text {inact }}(0)$ & Initial pension/social benefits in mln. Euro & 0.0022 \\
$s b^{\text {other }}(0)$ & Initial social benefits received by all households in mln. Euro & 0.0007 \\
$L^{\mathrm{G}}(0)$ & Initial government debt (in mln. Euro) & 243871.1 \\
$\Pi_{k}(0)$ & Initial banks' profits (in mln. Euro) & 97802.3 \\
$E_{k}(0)$ & Initial banks' equity (in mln. Euro) & 115947.6 \\
$E^{\mathrm{CB}}(0)$ & Initial central banks' equity (in mln. Euro) & 0 \\
$D^{\mathrm{Row}}(0)$ & Initial net creditor/debtor position of the national economy to RoW (in mln. Euro) & see Appendix C.4 \\
\hline
\end{tabular}

Notes: Initial condition are shown for 2010:Q4.

Table C.10: Initial conditions for the institutional sectors

\begin{tabular}{llr}
\multicolumn{2}{c}{ Table C.10: Initial conditions for the institutional sectors } & Value \\
\hline Initial condition & Description & 52141.2 \\
$D^{\mathrm{I}}$ & Initial liquidity (deposits) of the firm sector (in mln. Euro) & 244953.2 \\
$L^{\mathrm{I}}$ & Initial debt of the firm sector (in mln. Euro) & 0.85 \\
$\omega$ & Desired capacity utilization rate & 0.0038 \\
$w^{\mathrm{UB}}$ & Initial unemployment benefits (in mln. Euro) & 222933.2 \\
$D^{\mathrm{H}}$ & Initial personal assets (deposits) of the household sector (in mln. Euro) \\
$K^{\mathrm{H}}$ & Initial capital (dwellings) of the household sector (in mln. Euro) & 401079.7 \\
\hline
\end{tabular}

Notes: Initial condition are shown for 2010:Q4.

\section{Appendix C.1. Firms}

The distribution of firm sizes in industrial countries is well-known to be highly skewed, with large numbers of small firms coexisting with small numbers of large firms (Ijiri and Simon, 1977; Axtell, 2001). Initial employment of firm $i\left(N_{i}(0) \quad \forall i \in I_{s}\right)$ is therefore drawn from a power law distribution with exponent -2 (where $\sum_{i \in I_{s}} N_{i}(0)=N_{s}$ and $\left.N_{i}(0)>0\right)$, which approximately corresponds to firm size distribution in Austria. ${ }^{45}$ To determine initial production

\footnotetext{
${ }^{45}$ The firm size distribution is obtained from the SABINA database.
} 
$Y_{i}(0)$ of the $i^{\text {th }}$ firm, we use the initial employment by firm $N_{i}(0)$, and compute the corresponding amount of production by the productivity of labour per unit of output $\bar{\alpha}_{i}$ :

$$
Y_{i}(0)=Q_{i}^{\mathrm{d}}(0)=\bar{\alpha}_{i} N_{i}(0) .
$$

Initial capital of firm $i, K_{i}(0),(i$ is part of industry $s)$ is then obtained by dividing firm $i$ 's initial level of production $Y_{i}(0)$ by the productivity of capital $\kappa_{i}$ and the desired rate of capacity utilization $\omega$.

$$
K_{i}(0)=\frac{Y_{i}(0)}{\kappa_{i} \omega}
$$

Thus, it is the share of capital of the $i^{\text {th }}$ firm in sector $s$ as measured by production, accounting for the reserve capacity of its capital stock targeted by firm $i$. The initial stocks of raw materials, consumables, supplies, and spare parts (i.e. intermediate inputs) of the $i^{\text {th }}$ firm $\left(M_{i}(0)\right)$ are set such that-given the initial level of production by firm $i$, the productivity of intermediate inputs $\beta_{i}$ and a buffer stock of material inputs $1 / \omega$-firms hold enough intermediate inputs to be able to provide for expected use of these inputs as well as accounting for their desired buffer stock:

$$
M_{i}(0)=\frac{Y_{i}(0)}{\omega \beta_{i}} .
$$

Regarding financial and current assets cross-classification tables are not available. Correspondingly, a breakdown of financial and current assets for the 64 economic activities (NACE*64) is not available in macroeconomic data. Thus, we apportion initial debt $L_{i}(0)$ to the $i^{\text {th }}$ individual firm by disaggregating total firm debts according to the share of the firms' capital stock $K_{i}(0)$ in the total capital stock $\sum_{i} K_{i}(0)$ :

$$
L_{i}(0)=L^{\mathrm{I}} \frac{K_{i}(0)}{\sum_{i} K_{i}(0)},
$$

where the total amount of firm debt $L^{\mathrm{I}}$ is obtained from national accounting data (financial balance sheets (nasa_10_f_bs), loans (F.4) of non-financial corporations (S.11), non-consolidated liability position). The total initial liquidity (deposits) of all firms as an aggregate, $D^{\mathrm{I}}$, is set according to national accounting data (financial balance sheets (nasa_10_f_bs), non-consolidated deposits (F.2) held by the non-financial corporations sector (S.11)). This aggregate is broken down onto single firms by the share of firm $i$ 's operating surplus in the overall operating surplus, where we assume that firm liquidity (deposits) moves in line with its production as a liquid form of working capital used for current expenditures:

$$
D_{i}(0)=D^{\mathrm{I}} \frac{\max \left(\bar{\pi}_{i} Y_{i}(0), 0\right)}{\sum_{i} \max \left(\bar{\pi}_{i} Y_{i}(0), 0\right)},
$$

where $\bar{\pi}_{i}=\left(1-\left(\left(1+\tau^{\mathrm{SIF}}\right) \frac{\bar{w}_{i}}{\bar{\alpha}_{i}}+\frac{\delta_{i}}{\kappa_{i}}+\frac{1}{\beta_{i}}\right)\right)-\tau_{i}^{\mathrm{K}}-\tau_{i}^{\mathrm{Y}}$ is the operating margin. Initial profit of the $i^{\text {th }}$ firm is given by the initial operating surplus and the initial income from interest less interest payments:

$$
\Pi_{i}(0)=\bar{\pi}_{i} Y_{i}(0)-r(0) L_{i}(0)+\bar{r}(0) D_{i}(0) .
$$

The initial inventories of finished goods $S_{i}(t)$ of firm $i$ is assumed to be equal to zero due to a lack of reliable data sources. The initial price of the $i^{\text {th }}$ firm $P_{i}(0)$ is set to one.

\section{Appendix C.2. Households}

Initial personal assets (deposits) of the $h^{\text {th }}$ household $\left(D_{h}(0)\right)$ are obtained from national accounting data (financial balance sheets (nasa_10_f_bs), F.2, currency and deposits held by the household and NPISH sectors, S14_S15, non-consolidated asset position), which is disaggregated onto the individual level according to the share of each household's income in total income as a proxy for the household's wealth:

$$
D_{h}(0)=D^{\mathrm{H}} \frac{Y_{h}(0)}{\sum_{h} Y_{h}(0)},
$$

where $D^{\mathrm{H}}$ are the initial personal assets (deposits) of the household sector and $Y_{h}(0)$ is determined according to equation (A.49). Initial capital (dwellings) of the $h^{\text {th }}$ household $\left(K_{h}(0)\right)$ is set to match dwellings $(\mathrm{N} 111 \mathrm{~N})$ as obtained 
from balance sheets for non-financial assets (nama_10_nfa_st) and is again disaggregated onto the individual level according to the share of each household's income in total income as a proxy for the household's wealth:

$$
K_{h}(0)=K^{\mathrm{H}} \frac{Y_{h}(0)}{\sum_{h} Y_{h}(0)},
$$

where $K^{\mathrm{H}}$ is the initial capital (dwellings) of the household sector.

The initial wage of the $h^{\text {th }}$ household $\left(w_{h}(0)\right)$ is equal to the initial wage paid by firm $i\left(\bar{w}_{i}\right)$, if $i$ is the employer of household $h$; or it is equal to the initial unemployment benefits $w^{\mathrm{UB}}$, if the household is unemployed. Initial unemployment benefits are set by dividing the total flow of unemployment payments (GF.1005), as obtained from the Eurostat data set government expenditure by funcion (gov_10a_exp), by the amount of unemployed persons (wstatus=UNE), which is determined according to the statistics on population by current activity status, NACE Rev. 2 activity and NUTS 2 region (cens_11an_r2). Thus, $w_{h}(0)$ is determined as follows:

$$
w_{h}(0)=\left\{\begin{array}{ll}
w^{\mathrm{UB}} & \text { if unemployed } \\
\bar{w}_{i} & \text { if employed by firm } i
\end{array} .\right.
$$

Transfers other than consumption, savings, taxes and subsidies ${ }^{46}$ are netted out for the government and household sectors, and treated as a net transfer from the government to the household sector. Government transfers to households in the form of social benefits (D.62) are attributed to the different household (consumer) types according to their employment status. The data are taken from national accounting statistics on general government expenditures by function (COFOG classification, Eurostat table gov_10a_exp), which are used to allocate the total flow of the different social benefits $\left(s b^{\text {inact }}(0), s b^{\text {other }}(0)\right)$ from the government to persons to whom this transfer applies. To break the overall economic flows of social benefits down onto an individual household level, we follow the following procedure: all social benefits are given in equal proportion to the different household types such that the sum of individual flows adds up to total macroeconomic flows.

\section{Appendix C.3. The general government}

Initial government debt $\left(L^{\mathrm{G}}(0)\right)$ is set according to the Austrian government's (sector S.13) consolidated gross debt (GD) as obtained from the Eurostat data set government deficit/surplus, debt and associated data (gov_10dd_edpt1).

\section{Appendix C.4. The Bank}

Initial bank's equity $\left(E_{k}(0)\right)$ is obtained from national accounting data (financial balance sheets (nasa_10_f_bs), F.5 and BF.90, non-consolidated equity and financial net worth of monetary financial institutions other than the central bank (S122_S123)). Initial bank's profits are given by the initial income from interest less interest payments:

$$
\Pi_{k}(0)=r(0) \sum_{i} L_{i}(0)+\bar{r}(0)\left(\sum_{i} D_{i}(0)+\sum_{h} D_{h}(0)-D_{k}(0)\right),
$$

where initial advances from the central bank $\left(D_{k}(0)\right)$ are set according to equation (A.68).

\section{Appendix C.5. The Central Bank}

Initial central bank's equity $\left(E^{\mathrm{CB}}(0)\right)$ is the residual on the central bank's passive side, obtained by deducting initial bank reserves held $\left(D_{k}(0)\right)$ and the initial net creditor/debtor position with the rest of the world $\left(D^{\mathrm{RoW}}(0)\right)$ from the central bank's assets (initial government debt $\left.\left(L^{\mathrm{G}}(0)\right)\right)$. Thus, the initial central bank's equity $\left(E^{\mathrm{CB}}(0)\right)$ is set according to equation (A.76) where the initial balance of trade with the rest of the world $\left(D^{\mathrm{RoW}}(0)\right)$ is assumed to be zero and the initial bank reserves held $\left(D_{k}(0)\right)$ are set according to equation (A.68).

\footnotetext{
${ }^{46}$ In particular property and interest income (D.4) in the government sector, other current transfers (D.7), adjustments for changes in pension entitlements (D.8), as well as capital transfers other than capital taxes (D.9 - D.91)
} 


\section{Appendix D. Conditional forecasts with the agent-based model}

We generate forecasts conditional on exogenous paths for imports, exports and government consumption, corresponding to a small open economy setting and exogenous policy decisions. In this setup, we assume that imports and exports, as well as government consumption, are exogenously given from data. Thus, in this setup we replace equations (A.77), (A.81), and (A.51) and set imports, exports and government consumption according to observed data.

Furthermore, in this setup we assume that agents' forecasts take into account expectations on imports, exports and government consumption. Thus, we replace equations (A.6) and (A.9), and assume expectations on economic growth and inflation to be formed using an autoregressive model with exogenous predictors and lag order one (ARX(1)). Thus, in this setup expectations on economic growth are formed according to an ARX(1) rule:

$$
\log \left(Y^{\mathrm{e}}(t)\right)=\alpha^{\mathrm{Y}}(t) \log \left(\sum_{i} Y_{i}(t-1)\right)+\gamma^{\mathrm{I}}(t) \log \left(Y^{\mathrm{I}}(t)\right)+\gamma^{\mathrm{G}}(t) \log \left(C^{\mathrm{G}}(t)\right)+\gamma^{\mathrm{E}}(t) \log \left(C^{\mathrm{E}}(t)\right)+\beta^{\mathrm{Y}}(t)+\epsilon^{\mathrm{Y}}(t),
$$

where $\alpha^{\mathrm{Y}}(t), \gamma^{\mathrm{I}}(t), \gamma^{\mathrm{E}}(t), \gamma^{\mathrm{G}}(t), \beta^{\mathrm{Y}}(t)$, and $\epsilon^{\mathrm{Y}}(t)$ are re-estimated every period on the time series of aggregate output of firms $\sum_{i} Y_{i}\left(t^{\prime}\right)$ and the exogenous predictors imports $Y^{\mathrm{I}}\left(t^{\prime}\right)$, exports $C^{\mathrm{E}}\left(t^{\prime}\right)$ as well as government consumption $C^{\mathrm{G}}\left(t^{\prime}\right)$, where $t^{\prime}=-T^{\prime},-T^{\prime}+1,-T^{\prime}+2, \ldots, 0,1,2, \ldots, t-1$. To allow the data to decide on the degree of persistence and cointegration, output, imports and exports as well as government consumption are entered in log levels.

Similarly, in this setup expectations on inflation are formed using an autoregressive model with exogenous predictors and lag order one (ARX(1)):

$$
\log \left(1+\pi^{\mathrm{e}}(t)\right)=\alpha^{\pi}(t) \pi(t-1)+\gamma^{\mathrm{I}}(t) \log \left(Y^{\mathrm{I}}(t)\right)+\gamma^{\mathrm{G}}(t) \log \left(C^{\mathrm{G}}(t)\right)+\gamma^{\mathrm{E}}(t) \log \left(C^{\mathrm{E}}(t)\right)+\beta^{\pi}(t)+\epsilon^{\pi}(t),
$$

where $\alpha^{\pi}(t), \gamma^{\mathrm{I}}(t), \gamma^{\mathrm{E}}(t), \gamma^{\mathrm{G}}(t), \beta^{\pi}(t)$, and $\epsilon^{\pi}(t)$ are re-estimated every period on the time series of inflation $\pi\left(t^{\prime}\right)$, and the exogenous predictors are imports $Y^{\mathrm{I}}\left(t^{\prime}\right)$, exports $C^{\mathrm{E}}\left(t^{\prime}\right)$ and government consumption $C^{\mathrm{G}}\left(t^{\prime}\right)$, where $t^{\prime}=$ $-T^{\prime},-T^{\prime}+1,-T^{\prime}+2, \ldots, 0,1,2, \ldots, t-1$. Again, imports and exports as well as government consumption are entered in $\log$ levels. 


\section{Appendix E. Macroeconomic variables}

Appendix E.1. Gross domestic product

GDP in our model can be defined by the production, expenditure and income approaches:

$$
\begin{aligned}
& G D P(t)=\underbrace{\sum_{i} \tau_{i}^{\mathrm{Y}} P_{i}(t) Y_{i}(t)+\sum_{h} \tau^{\mathrm{VAT}} C_{h}(t)+\sum_{h} \tau^{\mathrm{CF}} I_{h}(t)+\sum_{j} \tau^{\mathrm{G}} C_{j}(t)+\sum_{l} \tau^{\mathrm{EXPORT}} C_{l}(t)}_{\text {Taxes on products }} \\
& +\underbrace{\sum_{i}\left(1-\tau_{i}^{\mathrm{Y}}\right) P_{i}(t) Y_{i}(t)}_{\text {Total sales of goods and services }}-\underbrace{\sum_{g, s, i \in I_{s}} \bar{P}_{g}(t) a_{s g} \frac{Y_{i}(t)}{\beta_{i}}}_{\text {Intermediate inputs }} \quad \text { (Production approach) } \\
& =\underbrace{\sum_{h}\left(1+\tau^{\mathrm{VAT}}\right) C_{h}(t)}_{\text {Household consumption }}+\underbrace{\sum_{j}\left(1+\tau^{\mathrm{G}}\right) C_{j}(t)}_{\text {Government consumption }}+\underbrace{\sum_{h}\left(1+\tau^{\mathrm{CF}}\right) I_{h}(t)+\sum_{i} \bar{P}^{\mathrm{CF}}(t) I_{i}(t)}_{\text {Gross fixed capital formation }} \\
& +\underbrace{\sum_{i} P_{i}(t) \Delta S_{i}(t)+\sum_{g, s, i \in I_{s}} \bar{P}_{g}(t)\left(\Delta M_{i g}(t)-a_{s g} \frac{Y_{i}(t)}{\beta_{i}}\right)}_{\text {Changes in inventories }} \\
& +\underbrace{\sum_{l}\left(1+\tau^{\mathrm{EXPORT}}\right) C_{l}(t)}_{\text {Exports }}-\underbrace{\left.\sum_{m} P_{m}(t) Q_{m}(t)\right)}_{\text {Imports }} \text { (Expenditure approach) } \\
& =\underbrace{\sum_{i} \tau_{i}^{\mathrm{Y}} P_{i}(t) Y_{i}(t)+\sum_{h} \tau^{\mathrm{VAT}} C_{h}(t)+\sum_{h} \tau^{\mathrm{CF}} I_{h}(t)+\sum_{j} \tau^{\mathrm{G}} C_{j}(t)+\sum_{l} \tau^{\mathrm{EXPORT}} C_{l}(t)}_{\text {Taxes on products }}+\underbrace{\left(1+\tau^{\mathrm{SIF}}\right) \bar{P}^{\mathrm{HH}}(t) \sum_{h} w_{h}(t)}_{\text {Compensation of employees }} \\
& +\underbrace{\sum_{i}\left(\Pi_{i}(t)+r(t) L_{i}(t)+\bar{P}^{\mathrm{CF}}(t) \frac{\delta_{i}}{\kappa_{i}} Y_{i}(t)\right)}_{\text {Gross operating surplus and mixed income }}+\underbrace{\sum_{i} \tau_{i}^{\mathrm{K}} P_{i}(t) Y_{i}(t)}_{\text {Net taxes on production }} \text { (Income approach) }
\end{aligned}
$$

\section{Appendix E.2. Inflation}

Inflation, which is measured by the GVA deflator, is the economy-wide average price of all goods and services produced and sold:

$$
G V A \text { deflator }(t)=\frac{\sum_{i}\left(1-\tau_{i}^{\mathrm{Y}}\right) P_{i}(t) Y_{i}(t)-\sum_{g, s, i \in I_{s}} \bar{P}_{g}(t) a_{s g} \frac{Y_{i}(t)}{\beta_{i}}}{\sum_{i}\left(1-\tau_{i}^{\mathrm{Y}}\right) Y_{i}(t)-\sum_{g, s, i \in I_{s}} a_{s g} \frac{Y_{i}(t)}{\beta_{i}}}
$$

where $P_{i}(t)$ and $Y_{i}(t)$ are price and production of firm $i$, respectively.

\section{Appendix E.3. Household Consumption}

Household consumption is the sum of the realized consumption of all individual households, i.e. $\sum_{h}\left(1+\tau^{\mathrm{VAT}}\right) C_{h}(t)$.

\section{Appendix E.4. Investment}

Total fixed investment in the model is the sum of realized investment by individual firms plus the sum of realized investment by individual households, that is, $\sum_{h}\left(1+\tau^{\mathrm{CF}}\right) I_{h}(t)+\sum_{i} \bar{P}^{\mathrm{CF}}(t) I_{i}(t)$.

\section{Appendix E.5. Government Consumption}

Government consumption is the sum of the realized consumption of all government entities, i.e. $\sum_{h=1}^{\mathrm{H}} C_{h}(t)$.

\section{Appendix E.6. Exports}

Export is the sum of the realized consumption of all foreign consumers, i.e. $\sum_{l}\left(1+\tau^{\mathrm{EXPORT}}\right) C_{l}(t)$.

\section{Appendix E.7. Imports}

Import is defined as the total sales of all goods and services produces by foreign firms, i.e. $\left.\sum_{m} P_{m}(t) Q_{m}(t)\right)$. 


\section{Appendix F. DSGE model used for out-of-sample-prediction}

\section{Appendix F.1. DSGE model: Short description}

The DSGE model used for out-of-sample forecasting is a two-country New Keynesian New Open Economy macro model of the Austrian economy (home) and the EA (foreign), constructed tightly along the lines of Smets and Wouters (2007). ${ }^{47}$ It is a modified version of the two-country DSGE model as put forth in Breuss and Rabitsch (2009). Specifically, this model was modified to achieve comparability with the Smets and Wouters (2007) model through the rescaling of several shocks and estimating the model to growth rates, both of which stabilized the Bayesian estimation procedure.

The two-country economy is normalized to one, where the size of the home economy equals $n$, the size of the foreign economy equals $(1-n)$. Firms in each region produce goods using capital and labor according to a CobbDouglas production function. Each of the two countries specializes in the production of one region-specific good, i.e., there are both domestic and foreign tradable goods. These domestic and foreign tradable goods come in several varieties, over which producers have some degree of power in price setting. Investment is assumed to be a constant elasticity of substitution (CES) index over domestic and foreign investment goods. Financial markets are assumed to be complete, that is, a full set of Arrow-Debreu securities is assumed to exist. Households receive utility from consumption and disutility from working. They also own the economy's capital stock, which they rent to firms as means of production, and supply a variety of differentiated labor services, over which they have some degree of power in wage setting. Furthermore, household consumption is assumed to be a CES index over domestic and foreign consumption goods, which is possibly different from the CES investment index. In line with recent literature on DSGE models, a number of both real and nominal frictions is assumed. First, costs for capital adjustment and habit formation are imposed. Second, some degree of stickiness for both prices set by firms and wages demanded by households is assumed according to Calvo (Calvo, 1983) staggered price and wage setting mechanisms. Both prices and wages are partially indexed, that is, they are to some degree inflation-adjusted in the event that price or wage changes are not possible. The DSGE model is estimated using Bayesian methods on a quarterly basis and on the same data set as the time series models.

Below, the model equations for the home economy are set out, assuming that the foreign economy is described by an analogous set of equations unless this is explicitly stated otherwise. All foreign variables are denoted with an asterisk $\left({ }^{*}\right)$.

\section{Appendix F.2. Consumption}

\section{Appendix F.2.1. Households' intertemporal optimization}

The domestic economy is assumed to be populated by a continuum of household agents over the interval $[0, n)$, foreign household agents are populated over $(\mathrm{n}, 1]$. Each household is indicated by the index $j$. Household $j$ intends to maximize her discounted expected lifetime utility, which is assumed to be separable in consumption and leisure. Household $j$ derives utility from consumption $C_{t}(j)$ in relation to a habit level $H_{t}$, and disutility from providing a differentiated type of labor $L_{t}(j)$ :

$$
\max _{C_{t}(j), l_{t}(j), B_{t+1}(j), K_{t+1}(j)} E_{0} \sum_{t=0}^{\infty} \beta^{t}\left\{\left(\frac{\left(C_{t}(j)-H_{t}\right)^{1-\sigma_{c}}}{1-\sigma_{c}}\right) \exp \left(\frac{-\left(1-\sigma_{c}\right)}{1+\sigma_{l}} L_{t}(j)^{1+\sigma_{l}}\right)\right\}
$$

where $\beta$ is the discount factor, $\sigma_{c}$ is the coefficient of relative risk aversion (the inverse of the intertemporal elasticity of substitution), and $\sigma_{l}$ is the inverse of the elasticity of work effort with respect to the real wage.

The habit level $H_{t}$ is assumed to be proportional to aggregate past consumption:

$$
H_{t}=h C_{t-1} \text {. }
$$

The (domestic) household budget constraint is determined by total household income from different sources, and by nominal expenditures for consumption $\left(P_{t} C_{t}(j)\right)$ and investment $\left(P_{t}^{X} X_{t}(j)\right)$, where $P_{t}$ and $P_{t}^{X}$ are the price indices for consumption and investment goods, respectively, which may differ from each other. Sources of income for

\footnotetext{
${ }^{47}$ We would like to thank Katrin Rabitsch from the Vienna University of Economics and Business (WU Wien) for providing us with the codes of an improved version of the DSGE model developed in Breuss and Rabitsch (2009), as well as for her advice and assistance.
} 
household $j$ are wages received $\left(W_{t}^{h h, n o m}(h, j) L_{t}(j) d h\right)$, income from rental of capital to firms for production purposes $\left(R_{t}^{k, n o m} u_{t}(j) \bar{K}_{t-1}\right)$, dividend payments from firm ownership $\left(\frac{1}{n} \int_{0}^{n} \operatorname{Div}(h, j) d h\right)$, and net government transfers $T_{t}(j)$. Under the assumption of complete markets, each individual household has access to a full set of state-contingent (ArrowDebreu) securities. In the following, we denote the price of one unit of domestic currency available in period $t+1$ contingent on the state of nature at $t+1$ being $s_{t+1}$ by $Q\left(s_{t+1} \mid s_{t}\right)$. Assuming complete markets, $Q\left(s_{t+1} \mid s_{t}\right)$ is the same for all individual households. If now $B_{H, t}\left(j, s_{t+1}\right)$ represents the claim to $B_{H, t}$ units of domestic currency at time $t+1$ for the state of nature $s_{t+1}$, which a household $j$ can buy at time $t$ and carry over into time $t+1$. $Q^{*}\left(s_{t+1} \mid s_{t}\right)$ and $B_{F, t}\left(j, s_{t+1}\right)$ are defined analogously in terms of foreign currency. Nominal interest rates can thus be expressed by $R_{t}=1 /\left(\sum_{s_{t+1}} Q\left(s_{t+1} \mid s_{t}\right)\right)$ and $R_{t}^{*}=1 /\left(\sum_{s_{t+1}} Q^{*}\left(s_{t+1} \mid s_{t}\right)\right)$. Now let $S_{t}$ denote the nominal exchange rate of domestic currency per unit of foreign currency.

The household budget constraint, which is subject to a risk shock $\varepsilon_{t}^{b}$, is thus given by:

$$
\left.\begin{array}{c}
\sum_{s_{t+1}} Q\left(s_{t+1} \mid s_{t}\right) \varepsilon_{t}^{b} B_{H, t}\left(j, s_{t+1}\right)+\sum_{s_{t+1}} Q^{*}\left(s_{t+1} \mid s_{t}\right) \varepsilon_{t}^{b} S_{t} B_{F, t}\left(j, s_{t+1}\right)= \\
B_{H, t-1}\left(j, s_{t}\right)+S_{t} B_{F, t-1}\left(j, s_{t}\right)+ \\
W_{t}^{h h, n o m}(h, j) L_{t}(j) d h+R_{t}^{k, n o m} u_{t}(j) \bar{K}_{t-1}(j)+a\left(u_{t}(j) \bar{K}_{t-1}(j)\right) P_{t} \\
+\frac{1}{n} \int_{0}^{n} \operatorname{Div}(h, j) d h+T_{t}(j)-P_{t}^{X} X_{t}(j)-P_{t} C_{t}(j)
\end{array}\right],
$$

where $R_{t}^{k, n o m}$ is the nominal return rate to physical capital, $u_{t}(j)$ is the capital utilization rate as chosen by the household agent, and $\bar{K}_{t-1}$ is previous period's physical capital stock.

Since households choose the utilization rate of capital, the amount of effective capital that households rent to firms is:

$$
K_{t}(j)=u_{t}(j) \bar{K}_{t-1}(j) .
$$

Furthermore, $a\left(u_{t}(j) \bar{K}_{t-1}(j)\right)$ are costs for the utilization of capital that depend on the real return rate on capital, the utilization rate of capital and a fixed parameter $\phi_{a}$ as follows:

$$
a\left(u_{t}(j) \bar{K}_{t-1}(j)\right)=\left[\bar{r}^{k}\left(u_{t}(j)-1\right)+\frac{\phi_{a}}{2}\left(u_{t}(j)-1\right)^{2}\right] \bar{K}_{t-1}(j)
$$

where $\bar{r}^{k}$ denotes the real rate of return on capital in steady state $\left(\bar{r}^{k}=\frac{\bar{R}^{k, \text { nom }}}{\bar{P}}\right)$. The law of motion for capital reads as follows:

$$
\bar{K}_{t}(j)=(1-\delta) \bar{K}_{t-1}(j)+\varepsilon_{t}^{X}\left[1-\frac{\phi_{K}}{2}\left(\frac{X_{t}(j)}{X_{t-1}(j)}-\gamma\right)^{2}\right] X_{t}(j),
$$

where $\delta$ is the depreciation rate of physical capital, and $\left[1-\frac{\phi_{K}}{2}\left(\frac{X_{t}(j)}{X_{t-1}(j)}-\gamma\right)^{2}\right]$ is a function that transforms investment into physical capital stock including adjustment costs for investment, where, similar to the utilization of capital above, investment above the steady state growth rate $\gamma$ bears additional costs. Furthermore, $\phi_{K}$ represents a fixed parameter for investment adjustment costs, $\gamma$ is the trend growth rate in the steady state of the exogenous productivity factor, and $\varepsilon_{t}^{X}$ is an exogenous shock to investment. The shocks to household bond holdings and investment follow autoregressive processes with coefficients $\rho_{b}, \rho_{X}$ and i.i.d. error terms $\eta_{t}^{b}, \eta_{t}^{X}$ with variances $\sigma_{B}, \sigma_{X}$ :

$$
\begin{array}{r}
\ln \varepsilon_{t}^{b}=\rho_{b} \ln \varepsilon_{t-1}^{b}+\eta_{t}^{b}, \eta_{t}^{b} \sim N\left(0, \sigma_{B}\right) \\
\ln \varepsilon_{t}^{X}=\rho_{X} \ln \varepsilon_{t-1}^{X}+\eta_{t}^{X}, \eta_{t}^{X} \sim N\left(0, \sigma_{X}\right)
\end{array}
$$

Households maximize utility, equation (F.1) subject to the demand for labor, equation (F.39) as defined below, the budget constraint, equation (F.2), and the capital law of motion, equation (F.4). If one denotes the Lagrange multiplier 
of the household budget constraint by $\Lambda_{t}(j)$, and the household constraint regarding the capital law of motion by $Q_{t}(j)$, one can derive the respective first order conditions listed as follows.

Consumption $C_{t}^{j}$ :

$$
\Lambda_{t}(j)=\left(C_{t}(j)-h C_{t-1}\right)^{-\sigma_{c}} \exp \left(\frac{-\left(1-\sigma_{c}\right)}{1+\sigma_{l}} L_{t}(j)^{1+\sigma_{l}}\right)
$$

Labor supply $L_{t}^{j}$ :

$$
\left[\frac{\left(C_{t}(j)-h C_{t-1}\right)^{1-\sigma_{c}}}{1-\sigma_{c}}\right] \exp \left(\frac{-\left(1-\sigma_{c}\right)}{1+\sigma_{l}} L_{t}(j)^{1+\sigma_{l}}\right)\left(\sigma_{c}-1\right) L_{t}(j)^{\sigma_{l}}=-\Lambda_{t}(j) \frac{W_{t}^{h h, \text { nom }}(h, j)}{P_{t}}
$$

Domestic and foreign Arrow-Debreu securities holdings, $B_{H, t}^{j}$ and $B_{F, t}^{j}$ :

$$
\begin{aligned}
\Lambda_{t}(j) \sum_{s_{t+1}} Q\left(s_{t+1} \mid s_{t}\right) \varepsilon_{t}^{b} & =\beta E_{t}\left\{\Lambda_{t+1}(j) \frac{P_{t}}{P_{t+1}}\right\} \\
\Lambda_{t}(j) \sum_{s_{t+1}} Q^{*}\left(s_{t+1} \mid s_{t}\right) \varepsilon_{t}^{b} S_{t} & =\beta E_{t}\left\{\Lambda_{t+1}(j) \frac{S_{t+1}}{S_{t}} \frac{P_{t}}{P_{t+1}}\right\}
\end{aligned}
$$

where $S_{t}$ denotes the nominal exchange rate of domestic currency per unit of foreign currency. Investment $X_{t}^{j}$ :

$$
\begin{aligned}
\Lambda_{t}(j) \frac{P_{t}^{X}}{P_{t}}= & Q_{t}(j) \Lambda_{t}(j) \frac{P_{t}^{X}}{P_{t}}\left\{\begin{array}{c}
\varepsilon_{t}^{X}\left[1-\frac{\phi_{K}}{2}\left(\frac{X_{t}(j)}{X_{t-1}(j)}-\gamma\right)^{2}\right] \\
-\varepsilon_{t}^{X} \phi_{K}\left(\frac{X_{t}(j)}{X_{t-1}(j)}-\gamma\right) \frac{X_{t}(j)}{X_{t-1}(j)}
\end{array}\right\} \\
& +\beta Q_{t+1}(j) \Lambda_{t+1}(j) \frac{P_{t+1}^{X}}{P_{t+1}} \varepsilon_{t+1}^{X}\left[\phi_{K}\left(\frac{X_{t+1}(j)}{X_{t}(j)}-\gamma\right)\right]\left(\frac{X_{t+1}(j)}{X_{t}(j)}\right)^{2}
\end{aligned}
$$

Capital stock $\bar{K}_{t}^{j}$ :

$$
Q_{t}(j) \Lambda_{t}(j) \frac{P_{t}^{X}}{P_{t}}=\left\{\begin{array}{c}
\beta E_{t} Q_{t+1}(j) \Lambda_{t+1}(j) \frac{P_{t+1}^{X}}{P_{t+1}}(1-\delta)+ \\
\beta E_{t} \Lambda_{t+1}(j)\left[\frac{R_{t+1}^{k n o m}}{P_{t+1}} u_{t+1}(j)-\left[\bar{r}^{k}\left(u_{t+1}(j)-1\right)+\frac{\phi_{a}}{2}\left(u_{t+1}(j)-1\right)^{2}\right]\right]
\end{array}\right\}
$$

Capacity utilization $u_{t}^{j}$ :

$$
\frac{R_{t}^{k, n o m}}{P_{t}}=\left(\bar{r}^{k}+\phi_{a}\left(u_{t}(j)-1\right)\right)
$$

\section{Appendix F.2.2. Households' intratemporal optimization}

Consumption. Each consumer j's overall consumption, $C_{t}(j)$, is composed of a bundle of domestic and foreign consumption goods indexed by $\mathrm{H}$ and $\mathrm{F}$, which are subject to a constant elasticity of substitution (CES):

$$
C_{t}(j)=\left[\gamma_{c}^{\frac{1}{\epsilon}} C_{H, t}^{\frac{\epsilon-1}{\epsilon}}(j)+\left(1-\gamma_{c}\right)^{\frac{1}{\epsilon}} C_{F, t}^{\frac{\epsilon-1}{\epsilon}}(j)\right]^{\frac{\epsilon}{\epsilon-1}}
$$

where $\epsilon$ denotes the elasticity of substitution between the bundles of domestic and foreign goods, and $\gamma_{c}$ is the share parameter in the CES consumption function. Domestic (foreign) consumption $C_{H, t}\left(C_{F, t}\right)$ again are CES bundles over many varieties of domestic (foreign) goods $\left(c_{t}(h, j), c_{t}(f, j)\right)$, according to a constant elasticity of substitution $\theta$ : 


$$
\begin{gathered}
C_{H, t}(j)=\left[\left(\frac{1}{n}\right)^{\frac{1}{\theta}} \int_{0}^{n} c_{t}(h, j)^{\frac{\theta-1}{\theta}} d h\right]^{\frac{\theta}{\theta-1}} \\
C_{F, t}(j)=\left[\left(\frac{1}{1-n}\right)^{\frac{1}{\theta}} \int_{n}^{1} c_{t}(f, j)^{\frac{\theta-1}{\theta}} d f\right]^{\frac{\theta}{\theta-1}}
\end{gathered}
$$

In each period, the consumer allocates her consumption of domestic varieties by minimizing expenditure: $\min _{c_{t}(h)} \int_{0}^{n} p_{t}(h) c_{t}(h, j) d h-P_{H, t} C_{H, t}(j)$. By inserting equation (F.13) and minimizing with respect to $c_{t}(h, j)$, one obtains the optimal demand function as follows:

$$
c_{t}(h, j)=\frac{1}{n}\left(\frac{p_{t}(h)}{P_{H, t}}\right)^{-\theta} C_{H, t}(j)
$$

One can derive the optimal domestic CES price index $P_{H, t}$ by inserting the demand function for the $h$ good, equation (F.15), into the CES consumption bundle, equation (F.13), to obtain:

$$
P_{H, t}=\left[\frac{1}{n} \int_{0}^{n} p_{t}(h)^{1-\theta} d h\right]^{\frac{1}{1-\theta}}
$$

Solving the analogous problem for the consumption of varieties of foreign goods,

$$
\min _{c_{t}(f)}\left(\int_{n}^{1} p_{t}(f) c_{t}(f, j) d f-P_{F, t}\left[\left(\frac{1}{1-n}\right)^{\frac{1}{\theta}} \int_{n}^{1} c_{t}(f, j)^{\frac{\theta-1}{\theta}} d f\right]^{\frac{\theta}{\theta-1}}\right),
$$

yields the optimal demand functions and price indices for varieties of foreign goods:

$$
\begin{gathered}
c_{t}(f, j)=\frac{1}{1-n}\left(\frac{p_{t}(f)}{P_{F, t}}\right)^{-\theta} C_{F, t}(j) \\
P_{F, t}=\left[\frac{1}{1-n} \int_{n}^{1} p_{t}(f)^{1-\theta} d f\right]^{\frac{1}{1-\theta}} .
\end{gathered}
$$

Using equation (F.12), and minimizing with respect to $C_{H, t}(j)$ and $C_{F, t}(j)$, one can derive optimal demand functions for bundles of home and foreign goods:

$$
\begin{array}{r}
C_{H, t}(j)=\gamma_{c}\left(\frac{P_{H, t}}{P_{t}}\right)^{-\epsilon} C_{t}(j) \\
C_{F, t}(j)=\left(1-\gamma_{c}\right)\left(\frac{P_{F, t}}{P_{t}}\right)^{-\epsilon} C_{t}(j) .
\end{array}
$$

By inserting the input demand functions, equations (F.19) and (F.20), into the aggregate CES bundle of home and foreign goods, equation (F.12), one obtains the optimal price index $P_{t}$ as:

$$
P_{t}=\left[\gamma_{c} P_{H, t}^{1-\epsilon}+\left(1-\gamma_{c}\right) P_{F, t}^{1-\epsilon}\right]^{\frac{1}{1-\epsilon}}
$$


Investment. Investment by household $j\left(X_{t}(j)\right)$ is modelled in a fashion similar to that of consumption, that is, as CES indices over domestic and foreign (varieties of) investment goods $x_{t}(h, j)$, with the same elasticity of substitution $\epsilon$, but a different share parameter $\gamma_{x}$. Investment demand functions and prices are thus given by:

$$
\begin{gathered}
x_{t}(h, j)=\frac{1}{n}\left(\frac{p_{t}(h)}{P_{H, t}}\right)^{-\theta} X_{H, t}(j)=\frac{1}{n}\left(\frac{p_{t}(h)}{P_{H, t}}\right)^{-\theta}\left[\gamma_{x}\left(\frac{P_{H, t}}{P_{t}^{X}}\right)^{-\epsilon} X_{t}(j)\right] \\
x_{t}(f, j)=\frac{1}{1-n}\left(\frac{p_{t}(f)}{P_{F, t}}\right)^{-\theta} X_{F, t}(j)=\frac{1}{1-n}\left(\frac{p_{t}(f)}{P_{F, t}}\right)^{-\theta}\left[\left(1-\gamma_{x}\right)\left(\frac{P_{F, t}}{P_{t}^{X}}\right)^{-\epsilon} X_{t}(j)\right] \\
P_{t}^{X}=\left[\gamma_{x} P_{H, t}^{1-\epsilon}+\left(1-\gamma_{x}\right) P_{F, t}^{1-\epsilon}\right]^{\frac{1}{1-\epsilon}}
\end{gathered}
$$

\section{Appendix F.2.3. Government purchases}

Public consumption of government agent $j, G_{t}(j)$, is modelled in a fashion similar to that for private consumption, that is, as CES indices over domestic and foreign varieties of goods. Analogously to above, one can derive demand functions and prices for the government as follows:

$$
\begin{gathered}
g_{t}(h, j)=\frac{1}{n}\left(\frac{p_{t}(h)}{P_{H, t}}\right)^{-\theta} G_{H, t}(j)=\frac{1}{n}\left(\frac{p_{t}(h)}{P_{H, t}}\right)^{-\theta}\left[\gamma_{G}\left(\frac{P_{H, t}}{P_{t}^{G}}\right)^{-\epsilon} G_{t}(j)\right] \\
g_{t}(f, j)=\frac{1}{1-n}\left(\frac{p_{t}(f)}{P_{F, t}}\right)^{-\theta} G_{F, t}(j)=\frac{1}{1-n}\left(\frac{p_{t}(f)}{P_{F, t}}\right)^{-\theta}\left[\left(1-\gamma_{G}\right)\left(\frac{P_{F, t}}{P_{t}^{G}}\right)^{-\epsilon} G_{t}(j)\right] \\
P_{t}^{G}=\left[\gamma_{G} P_{H, t}^{1-\epsilon}+\left(1-\gamma_{G}\right) P_{F, t}^{1-\epsilon}\right]^{\frac{1}{1-\epsilon}}
\end{gathered}
$$

Appendix F.3. Intermediate labor union sector and wage setting

Following Smets and Wouters (2007), households supply their homogenous labor to an intermediate labor union, which differentiates the labor services from labor varieties of type $l$ and sets wages in a Calvo fashion, selling the labor varieties of type $l$ to labor packers. Labor used by the intermediate goods producer of variety $h, L_{t}(h)$ - henceforth for reasons of simplicity referred to as $L_{t}$-is then a Dixit-Stiglitz composite of varieties of labor $l$ :

$$
L_{t}=\left[\int_{0}^{n} L_{t}(l)^{\frac{1}{1+\lambda_{w}}} d l\right]^{1+\lambda_{w}}
$$

(or, more precisely, $L_{t}(h)=\left[\int_{0}^{n} l_{t}(l, h)^{\frac{1}{1+\lambda_{w}}} d l\right]^{1+\lambda_{w}}$ ),

where $\lambda_{w}$ is the elasticity of substitution among differentiated labor types. There are labor packers who buy the labor from the unions, package $L_{t}$ (or $L_{t}(h)$ to be precise), and resell it to intermediate goods producing firms. Labor packers maximize profits in a perfectly competitive environment. From the optimization problem of labor packers $\left(W_{t}^{n o m} L_{t}-\int_{0}^{n} W_{t}^{n o m}(l) l_{t}(l) d l\right)$, one can derive labor input demand of variety $l$. The corresponding aggregate wage index is given by:

$$
\begin{aligned}
L_{t}(l) & =\frac{1}{n}\left(\frac{W_{t}^{n o m}(l)}{W_{t}^{n o m}}\right)^{-\frac{1+\lambda_{w}}{\lambda_{w}}} L_{t} \\
W_{t}^{n o m} & =\left[\frac{1}{n} \int_{0}^{n} W_{t}^{n o m}(l)^{\frac{1}{\lambda_{w}}} d l\right]^{\lambda_{w}}
\end{aligned}
$$




$$
\begin{aligned}
& \text { or, in more precise notation: }{ }^{48} \\
& L_{t}(h, l)=\frac{1}{n}\left(\frac{W_{t}^{n o m}(h, l)}{W_{t}^{n o m}}\right)^{-\frac{1+\lambda_{w}}{\lambda_{w}}} L_{t}(h) \\
& W_{t}^{\text {nom }}=\left[\frac{1}{n} \int_{0}^{n} W_{t}^{n o m}(h, l)^{\frac{1}{\lambda_{w}}} d l\right]^{\lambda_{w}}
\end{aligned}
$$

Labor unions take the households' marginal rate of substitution as the cost of the labor services in their negotiations with labor packers. The (nominal) household's marginal rate of substitution is given by equation (F.6), rearranging this equation yields the nominal wage level for households that unions take to wage negotiations $W_{t}^{\text {hh,nom }}$ :

$$
W_{t}^{h h, \text { nom }}=\frac{P_{t}\left[\frac{\left(C_{t}-h C_{t-1}\right)^{1-\sigma_{c}}}{1-\sigma_{c}}\right] \exp \left(\frac{-\left(1-\sigma_{c}\right)}{1+\sigma_{l}} L_{t}(l)^{1+\sigma_{l}}\right)\left(\sigma_{c}-1\right) L_{t}(l)^{\sigma_{l}}}{-\Lambda_{t}} .
$$

The markup above the marginal disutility of labor is distributed back to households. In setting the wage rate for labor of type $l$, the union is subject to nominal rigidities à la Calvo. In particular, the union can reset the wage in the current period with probability $1-\xi_{w}$. Where the wage rate cannot be reset, the wage rate $W_{t}^{\text {nom }}(l)$ increases with the deterministic GDP trend growth rate $\gamma$, a weighted average of the steady state inflation, $\pi$, and last period's inflation, $\pi_{t-1}$. The wage setting problem of the labor union is then described as:

$$
\max _{W_{t}^{n o m}(l)} E_{t} \sum_{k=0}^{\infty}\left(\beta \xi_{w}\right)^{k} \frac{\Lambda_{t+k}}{\Lambda_{t}} \frac{P_{t}}{P_{t+k}}\left\{W_{t+k}^{\text {nom,ind }}(l)-W_{t+k}^{h h, n o m}\right\} L_{t+k}(l)
$$

subject to

$$
\begin{aligned}
L_{t+k}(l) & =\frac{1}{n}\left(\frac{W_{t+k}^{\text {nom,ind }}(l)}{W_{t+k}^{n o m}}\right)^{-\frac{1+\lambda_{W}}{\lambda_{w}}} L_{t+k} \\
W_{t+k}^{\text {nom, ind }}(l) & =W_{t}^{\text {nom }}(l) I n d_{t, k}^{w} \\
W_{t+k}^{\text {hh,nom }} & =\frac{P_{t+k}\left[\frac{\left(C_{t+k}-h C_{t+k-1}\right)^{1-\sigma_{c}}}{1-\sigma_{c}}\right] \exp \left(\frac{-\left(1-\sigma_{c}\right)}{1+\sigma_{l}} L_{t+k}(l)^{1+\sigma_{l}}\right)\left(\sigma_{c}-1\right) L_{t+k}(l)^{\sigma_{l}}}{-\Lambda_{t+k}} .
\end{aligned}
$$

Here, $I n d_{t, k}^{w}$ denotes the rule for wage indexation, which is given by:

$$
\operatorname{Ind} d_{t, k}^{w}=\left\{\begin{array}{c}
1 \text { for } k=0 \\
\left(\Pi_{l=1}^{k} \gamma \pi_{t+l-1}^{\iota_{w}} \pi^{1-l_{w}}\right) \text { for } k=1, \ldots, \infty
\end{array}\right\},
$$

and where $\iota_{w}$ is a parameter governing the degree of this wage indexation.

Solving this maximization problem, one arrives at the following markup equation for the optimal nominal wage $W_{t}^{o, \text { nom }}$

$$
W_{t}^{o, n o m}(l)=\left(1+\lambda_{w}\right) \frac{E_{t} \sum_{k=0}^{\infty}\left(\beta \xi_{w}\right)^{k} \frac{\Lambda_{t+k}}{\Lambda_{t}} \frac{P_{t}}{P_{t+k}} W_{t+k}^{h h, n o m}\left[\frac{1}{n}\left(\frac{\operatorname{Ind} n_{t, k}^{w}}{W_{t+k}^{n+m}}\right)^{-\frac{1+\lambda \lambda_{w}}{\lambda_{w}}} L_{t+k}\right]}{E_{t} \sum_{k=0}^{\infty}\left(\beta \xi_{w}\right)^{k} \frac{\Lambda_{t+k}}{\Lambda_{t}} \frac{P_{t}}{P_{t+k}}\left[\left[\frac{\operatorname{Ind} d_{t, k}^{w}}{n}\left(\frac{I n d_{t, k}^{w}}{\left.W_{t+k}^{n+m}\right)^{-\frac{1+\lambda_{w}}{\lambda_{w}}}} L_{t+k}\right]\right]\right.} .
$$

Households' wages that could not be chosen optimally due to the Calvo pricing mechanism (those which could not adapt their wages according to the Calvo probability of rigid wages $\xi_{w}$ ), are subject to a standard wage indexing related to the development of the general price level in the economy and the trend GDP growth rate. The wage index of these households evolves according to:

\footnotetext{
${ }^{48}$ In the following, the $h$ index of the $h$-variety firm will be abstracted from to simplify notation.
} 


$$
\left(W_{t}^{n o m}\right)^{-\frac{1}{\lambda_{w}}}=\xi_{w}\left(W_{t-1}^{n o m} \gamma \pi_{t-1}^{\iota_{w}} \pi^{1-\iota_{w}}\right)^{-\frac{1}{\lambda_{w}}}+\left(1-\xi_{w}\right)\left(W_{t}^{n o m, o}(l)\right)^{-\frac{1}{\lambda_{w}}}
$$

Finally, $\lambda_{w}$ is not a fixed parameter, but follows the exogenous ARMA process with an AR coefficient $\rho_{w}$, an MA coefficient $\theta_{w}$, and an i.i.d. error term $\epsilon_{w, t}$ with variance $\sigma_{w}$ :

$$
\ln \lambda_{w, t}=\left(1-\rho_{w}\right) \lambda_{w}+\rho_{w} \ln \lambda_{w, t-1}-\theta_{w} \epsilon_{w, t-1}+\epsilon_{w, t}, \epsilon_{w} \sim N\left(0, \sigma_{w}\right)
$$

\section{Appendix F.4. Production}

\section{Appendix F.4.1. Domestic good producers}

The domestic consumption goods come in many varieties. Each domestic firm $h$ specializes in one variety of goods, producing according to a Cobb-Douglas production function:

$$
Y_{t}(h)=F\left(K_{t}(h), L_{t}(h)\right)=A_{t} K_{t}(h)^{\alpha}\left[Z_{t} L_{t}(h)\right]^{1-\alpha}-\Phi Z_{t},
$$

where $K_{t}(h)$ denotes the physical capital stock used by firm $h$ for production, $L_{t}(h)$ is an index of different types of labor services, $A_{t}$ denotes total factor productivity, $Z_{t}$ is a long-run labor-augmenting productivity factor that grows with the exogenous rate $(\gamma)$, and $\Phi$ is a constant parameter indicating fixed costs of production in relation to the exogenous productivity factor. Each firm behaves as a monopolistic competitor, setting prices $p_{t}(h)$ and $p_{t}^{*}(h)$ in the local and foreign market to maximize profits, taking as given the households' and government's demand for that good, $c_{t}(h, j), x_{t}(h, j), c_{t}^{*}\left(h, j^{*}\right), x_{t}^{*}\left(h, j^{*}\right), g_{t}(h, j), g_{t}^{*}\left(h, j^{*}\right)$. The firm's problem can be decomposed into a cost minimization problem and a profit maximization problem, as set out in the following.

\section{Appendix F.4.2. Producer as a cost minimizer}

Cost minimization by the firm provides information on the optimal capital-labor ratio. The minimization problem of an individual firm $h$ is given by

$$
\min _{L_{t}(h), K_{t}(h)}\left\{\begin{array}{c}
W_{t}^{\text {nom }} L_{t}(h)+R_{t}^{k, n o m} K_{t}(h)+ \\
M C_{t}^{n o m}(h)\left[Y_{t}(h)-A_{t} K_{t}(h)^{\alpha}\left[Z_{t} L_{t}(h)\right]^{1-\alpha}-\Phi Z_{t}\right]
\end{array}\right\},
$$

which yields first order conditions for firm $h$ described in the following.

Labor demand $L_{t}(h)$ :

$$
W_{t}^{n o m}=M C_{t}^{n o m}(h)(1-\alpha) A_{t} K_{t}(h)^{\alpha} L_{t}(h)^{-\alpha} Z_{t}^{1-\alpha},
$$

or rewriting it as the labor demand function:

$$
L_{t}(h)=(1-\alpha)\left(\frac{W_{t}^{n o m}}{M C_{t}^{n o m}}\right)^{-1} Y_{t}(h)
$$

Capital demand $K_{t}(h)$ :

$$
R_{t}^{k, \text { nom }}=M C_{t}^{\text {nom }} \alpha A_{t} K_{t}(h)^{\alpha-1}\left[Z_{t} L_{t}(h)\right]^{1-\alpha},
$$

or rewriting it as the capital demand function:

$$
K_{t}(h)=\alpha\left(\frac{R_{t}^{k, n o m}}{M C_{t}^{n o m}}\right)^{-1} Y_{t}(h)
$$


If the labor demand function, equation (F.39), is joined with the capital demand function, equation (F.40), the optimal capital-labor ratio is obtained. This optimal ratio will be the same for all domestic intermediate goods producers, and thus concurs with the economy-wide capital-labor ratio:

$$
\frac{1-\alpha}{\alpha}=\frac{W_{t}^{\text {nom }} L_{t}(h)}{R_{t}^{k, n o m} K_{t}(h)} .
$$

By inserting the labor and capital demand functions into the production function, equation (F.38), one can derive the following expression for nominal marginal costs, which is the same for all firms, i.e., $M C_{t}^{\text {nom }}(h)=M C_{t}^{\text {nom }}$, as it only depends on aggregate prices:

$$
M C_{t}^{n o m}=\frac{1}{A_{t}} \frac{\left(R_{t}^{k, n o m}\right)^{\alpha}\left(W_{t}^{n o m}\right)^{1-\alpha}}{\alpha^{\alpha}(1-\alpha)^{1-\alpha}} \frac{1}{Z_{t}^{1-\alpha}} .
$$

\section{Appendix F.4.3. Producer as a profit maximizer}

According to the Calvo price setting mechanism, firms may not be allowed to change their price every period. Rather, it is assumed that they cannot change their price unless they receive a price-change signal. The probability that a given price can be re-optimized at period $t$ is assumed to be constant and equal to $\xi_{P}$. Furthermore, it is assumed that each firm $h$ has market power in the market for the good it produces, and maximizes expected profit according to a discount rate (from period $t$ to period $t+k$ ). Define by $\Omega_{t, t+k}=\beta \frac{\Lambda_{t, t+k}}{\Lambda_{t}} \frac{P_{t}}{P_{t+k}}$ the households' stochastic discount factor from period $t$ to period $t+k$. Under sticky prices according to the Calvo mechanism, with partial indexation to producer prices $\left(\operatorname{Ind} d_{t, k}^{p}\right)$, and assuming producer currency price setting, the firm maximization problem is given by:

$$
\max _{p_{t}^{o}(h), S_{t} p_{t}^{*}(h)} E_{t} \sum_{k=0}^{\infty} \xi_{P}^{k} \Omega_{t, t+k}\left\{\begin{array}{c}
{\left[p_{t}(h) \operatorname{Ind}_{t, k}^{p}-M C_{t}^{n o m}(h)\right]\left[\frac{1}{n}\left(\frac{p_{t}(h)}{P_{H, t+k}} \operatorname{Ind} d_{t, k}^{p}\right)^{-\theta}\left(A_{H, t+k}\right)\right]+} \\
{\left[S_{t} p_{t}^{*}(h)-M C_{t+k}^{n o m}(h)\right]\left[\frac{1}{n}\left(\frac{S_{t} p_{t}^{*}(h)}{S_{t+k} P_{H, t+k}^{*}} \operatorname{In} d_{t, k}^{p}\right)^{-\theta}\left(A_{H, t+k}^{*}\right)\right]}
\end{array}\right\},
$$

where the producer price indexation rule $\operatorname{In} d_{t, k}^{p}$, similarly to the case for wages above, is given by

$$
\operatorname{Ind} d_{t, k}^{p}=\left\{\begin{array}{c}
1 \text { for } k=0 \\
\left(\Pi_{l=1}^{k} \pi_{H, t+l-1}^{\iota_{p}} \pi_{H}^{1-\iota_{p}}\right) \text { for } k=1, \ldots, \infty
\end{array}\right\} .
$$

The parameter $\iota_{p}$ indicates the degree of price indexation.

Solving this maximization problem with respect to the price charged by firm $h, p_{t}(h)$, yields the following optimal price for firm $h, p_{t}^{o}(h)$ :

$$
\frac{p_{t}^{o}(h)}{P_{H, t}}=\frac{\left(\frac{\theta}{\theta-1}\right) E_{t} \sum_{k=0}^{\infty}\left(\beta \xi_{P}\right)^{k} \frac{\Lambda_{t+k}}{\Lambda_{t}}\left\{\frac{M C_{t+k}^{n o m}(h)}{P_{t+k}}\left[\left(\frac{P_{H, t}}{P_{H, t+k}} \operatorname{Ind}_{t, k}^{p}\right)^{-\theta}\left(A_{H, t+k}+A_{H, t+k}^{*}\right)\right]\right\} \frac{1}{Z_{t}}}{E_{t} \sum_{k=0}^{\infty}\left(\beta \xi_{P}\right)^{k} \frac{\Lambda_{t+k}}{\Lambda_{t}} \frac{P_{H, t+k}}{P_{t+k}}\left\{\left[\left(\frac{P_{H, t}}{P_{H, t+k}} \operatorname{Ind}_{t, k}^{p}\right)^{1-\theta}\left(A_{H, t+k}+A_{H, t+k}^{*}\right)\right]\right\} \frac{1}{Z_{t}}} .
$$

Under the assumption of producer currency price setting, the law of one price holds at the level of individual goods, and the price level of firm $h$ in the foreign economy, $p_{t}^{*}(h)$, is given by:

$$
S_{t} p_{t}^{*}(h)=p_{t}^{o}(h) .49
$$

From these equilibrium price indices and the optimal price setting relation, one can derive how prices evolve over time (with indexation):

\footnotetext{
${ }^{49}$ Note that when prices are not sticky, equation (F.45)) reduces to the standard expression:
}

$$
p_{t}(h)=\frac{\theta}{1-\theta} M C_{t}^{\text {nom }}(h)
$$




$$
1=\xi_{P}\left(\frac{P_{H, t-1}}{P_{H, t}} \pi_{H, t-1}^{\iota_{p}} \pi_{H}^{1-\iota_{p}}\right)^{1-\theta}+\left(1-\xi_{P}\right)\left(\frac{p_{t}^{o}(h)}{P_{H, t}}\right)^{1-\theta},
$$

where $\pi_{H, t}=\frac{P_{H, t}}{P_{H, t-1}}$.

\section{Appendix F.4.4. Good Market Clearing}

According to the optimality conditions described above, the goods market clearing condition is then given as follows:

$$
Y_{t}(h)=A_{t} K_{t}^{\alpha}\left[Z_{t} L_{t}\right]^{1-\alpha}-\Phi Z_{t}=\left[\begin{array}{c}
{\left[\gamma_{c}\left(\frac{P_{H, t}}{P_{t}}\right)^{-\epsilon} C_{t}+\gamma_{x}\left(\frac{P_{H, t}}{P_{t}^{X}}\right)^{-\epsilon} X_{t}+G_{t}\right]+} \\
\frac{1-n}{n}\left[\gamma_{c}^{*}\left(\frac{P_{H, t}^{*}}{P_{t}^{*}}\right)^{-\epsilon} C_{t}^{*}+\gamma_{x}^{*}\left(\frac{P_{H, t}^{*} P_{t}^{*}}{P^{*}}\right)^{-\epsilon} X_{t}^{*}\right.
\end{array}\right] .
$$

\section{Appendix F.5. Fiscal Authority}

The role of fiscal policy in the model is highly simplified. Government spending is assumed to be financed by lump-sum taxes ( $T_{t}$ below denotes net transfers, that is, total government transfers minus taxes). The government is not allowed to run budget deficits, and its budget constraint therefore is:

$$
G_{t}+T_{t}=0
$$

\section{Appendix F.6. Monetary Authority}

The monetary authority is assumed to apply a standard interest-feedback rule. The interest rate targets inflation as well as the output gap, and is set according to a Taylor rule:

$$
\frac{R_{t}}{R}=\left(\frac{R_{t-1}}{R}\right)^{\rho_{R}}\left[\left(\frac{\pi_{t}}{\bar{\pi}}\right)^{\rho_{\pi}}\left(\frac{y_{t}}{\bar{y}}\right)^{\rho_{Y}}\right]^{1-\rho_{R}} \varepsilon_{t}^{R},
$$

where $R_{t}$ is the short term money market interest rate (policy rate) set exogenously by the central bank (and thus also the interest rate on bond holdings by households as in the household budget constraint, see equation (F.2)), $R$ is the policy rate in the steady state, $\pi_{t}$ is inflation at time $t, \bar{\pi}$ is the inflation target set by the central bank, $y_{t}$ is output at time t, $\bar{y}$ is the output target by the central bank, $\rho^{R}$ is the degree of interest rate smoothing by the central bank, $\rho^{\pi}$ denotes the weight the central bank places on inflation targeting, $\rho^{Y}$ is the weight the central bank places on the output gap, and $\varepsilon_{t}^{R}$ is an exogenous shock to monetary policy.

\section{Appendix F.7. Additional Equilibrium Conditions}

Arrow-Debreu securities are in zero net supply (the only security traded internationally is the $F$-bond; the $H$ security is traded only domestically):

$$
\begin{aligned}
\int_{0}^{n} B_{H, t}\left(j, s_{t+1}\right) d j & =0 \\
\int_{0}^{n} B_{F, t}\left(j, s_{t+1}\right) d j+\int_{n}^{1} B_{F, t}^{*}\left(j^{*}, s_{t+1}\right) d j^{*} & =0
\end{aligned}
$$

Equilibrium in the factor markets requires:

$$
L_{t}=\int_{0}^{n} L_{t}(h) d h=\int_{0}^{n} \int_{0}^{n} l_{t}(h, j) d h d j
$$




$$
\begin{gathered}
L_{t}^{*}=\int_{n}^{1} L_{t}^{*}(f) d f=\int_{n}^{1} \int_{n}^{1} l_{t}^{*}\left(f, j^{*}\right) d h d j^{*} \\
K_{t}=\int_{0}^{n} K_{t}(h) d h \\
K_{t}^{*}=\int_{n}^{1} K_{t}^{*}(f) d f
\end{gathered}
$$

\section{Appendix F.8. Exogenous shock processes}

Model dynamics are decisively driven by altogether 13 exogenous processes (shocks), i.e., 6 shocks each in the domestic (Austrian) and foreign (EA) economy, and a monetary policy shock common to both areas due to the monetary union. In all of the shocks below, $\rho$ signifies an autoregressive component of the shock process, while $u_{t}$ and $\eta_{t}$ are normally distributed white noise processes with a variance $\sigma$. The following equations denote these exogenous shocks:

Technology shock-here $A_{S S}$ denotes the steady state level of the technology shock, which is used to rescale the shock to better match the data:

$$
A_{t} \quad A_{t}=\rho_{A} A_{t-1}+\left(1-\rho_{A}\right) \ln A_{S S}+u_{A, t}, u^{A, t} \sim N\left(0, \sigma_{A}\right)
$$

Government spending shock-here $g_{S S}$ again is the steady state level of the shock for rescaling purposes, and $c_{g y}$ signifies a cross-correlation coefficient between technology and government spending shocks:

$g_{t} \quad g_{t}=\rho_{G} g_{t-1}+\left(1-\rho_{G}\right) \ln g_{S S}+c_{g y} u_{A, t}+u^{G, t}, u^{G, t} \sim N\left(0, \sigma_{G}\right)$

Shock to bond holdings by households:

$$
\varepsilon_{t}^{b} \quad \ln \varepsilon_{t}^{b}=\rho_{b} \ln \varepsilon_{t-1}^{b}+\eta_{t}^{b}, \eta_{t}^{b} \sim N\left(0, \sigma_{B}\right)
$$

Shock to investment demand:

$$
\varepsilon_{t}^{X} \quad \ln \varepsilon_{t}^{X}=\rho_{X} \ln \varepsilon_{t-1}^{X}+\eta_{t}^{X}, \eta_{t}^{X} \sim N\left(0, \sigma_{X}\right)
$$

Shock to monetary policy (only one shock due to common monetary union):

$$
\ln \varepsilon_{t}^{R}=\rho_{R} \ln \varepsilon_{t-1}^{R}+\eta_{t}^{R}, \eta_{t}^{R} \sim N\left(0, \sigma_{R}\right)
$$

Shock to elasticity of substitution among differentiated labor types-here a moving average (MA) $\theta_{w}$ term is also included in the shock process:

$$
\lambda_{w, t} \quad \ln \lambda_{w, t}=\left(1-\rho_{w}\right) \lambda_{w}+\rho_{w} \ln \lambda_{w, t-1}-\theta_{w} \epsilon_{w, t-1}+\epsilon_{w, t}, \epsilon_{w} \sim N\left(0, \sigma_{w}\right)
$$

Shock to price setting by firms-again with an additional MA term $\theta_{p}$ :

$$
\lambda_{p, t} \quad \ln \lambda_{p, t}=\left(1-\rho_{p}\right) \lambda_{p}+\rho_{p} \ln \lambda_{p, t-1}-\theta_{p} \epsilon_{p, t-1}+\epsilon_{p, t}, \epsilon_{p} \sim N\left(0, \sigma_{p}\right)
$$

\section{Appendix F.9. Deflating, detrending and model solution}

To solve the model, we transform all first order conditions that are in nominal terms and growing in terms of stationary, deflated quantities. All quantity variables are detrended by the exogenous productivity rate $Z_{t}, Z_{t}^{*}$, while all price variables are deflated by the price level $P_{t}, P_{t}^{*}$ for the home and foreign economies, respectively.

These detrended, deflated variables are given by the following expressions:

$$
\begin{aligned}
& c_{t}=\frac{C_{t}}{Z_{t}}, c_{H, t}=\frac{C_{H, t}}{Z_{t}}, c_{F, t}=\frac{C_{F, t}}{Z_{t}}, x_{H, t}=\frac{X_{H, t}}{Z_{t}}, x_{F, t}=\frac{X_{F, t}}{Z_{t}}, g_{H, t}=\frac{G_{H, t}}{Z_{t}}, g_{F, t}=\frac{G_{F, t}}{Z_{t}}, x_{t}=\frac{X_{t}}{Z_{t}}, c_{t}^{*}=\frac{C_{t}^{*}}{Z_{t}}, c_{H, t}^{*}=\frac{C_{H, t}^{*}}{Z_{t}}, c_{F, t}^{*}=\frac{C_{F, t}^{*}}{Z_{t}}, \\
& x_{H, t}^{*}=\frac{X_{H, t}^{*}}{Z_{t}}, x_{F, t}^{*}=\frac{X_{F, t}^{*}}{Z_{t}}, g_{H, t}^{*}=\frac{G_{H, t}^{*}}{Z_{t}}, g_{F, t}^{*}=\frac{G_{F, t}^{*}}{Z_{t}}, \widetilde{w}_{t}=\frac{W_{t}^{\text {onom }}(l)}{Z_{t} P_{t}}, w_{t}=\frac{W_{t}^{\text {nom }}}{Z_{t} P_{t}}, \widetilde{w}_{t}^{*}=\frac{W_{t}^{* 0, n o m}(l)}{Z_{t} P_{t}^{*}}, w_{t}^{*}=\frac{W_{t}^{* n o m}}{Z_{t} P_{t}^{*}}, \bar{k}_{t}=\frac{\bar{K}_{t}}{Z_{t}}, k_{t}=\frac{K_{t}}{Z_{t}}, \\
& x_{t}=\frac{X_{t}}{Z_{t}}, w_{t}^{h h}=\frac{W_{t}^{h h, \text { nom }}}{P_{t} Z_{t}}, y_{t}=\frac{Y_{t}}{Z_{t}}, p_{t}^{X}=\frac{P_{t}^{X}}{P_{t}}, r_{t}^{k}=\frac{R_{t}^{k, \text { nom }}}{P_{t}}, \pi_{t}=\frac{P_{t}}{P_{t-1}}, \pi_{t}^{*}=\frac{P_{t}^{*}}{P_{t-1}^{*}}, R E R_{t}=\frac{S_{t} P_{t}^{*}}{P_{t}}, T O T_{t}=\frac{P_{F, t}}{S_{t} P_{H, t}^{*}}, p_{H, t}=\frac{P_{H, t}}{P_{t}}, \\
& p_{F, t}=\frac{P_{F, t}}{P_{t}}, p_{t}^{X}=\frac{P_{t}^{X}}{P_{t}}, p_{t}^{G}=\frac{P_{t}^{G}}{P_{t}}, p_{H, t}^{*}=\frac{P_{H, t}^{*}}{P_{t}^{*}}, p_{F, t}^{*}=\frac{P_{F, t}^{*}}{P_{t}^{*}}, p_{t}^{X *}=\frac{P_{t}^{X_{*}^{*}}}{P_{t}^{*}}, p_{t}^{G *}=\frac{P_{t}^{G *}}{P_{t}^{*}},
\end{aligned}
$$

where $R E R_{t}$ is the real exchange rate, and $T O T_{t}$ are the terms of trade. 
Appendix F.10. Data sources and model estimation

Appendix F.10.1. Data sources

We use quarterly data from 1997:Q1-2013:Q4 from the following data sources available from the Eurostat bulk download facility, all seasonally and calendar adjusted:

1. GDP and main components - output, expenditure and income (quarterly time series) (namq_10_gdp)

2. Population and employment (quarterly time series) (namq_10_pe)

3. Money market interest rates - quarterly data (irt_st_q)

In particular, to take the DSGE to the data, the following time series from Eurostat data are used (all from namq_10_gdp):

- Gross domestic product at market prices, chain linked volumes (2010) (B1GQ),

- Final consumption expenditure, chain linked volumes (2010) (P3),

- Gross fixed capital formation, chain linked volumes (2010) (P5G),

- Compensation of employees, current prices, million euro (D1),

- inflation (GDP deflator: Gross domestic product at current prices divided by chain linked volumes GDP measure).

Furthermore, to determine the amount of employment, we use the variable employment in thousand persons according to the domestic concept (EMP_DC, from namq_10_pe), a proxy for aggregate hours worked, as these data are not available for Austria or the EA on a quarterly basis. ${ }^{50}$ The nominal interest rate represented by the three-month Euribor, i.e., short term money market interest rates (variable name MAT_M03 from irt_st_q).

\section{Appendix F.10.2. Measurement Equations: Growth rates used for estimations}

As is standard in the current DSGE literature, the model is estimated on growth rates. The measurement equations to estimate the model need at least the same amount of shocks as observable times series to allow for model estimation. Since we have 13 shocks in our model, we choose 13 observable time series to estimate the DSGE model. The time series used to estimate the log-linearized version of the model for both Austria and the EA are growth rates (in real terms) for GDP $\left(d Y, d Y^{*}\right)$, consumption $\left(d C C, d C C^{*}\right.$ - consumption of home and foreign goods in the respective country as a CES bundle), investment ( $d X X, d X X^{*}$ - again as a home-foreign goods CES bundle), employment ( $d E M P L, d E M P L^{*}$ - where a linear trend was removed to make the time series stationary), wages $\left(d W, d W^{*}\right)$, as well as inflation $\left(\Pi, \Pi^{*}\right)$. Furthermore, one time series of interest rates $\left(R^{o b s}\right)$ common to both areas is added. Summing up, the vector of observable variables in the DSGE model is:

$$
d Y, d C C, d X X, d E M P L, d W, \Pi^{\prime} d Y^{*}, d C C^{*}, d X X^{*}, d E M P L^{*}, d W^{*}, \Pi^{*}, R^{o b s} .
$$

\section{Appendix F.10.3. Bayesian estimation}

For reasons of parsimony, we refrain from a detailed repetition of the principles of Bayesian estimation. The interested reader is referred to the excellent reviews that can be found in Fernandez-Villaverde (2010); An and Schorfheide (2007); Schorfheide (2011), or the short expositions in Breuss and Rabitsch (2009); Smets and Wouters (2003), among others. The method used in this paper is quite standard in the literature and largely follows the procedure in Breuss and Rabitsch (2009): from the state space representation of the DSGE model solution, the log likelihood over the sample period 1997:Q1 - 2010:Q1 is estimated. For the forecast, the DSGE model is then re-estimated every quarter until 2013:Q4. The thereby obtained posterior distribution is maximized to compute the mode of the estimated parameters. The significance of the parameters can be examined by deriving the standard errors of these parameter estimated from the inverse Hessian matrix. After the mode of the posterior is calculated by this procedure, the mode is used as a starting point for a sampling algorithm in order to generate a large sample of MCMC (Markov-Chain Monte Carlo) draws to approximate the shape of the posterior parameter distribution. For this purpose, the Metropolic-Hastings algorithm is used, which is standard in the literature.

\footnotetext{
${ }^{50}$ As is also noted in Breuss and Rabitsch (2009).
} 


\section{Appendix F.10.4. Calibrated parameters}

Unless explicitly mentioned otherwise, the parameters described below are set equally for the home and foreign economy. Some parameters are not estimated but calibrated for this model, closely adhering to standard values that have been well-tested by a large body of DSGE literature. The discount factor $\beta$ is set to 0.9983 , which would approximately imply a real interest rate of 0.7 percent in the steady state, reflecting the low-interest environment in Europe since the financial crisis of 2007-2008. The depreciation rate $\delta$ is set to 2.5 percent to correspond to the sample mean of the labour-output and investment-output ratios. The capital share in production, the Cobb-Douglas production function parameter $\alpha$, is set to about 19 percent. The weight of domestic and foreign consumption goods in their respective overall aggregate net consumption index are reflected in the parameters $\gamma_{C}$ and $\gamma_{C}^{*}$, which are calibrated by using the measures of imports in private consumption from the GTAP database along the lines of Breuss and Rabitsch (2009). This implies a weight of $\gamma_{C}=0.8964$ on domestically produced consumption goods in Austria. For the EA this translates into a weight of goods produced in the EA without Austria of $\left(1-\gamma_{C}^{*}\right)=0.9974$, where for simplicity's sake it is assumed that the weights in the respective CES indices do not differ from each other. The country share $n$ of Austria in the total model economy in comparison to EA is set to 0.031, which approximately corresponds to the share of Austrian GDP in the EA within the calibration periods (2010:Q1-2013:Q4). This implies a size of the EA economy (1-n) of 0.969 .

\section{Appendix F.10.5. Prior and posterior distributions for estimated parameters}

Tables F.11 and F.13 show information about the prior and posterior distributions of the Bayesian estimation after the MCMC sampling procedure. For all parameter estimates used for simulations, part of which is shown below, the number of Metropolis-Hastings draws has been set to 250,000.

\section{Appendix F.11. Variance Decomposition}

A forecast error variance decomposition reveals which shocks drive different macro variables in the model economy by determining the extent to which the forecast error variance of each of these variables can be explained by the different exogenous shocks. For exposition, the unconditional variance decompositions (i.e., at horizon infinity) and the conditional variance decompositions (i.e., at the forecast horizon of 12 quarters) are shown for the first year to which the model is estimated (2010:Q1), as well as for the last year of model estimation (2013:Q4).

\section{Appendix F.11.1. 2010:Q1}

At first glance, the unconditional variance decomposition depicted in Table F.15 reveals some noteworthy results and valuable insights for the conditional forecast conducted in Section 3.3 above. This is especially so for the growth rates of consumption and investment, which are the variables that have to be partly controlled exogenously for the conditional forecast, as further laid out in Appendix F.12 below. ${ }^{51}$ Consumption growth in Austria $(d C C)$, as to be expected, is mostly determined by the risk shock to household bond holdings $\left(\eta_{t}^{b}\right.$, which in essence corresponds to a "consumption shock"), all other influences seem to be relatively minor. This picture is somewhat different for the EA, even though the consumption shock $\left(\eta_{t}^{b *}\right)$ there also plays the most important role in determining changes in EA consumption $\left(d C C^{*}\right)$. However, the importance of technology shocks, for consumption seems especially, to be higher in the EA. Investment growth both in Austria $(d X X)$ and the EA $\left(d X X^{*}\right)$, as would be expected according to economic intuition, are primarily determined by the shock to investment demand.

The conditional variance decomposition shown in Table F.16 below demonstrates that for the forecast horizon of 12 quarters (q), the decisive features of the unconditional variance decomposition remain unchanged. However, the importance of some shocks diminishes, while the influence of other shocks rises. Especially, in the short term, the degree of influence of the technology shock in the EA on employment and inflation is more than halved as compared to the long run variance decomposition. Compared to these noteworthy changes in the variance decompositions for the EA, it seems that for the Austrian economy the influences of shocks remain much more stable from the short to the long term, potentially related to the fact that economic developments in Austria are more subject to other exogenous influences such as exports or imports.

\footnotetext{
${ }^{51}$ The particular variance decompositions most relevant for the conditional forecasts are highlighted by red-colored cells in Tables F.15, F.16, F.17 and F.18 below.
} 
Table F.11: Results from Metropolis-Hastings (parameters) for 1997:Q1 - 2010:Q1

\begin{tabular}{|c|c|c|c|c|c|c|c|}
\hline & \multicolumn{3}{|c|}{ Prior } & \multicolumn{4}{|c|}{ Posterior } \\
\hline & Dist. & Mean & Stdev. & Mean & Stdev. & HPD inf & HPD sup \\
\hline$\rho_{A}^{*}$ & beta & 0.500 & 0.2000 & 0.995 & 0.0022 & 0.9918 & 0.9985 \\
\hline$\rho_{A}$ & beta & 0.500 & 0.2000 & 0.927 & 0.0376 & 0.8746 & 0.9866 \\
\hline$\rho_{B}^{*}$ & beta & 0.500 & 0.2000 & 0.392 & 0.1457 & 0.1573 & 0.6257 \\
\hline$\rho_{B}$ & beta & 0.500 & 0.2000 & 0.155 & 0.0837 & 0.0219 & 0.2723 \\
\hline$\rho_{G}^{*}$ & beta & 0.500 & 0.2000 & 0.791 & 0.0858 & 0.6478 & 0.9265 \\
\hline$\rho_{G}$ & beta & 0.500 & 0.2000 & 0.811 & 0.0787 & 0.6862 & 0.9367 \\
\hline$\rho_{X}^{*}$ & beta & 0.500 & 0.2000 & 0.499 & 0.0844 & 0.3591 & 0.6358 \\
\hline$\rho_{X}$ & beta & 0.500 & 0.2000 & 0.162 & 0.0881 & 0.0240 & 0.2878 \\
\hline$\rho_{R}^{*}$ & beta & 0.500 & 0.2000 & 0.579 & 0.0502 & 0.4995 & 0.6602 \\
\hline$\rho_{p}^{*}$ & beta & 0.500 & 0.2000 & 0.953 & 0.0236 & 0.9180 & 0.9886 \\
\hline$\rho_{p}$ & beta & 0.500 & 0.2000 & 0.915 & 0.0445 & 0.8506 & 0.9826 \\
\hline$\rho_{w}^{*}$ & beta & 0.500 & 0.2000 & 0.865 & 0.0609 & 0.7716 & 0.9565 \\
\hline$\rho_{w}$ & beta & 0.500 & 0.2000 & 0.674 & 0.1259 & 0.4680 & 0.8751 \\
\hline$\theta_{p}^{*}$ & beta & 0.500 & 0.2000 & 0.367 & 0.1439 & 0.1292 & 0.6016 \\
\hline$\theta_{p}$ & beta & 0.500 & 0.2000 & 0.463 & 0.1569 & 0.1953 & 0.7115 \\
\hline$\theta_{w}^{*}$ & beta & 0.500 & 0.2000 & 0.400 & 0.1469 & 0.1640 & 0.6493 \\
\hline$\theta_{w}$ & beta & 0.500 & 0.2000 & 0.338 & 0.1433 & 0.1035 & 0.5631 \\
\hline$\phi_{X}^{*}$ & norm & 4.000 & 1.5000 & 3.683 & 1.0613 & 2.0036 & 5.1631 \\
\hline$\phi_{X}$ & norm & 4.000 & 1.5000 & 4.796 & 1.2506 & 2.7309 & 6.8202 \\
\hline$\xi_{p}^{*}$ & beta & 0.500 & 0.1000 & 0.715 & 0.0419 & 0.6457 & 0.7814 \\
\hline$\xi_{p}$ & beta & 0.500 & 0.1000 & 0.600 & 0.0549 & 0.5031 & 0.6779 \\
\hline$\xi_{W}^{*}$ & beta & 0.500 & 0.1000 & 0.668 & 0.0530 & 0.5803 & 0.7524 \\
\hline$\xi_{W}$ & beta & 0.500 & 0.1000 & 0.719 & 0.0391 & 0.6574 & 0.7851 \\
\hline$\iota_{W}^{*}$ & beta & 0.500 & 0.1500 & 0.273 & 0.1113 & 0.0966 & 0.4489 \\
\hline$\iota_{W}$ & beta & 0.500 & 0.1500 & 0.358 & 0.1142 & 0.1623 & 0.5354 \\
\hline$\iota_{p}^{*}$ & beta & 0.500 & 0.1500 & 0.124 & 0.0543 & 0.0383 & 0.2042 \\
\hline$\iota_{p}$ & beta & 0.500 & 0.1500 & 0.370 & 0.1260 & 0.1663 & 0.5776 \\
\hline$\phi_{a}^{*}$ & beta & 0.500 & 0.1500 & 0.523 & 0.1383 & 0.2963 & 0.7551 \\
\hline$\phi_{a}$ & beta & 0.500 & 0.1500 & 0.511 & 0.1486 & 0.2737 & 0.7597 \\
\hline$\sigma_{C}^{*}$ & norm & 1.500 & 0.2500 & 1.180 & 0.0637 & 1.0777 & 1.2854 \\
\hline$h^{*}$ & beta & 0.700 & 0.1000 & 0.667 & 0.0549 & 0.5816 & 0.7616 \\
\hline$h$ & beta & 0.700 & 0.1000 & 0.787 & 0.0481 & 0.7092 & 0.8656 \\
\hline$\sigma_{L}^{*}$ & norm & 2.000 & 0.5000 & 0.721 & 0.3270 & 0.2153 & 1.2300 \\
\hline$\sigma_{L}^{L}$ & norm & 2.000 & 0.5000 & 2.101 & 0.4025 & 1.4266 & 2.7505 \\
\hline$\rho_{\pi}^{*}$ & norm & 1.500 & 0.2500 & 1.090 & 0.0362 & 1.0326 & 1.1484 \\
\hline$\rho_{r}^{*}$ & beta & 0.750 & 0.1000 & 0.657 & 0.0435 & 0.5886 & 0.7303 \\
\hline$\rho_{Y}^{*}$ & norm & 0.125 & 0.0500 & 0.002 & 0.0022 & 0.0000 & 0.0054 \\
\hline$\rho_{D Y}^{*}$ & norm & 0.125 & 0.0500 & 0.198 & 0.0423 & 0.1284 & 0.2676 \\
\hline$\pi_{S S} *$ & gamm & 0.625 & 0.1000 & 0.518 & 0.0651 & 0.4083 & 0.6215 \\
\hline$\pi_{S S}$ & gamm & 0.625 & 0.1000 & 0.564 & 0.0663 & 0.4546 & 0.6723 \\
\hline$\beta_{S S}$ & gamm & 0.250 & 0.1000 & 0.720 & 0.1272 & 0.5113 & 0.9305 \\
\hline$\gamma^{*}$ & norm & 0.400 & 0.1000 & 0.462 & 0.0453 & 0.3897 & 0.5371 \\
\hline$\gamma$ & norm & 0.400 & 0.1000 & 0.436 & 0.0525 & 0.3487 & 0.5193 \\
\hline$c_{g y}^{*}$ & norm & 0.500 & 0.2500 & 0.243 & 0.1089 & 0.0562 & 0.4137 \\
\hline$c_{g y}$ & norm & 0.500 & 0.2500 & 0.135 & 0.0980 & 0.0100 & 0.2717 \\
\hline$\alpha^{*}$ & norm & 0.300 & 0.0500 & 0.332 & 0.0259 & 0.2875 & 0.3738 \\
\hline$\alpha$ & norm & 0.300 & 0.0500 & 0.172 & 0.0391 & 0.1094 & 0.2368 \\
\hline$(1+\Phi)^{*}$ & norm & 1.250 & 0.1250 & 1.325 & 0.0980 & 1.1675 & 1.4892 \\
\hline $1+\Phi$ & norm & 1.250 & 0.1250 & 1.421 & 0.1089 & 1.2455 & 1.6053 \\
\hline$\xi_{\text {empl }}$ & beta & 0.700 & 0.2000 & 0.558 & 0.0457 & 0.4838 & 0.6349 \\
\hline$\xi_{e m p l}^{*}$ & beta & 0.700 & 0.2000 & 0.737 & 0.0322 & 0.6836 & 0.7901 \\
\hline$\epsilon_{s}$ & invg & 2.500 & 1.0000 & 1.763 & 0.2435 & 1.3605 & 2.1563 \\
\hline$\epsilon_{s}^{*}$ & invg & 2.500 & 1.0000 & 2.141 & 0.3776 & 1.5332 & 2.7934 \\
\hline
\end{tabular}


Table F.13: Results from Metropolis-Hastings (standard deviation of structural shocks) for 1997:Q1 - 2010:Q1

\begin{tabular}{ccccccccc}
\hline & \multicolumn{3}{c}{ Prior } & & \multicolumn{4}{c}{ Posterior } \\
\cline { 2 - 6 } \cline { 7 - 9 } & Dist. & Mean & Stdev. & & Mean & Stdev. & HPD inf & HPD sup \\
\hline$\sigma_{A}^{*}$ & invg & 0.100 & 2.0000 & & 0.393 & 0.0596 & 0.2986 & 0.4868 \\
$\sigma_{A}$ & invg & 0.100 & 2.0000 & & 0.578 & 0.0900 & 0.4351 & 0.7242 \\
$\sigma_{B}^{*}$ & invg & 0.100 & 2.0000 & & 0.154 & 0.0180 & 0.1246 & 0.1827 \\
$\sigma_{B}$ & invg & 0.100 & 2.0000 & & 0.304 & 0.0336 & 0.2490 & 0.3547 \\
$\sigma_{G}^{*}$ & invg & 0.100 & 2.0000 & & 0.302 & 0.0309 & 0.2513 & 0.3512 \\
$\sigma_{G}$ & invg & 0.100 & 2.0000 & & 0.606 & 0.0656 & 0.4960 & 0.7086 \\
$\sigma_{X}^{*}$ & invg & 0.100 & 2.0000 & & 0.364 & 0.0597 & 0.2660 & 0.4539 \\
$\sigma_{X}$ & invg & 0.100 & 2.0000 & & 1.168 & 0.1370 & 0.9501 & 1.4016 \\
$\sigma_{R}^{*}$ & invg & 0.100 & 2.0000 & & 0.133 & 0.0184 & 0.1046 & 0.1625 \\
$\sigma_{p}^{*}$ & invg & 0.100 & 2.0000 & & 0.137 & 0.0256 & 0.0965 & 0.1751 \\
$\sigma_{p}$ & invg & 0.100 & 2.0000 & & 0.415 & 0.0682 & 0.3039 & 0.5218 \\
$\sigma_{w}^{*}$ & invg & 0.100 & 2.0000 & & 0.140 & 0.0256 & 0.0977 & 0.1804 \\
$\sigma_{w}$ & invg & 0.100 & 2.0000 & & 0.157 & 0.0279 & 0.1111 & 0.2004 \\
\hline
\end{tabular}

Table F.15: Posterior mean unconditional variance decomposition at horizon infinity (in percent) for model parameter estimation to 2010:Q1

\begin{tabular}{lrrrrrrrrrrrrr}
\hline & $u_{A, t}$ & $u_{A, t}^{*}$ & $u_{G, t}$ & $u_{G, t}^{*}$ & $\eta_{t}^{b}$ & $\eta_{t}^{b *}$ & $\eta_{t}^{X}$ & $\eta_{t}^{X *}$ & $\eta_{t}^{R}$ & $\epsilon_{w}$ & $\epsilon_{w}^{*}$ & $\epsilon_{p, t}$ & $\epsilon_{p, t}^{*}$ \\
\hline$d Y$ & 15.55 & 0.11 & 40.54 & 0.02 & 7.68 & 0.01 & 8.68 & 6.41 & 4.03 & 1.55 & 0.03 & 15.23 & 0.17 \\
$d C C$ & 3.98 & 3.41 & 1.17 & 0.05 & 76.98 & 0.01 & 0.28 & 0.22 & 6.5 & 0.97 & 0.09 & 6.07 & 0.27 \\
$d X X$ & 4.08 & 0.23 & 0.49 & 0.02 & 0.11 & 0 & 86.27 & 0.92 & 1.16 & 0.39 & 0.04 & 5.97 & 0.3 \\
$d E M P L$ & 3.34 & 40.45 & 5.65 & 0.05 & 1.45 & 0.01 & 1.64 & 3.54 & 2.83 & 4.63 & 0.12 & 34.66 & 1.62 \\
$\Pi^{\text {obs }}$ & 16.33 & 26.94 & 2.84 & 0.57 & 0.52 & 0.11 & 0.81 & 7.73 & 15.67 & 1.68 & 0.93 & 18.52 & 7.34 \\
$d W$ & 6.26 & 1.65 & 3.58 & 0.04 & 0.38 & 0.01 & 1.25 & 0.74 & 3.14 & 12.02 & 0.11 & 70.39 & 0.42 \\
\hline$d Y^{*}$ & 0.01 & 13.4 & 0 & 20.6 & 0 & 4.42 & 0.01 & 32.44 & 14.75 & 0 & 2.76 & 0.02 & 11.59 \\
$d C C^{*}$ & 0.01 & 20.99 & 0 & 0.4 & 0 & 35.68 & 0 & 1.23 & 29.4 & 0 & 3.74 & 0 & 8.54 \\
$d X X^{*}$ & 0.03 & 2.49 & 0.01 & 0.31 & 0 & 0.08 & 0 & 73.73 & 8.24 & 0 & 2.07 & 0.01 & 13.03 \\
$d E M P L^{*}$ & 0.01 & 57.44 & 0 & 0.87 & 0 & 0.21 & 0 & 3.96 & 2.38 & 0 & 6.12 & 0 & 29 \\
$\Pi^{\text {obs* }}$ & 0.05 & 42.86 & 0.01 & 1.9 & 0 & 0.42 & 0.01 & 11.62 & 25.48 & 0 & 3.34 & 0.01 & 14.32 \\
$d W^{*}$ & 0 & 22.01 & 0 & 0.52 & 0 & 0.12 & 0 & 3.46 & 12.8 & 0 & 19.81 & 0 & 41.28 \\
\hline$R^{\text {obs }}$ & 0.08 & 59.63 & 0.01 & 2.44 & 0.01 & 0.52 & 0.01 & 15.9 & 2.22 & 0 & 2.97 & 0.02 & 16.19 \\
\hline
\end{tabular}


Table F.16: Posterior mean conditional variance decomposition for the forecast horizon of 12 quarters (in percent) for model parameter estimation to 2010:Q1

\begin{tabular}{lrrrrrrrrrrrrr}
\hline & $u_{A, t}$ & $u_{A, t}^{*}$ & $u_{G, t}$ & $u_{G, t}^{*}$ & $\eta_{t}^{b}$ & $\eta_{t}^{b *}$ & $\eta_{t}^{X}$ & $\eta_{t}^{X *}$ & $\eta_{t}^{R}$ & $\epsilon_{w}$ & $\epsilon_{w}^{*}$ & $\epsilon_{p, t}$ & $\epsilon_{p, t}^{*}$ \\
\hline$d Y$ & 15.08 & 0.13 & 41.02 & 0.02 & 8.22 & 0.01 & 8.67 & 5.23 & 4.73 & 1.52 & 0.04 & 15.1 & 0.25 \\
$d C C$ & 3.8 & 3.87 & 1.14 & 0.06 & 76.64 & 0.01 & 0.26 & 0.16 & 7.16 & 0.89 & 0.11 & 5.58 & 0.33 \\
$d X X$ & 4.21 & 0.29 & 0.5 & 0.02 & 0.12 & 0 & 86.25 & 0.69 & 1.36 & 0.36 & 0.05 & 5.74 & 0.39 \\
$d E M P L$ & 4.53 & 16.49 & 8.29 & 0.08 & 2.26 & 0.01 & 2.31 & 3.9 & 4.84 & 6.22 & 0.18 & 49.15 & 1.74 \\
$\Pi^{\text {obs }}$ & 20.52 & 7.76 & 3.76 & 0.86 & 0.71 & 0.16 & 1 & 7.43 & 23.11 & 2.12 & 1.48 & 23.47 & 7.6 \\
$d W$ & 5.85 & 1.93 & 3.56 & 0.05 & 0.4 & 0.01 & 1.19 & 0.58 & 3.58 & 12.52 & 0.14 & 69.64 & 0.55 \\
\hline$d Y^{*}$ & 0.01 & 14.63 & 0 & 23.38 & 0 & 4.67 & 0.01 & 23.99 & 15.69 & 0 & 3.35 & 0.02 & 14.25 \\
$d C C^{*}$ & 0.01 & 21.17 & 0 & 0.43 & 0 & 34.8 & 0 & 0.82 & 28.76 & 0 & 4.29 & 0 & 9.72 \\
$d X X^{*}$ & 0.03 & 3.32 & 0.01 & 0.39 & 0 & 0.1 & 0 & 63.93 & 10.4 & 0 & 2.92 & 0.01 & 18.88 \\
$d E M P L^{*}$ & 0.01 & 23.23 & 0 & 1.49 & 0 & 0.38 & 0 & 4.41 & 4.14 & 0 & 11.59 \\
$\Pi^{\text {obs* }}$ & 0.05 & 15.08 & 0.01 & 3.27 & 0 & 0.71 & 0.01 & 12.61 & 41.38 & 0 & 6.48 & 0.01 & 54.75 \\
$d W^{*}$ & 0 & 19.71 & 0 & 0.52 & 0 & 0.11 & 0 & 2.19 & 11.57 & 0 & 21.39 & 0 & 44.51 \\
\hline$R^{\text {obs }}$ & 0.11 & 22.5 & 0.03 & 6.24 & 0.01 & 1.34 & 0.02 & 26.14 & 5.58 & 0 & 8.52 & 0.03 & 29.45 \\
\hline
\end{tabular}

\section{Appendix F.11.2. 2013:Q4}

The unconditional and conditional variance decompositions for the model estimated for 2013:Q4 qualitatively show a very similar picture as for 2010:Q1, with only minor differences in the quantitative degree of the various shocks determining the development of macro aggregates in the model. This shows that, over the forecast horizon, the model behavior is not expected to change qualitatively to a high degree.

Table F.17: Posterior mean unconditional variance decomposition (at horizon infinity) for model parameter estimation to 2013:Q4

\begin{tabular}{lrrrrrrrrrrrrr}
\hline & $u_{A, t}$ & $u_{A, t}^{*}$ & $u_{G, t}$ & $u_{G, t}^{*}$ & $\eta_{t}^{b}$ & $\eta_{t}^{b *}$ & $\eta_{t}^{X}$ & $\eta_{t}^{X *}$ & $\eta_{t}^{R}$ & $\epsilon_{w}$ & $\epsilon_{w}^{*}$ & $\epsilon_{p, t}$ & $\epsilon_{p, t}^{*}$ \\
\hline$d Y$ & 18.38 & 0.16 & 37.58 & 0.08 & 7.35 & 0.01 & 8.85 & 6.18 & 4 & 1.8 & 0.05 & 15.28 & 0.28 \\
$d C C$ & 5.14 & 0.23 & 2.58 & 0.66 & 72.8 & 0.55 & 0.3 & 0 & 7.88 & 1.59 & 0.12 & 7.68 & 0.46 \\
$d X X$ & 3.81 & 0.11 & 0.45 & 0.1 & 0.07 & 0 & 87.99 & 0.51 & 1.26 & 0.51 & 0.07 & 4.12 & 0.99 \\
$d E M P L$ & 4.87 & 1.9 & 18.95 & 4.69 & 1.53 & 0.02 & 2.25 & 3.23 & 4.6 & 14.31 & 0.77 & 33.62 & 9.27 \\
$\Pi^{\text {obs }}$ & 12.84 & 7.84 & 4.24 & 10.51 & 0.28 & 0.1 & 0.61 & 3.69 & 12.22 & 1.22 & 3.44 & 14 & 29.02 \\
$d W$ & 8.17 & 0.24 & 4.68 & 0.21 & 0.31 & 0 & 1.43 & 0.86 & 3.63 & 9.68 & 0.15 & 70.09 & 0.54 \\
\hline$d Y^{*}$ & 0.01 & 11.33 & 0 & 16.23 & 0 & 5.36 & 0 & 27.15 & 13.78 & 0 & 5.34 & 0.02 & 20.78 \\
$d C C^{*}$ & 0.01 & 4.25 & 0 & 1.08 & 0 & 38.5 & 2.89 & 0 & 28.07 & 0 & 9.6 & 0 & 15.61 \\
$d X X^{*}$ & 0.01 & 5.42 & 0.01 & 0.11 & 0 & 0.05 & 0 & 58.08 & 7.53 & 0 & 3.37 & 0 & 25.42 \\
$d E$ MPL $^{*}$ & 0.02 & 1.71 & 0 & 12.6 & 0 & 0.09 & 0 & 1.19 & 1.62 & 0 & 16.04 \\
$\Pi^{\text {obs* }}$ & 0.1 & 15.35 & 0.04 & 17.47 & 0 & 0.29 & 0.01 & 4.49 & 16.16 & 0 & 6.98 \\
$d W^{*}$ & 0 & 6.76 & 0 & 0.21 & 0 & 0.13 & 0 & 2.54 & 8.06 & 0 & 20.82 \\
\hline$R^{\text {obs }}$ & 0.14 & 15.07 & 0.06 & 22.4 & 0 & 0.29 & 0.01 & 5.61 & 1.51 & 0 & 6 \\
\hline
\end{tabular}

\section{Appendix F.12. Conditional Forecasts with the DSGE Model: Method}

To replicate a setup of times series models with contemporaneous exogenous predictors for exports and imports $^{52,53}$ (as in the ARMAX and VARX models above) within a DSGE model, we run so called conditional forecasts

\footnotetext{
${ }^{52}$ Since government consumption in the DSGE model is represented by a stochastic exogenous shock, we do not consider government consumption as an exogenous predictor for the DSGE mode.

${ }^{53}$ For all analyses below and according to the logic of the DSGE model, exports from Austria to the EA (imports of EA from Austria) are represented by consumption $\left(C_{H}^{*}\right)$ and investment $\left(X_{H}^{*}\right)$ of Austrian goods in the EA, while imports of Austria from the EA (exports of EA to Austria) are represented by the domestic (Austrian) use of goods produces in the EA for consumption $\left(C_{F}\right)$ and investment $\left(X_{F}\right)$, respectively.
} 
Table F.18: Posterior mean conditional variance decomposition for the forecast horizon of 12 quarters (in percent) for model parameter estimation to $2013: \mathrm{Q} 4$

\begin{tabular}{lrrrrrrrrrrrrr}
\hline & $u_{A, t}$ & $u_{A, t}^{*}$ & $u_{G, t}$ & $u_{G, t}^{*}$ & $\eta_{t}^{b}$ & $\eta_{t}^{b *}$ & $\eta_{t}^{X}$ & $\eta_{t}^{X *}$ & $\eta_{t}^{R}$ & $\epsilon_{w}$ & $\epsilon_{w}^{*}$ & $\epsilon_{p, t}$ & $\epsilon_{p, t}^{*}$ \\
\hline$d Y$ & 17.87 & 0.18 & 38.82 & 0.08 & 7.83 & 0.01 & 8.38 & 5.62 & 3.95 & 1.89 & 0.05 & 15.01 & 0.3 \\
$d C C$ & 5.06 & 0.23 & 2.6 & 0.74 & 73.83 & 0 & 0.5 & 0.27 & 7.46 & 1.6 & 0.11 & 7.14 & 0.45 \\
$d X X$ & 4.15 & 0.13 & 0.5 & 0.13 & 0.08 & 0 & 87.54 & 0.45 & 1.3 & 0.54 & 0.07 & 4.04 & 1.07 \\
$d E M P L$ & 4.86 & 1.38 & 20.39 & 4.36 & 1.71 & 0.02 & 2.16 & 2.97 & 4.82 & 15.64 & 0.58 & 35.08 & 6.02 \\
$\Pi^{o b s}$ & 15.03 & 7.56 & 5.18 & 11.94 & 0.34 & 0.14 & 0.65 & 3.68 & 14.24 & 1.52 & 3.37 & 16.14 & 20.21 \\
$d W$ & 7.78 & 0.26 & 4.8 & 0.24 & 0.32 & 0 & 1.29 & 0.76 & 3.55 & 10.93 & 0.13 & 69.38 & 0.54 \\
\hline$d Y^{*}$ & 0.01 & 12.24 & 0 & 18.44 & 0 & 5.96 & 0 & 23.88 & 13.29 & 0 & 5 & 0.02 & 21.16 \\
$d C C^{*}$ & 0 & 4.52 & 0 & 1.2 & 0 & 41.34 & 0 & 2.53 & 26.29 & 0 & 8.91 & 0 & 15.2 \\
$d X X^{*}$ & 0.01 & 6.44 & 0.01 & 0.13 & 0 & 0.06 & 0 & 54.46 & 7.74 & 0 & 3.34 & 0 & 27.81 \\
$d E M P L^{*}$ & 0.01 & 1.47 & 0 & 11.48 & 0 & 0.1 & 0 & 0.99 & 1.61 & 0 & 15.52 \\
$\Pi^{\text {obs* }}$ & 0.08 & 17.14 & 0.05 & 21.11 & 0 & 0.4 & 0.01 & 4.55 & 19.21 & 0 & 7.67 & 0 & 29.78 \\
$d W^{*}$ & 0 & 6.72 & 0 & 0.22 & 0 & 0.14 & 0 & 2.11 & 7.61 & 0 & 20.45 & 0 & 62.74 \\
\hline$R^{\text {obs }}$ & 0.11 & 16.47 & 0.07 & 28.88 & 0 & 0.44 & 0.01 & 6.13 & 1.94 & 0 & 7.75 & 0.01 & 38.17 \\
\hline
\end{tabular}

in the DSGE model. For this purpose, we have to compute forecasts for a given constrained path of an endogenous variable. ${ }^{54}$ While for the time series models these exogenous data directly enter the parameter estimation procedure, in the DSGE model—following Leeper and Zha (2003) or Smets and Wouters (2004) (where this conditional forecasting procedure is applied to interest rate paths) - it is necessary to control certain exogenous shocks. These exogenous shocks are unanticipated by the optimizing agent in the DSGE model, and are chosen so as to match the corresponding values of the exogenous predictors, which are the conditioning information, that is, in our case Austria's exports to and imports from the EA. In particular, the reduced-form, first-order, state-space representation is used to find the structural shocks that are needed to match the restricted, exogenous paths. When these controlled shocks are used, the state-space representation can be applied to forecasting. According to the variance decomposition conducted in Appendix F.11 above, we use the consumption shocks at home and abroad as the controlled exogenous shocks, which account for the large bulk of Austria's exports—namely, foreign consumption of goods produced at home-and imports, namely, consumption in Austria of goods produced abroad. Intensive testing of the DSGE model revealed that including additional controlled shocks for the conditional forecasts worsened the forecast performance. This also pertains to shocks to investment, which account for a minority of trade between Austria and the EA. For these reasons, and in line with the results from the variance decomposition, we restricted the amount of controlled shocks to consumption shocks.

\section{Appendix F.13. Forecast performance: the DSGE model and a VAR(1) in comparison}

\section{Appendix F.13.1. Unconditional forecasts}

As a simple validation exercise for the DSGE model, Tables F.19 and F.20 compare the out-of-sample forecast performance of the DSGE model to that of an unconstrained VAR(1) model according to a traditional root mean squared error (RMSE) measure of fit, analogous to Section 3 above. The unconstrained VAR(1) is again chosen as a natural benchmark model for forecasting quality. To allow the data to decide on the degree of persistence and cointegration, GDP, consumption, investment, and wages enter the VAR model in log levels for the estimation, while the other variables enter in log differences. As before, the different models are estimated on the same time series data (1997:Q1 - 2013:Q1), and are then re-estimated every quarter for the forecasting period (2010:Q2-2013:Q4). Each quarter of the forecasting period is then used as a starting point to conduct forecasts for horizons of one quarter (q), 2q, $4 \mathrm{q}, 8 \mathrm{q}$ and $12 \mathrm{q}$. The forecasts are compared for GDP and its main components, consumption (CONS) and investment (INV), for the wage level (Wage), for inflation as measured by the GDP deflator (dP), and hours worked (Hours). Additionally for the EA, interest rates set by the central bank (Euribor) are considered for the forecast.

\footnotetext{
${ }^{54}$ See the Dynare Manual, pp. 97-100 for additional information on conditional forecasts.
} 
The unconditional forecasting results for Austria shown in Table F.19 clearly indicate that the DSGE model outperforms the VAR(1) model especially for medium to long term horizons. DSGE forecasts for GDP improve on VAR(1) predictions by a considerable margin for a horizon up to $12 q$, while the VAR model has some advantages for shorter horizons of $1 \mathrm{q}$ and $2 \mathrm{q}$. Moreover, the additional economic structure embedded in the theory-driven DSGE model seems to increase its forecasting performance over the VAR model for all other variables, and also for shorter horizons. Accordingly, the DSGE model outperforms the VAR(1) for almost all horizons-sometimes by a margin over 50 percent for longer horizons-for inflation, hours worked, wages, consumption and investment.

\begin{tabular}{|c|c|c|c|c|c|c|}
\hline & GDP & $\mathrm{dP}$ & Hours & Wage & CONS & INV \\
\hline $\operatorname{VAR}(1)$ & \multicolumn{6}{|c|}{ RMSE-statistic for different forecast horizons } \\
\hline $1 \mathrm{q}$ & 0.56 & 0.56 & 0.22 & 0.67 & 0.62 & 1.97 \\
\hline $2 q$ & 0.82 & 0.51 & 0.33 & 0.84 & 0.93 & 3.06 \\
\hline $4 \mathrm{q}$ & 1.34 & 0.43 & 0.76 & 1.21 & 1.22 & 4.71 \\
\hline $8 \mathrm{q}$ & 2.37 & 0.49 & 1.72 & 2.64 & 2.34 & 5.64 \\
\hline $12 q$ & 3.53 & 0.57 & 2.65 & 4.95 & 3.96 & 7.19 \\
\hline DSGE & \multicolumn{6}{|c|}{ Percentage gains (+) or losses $(-)$ relative to VAR(1) model } \\
\hline $1 \mathrm{q}$ & -16.06 & 37.09 & 28.89 & 17.43 & 2.17 & 44.72 \\
\hline $2 q$ & -12.16 & 15.26 & 41.05 & 2.75 & 7.17 & 50.40 \\
\hline $4 q$ & 15.85 & 13.72 & 56.16 & -4.19 & 19.30 & 53.89 \\
\hline $8 \mathrm{q}$ & 61.98 & 26.43 & 72.12 & 38.72 & 40.39 & 50.81 \\
\hline $12 \mathrm{q}$ & 73.53 & 39.91 & 81.38 & 59.48 & 53.04 & 58.29 \\
\hline
\end{tabular}

The unconditional forecasting results for the EA depicted in Table F.20, show a similar picture to the results for Austria, but with slight variations. Interestingly, the DSGE model outperforms the VAR(1) model for all horizons in GDP forecasts, even in the short term of $1 \mathrm{q}$ and $2 \mathrm{q}$, but has a smaller margin over the VAR(1) model in the longer run than for the Austrian case. This difference also relates to the forecast performance of the VAR model estimated to EA data, which is slightly worse than that of the VAR model for Austria especially for longer horizons. DSGE model forecasts of consumption in the EA are worse in relation to the VAR model compared with Austria. However, this deterioration in the forecast performance of the DSGE model for the EA in comparison with Austria is due to the performance of the VAR model, as the VAR model estimated to EA data seems to forecast consumption particularly well in comparison with other variables. What could also be noteworthy is that the Taylor rule embedded in the DSGE model tends to capture interest rates better at shorter than at longer horizons in comparison with the VAR model.

Table F.20: RMSE-statistic of euro area variables for different forecast horizons of DSGE in comparison to a VAR(1).

\begin{tabular}{|c|c|c|c|c|c|c|c|}
\hline & GDP & $\mathrm{dP}$ & Euribor & Hours & Wage & CONS & INV \\
\hline VAR(1) & \multicolumn{7}{|c|}{ RMSE-statistic for different forecast horizons } \\
\hline $1 \mathrm{q}$ & 0.60 & 0.23 & 0.07 & 0.14 & 0.35 & 0.39 & 1.32 \\
\hline $2 q$ & 1.03 & 0.27 & 0.14 & 0.30 & 0.65 & 0.64 & 2.03 \\
\hline $4 q$ & 1.86 & 0.34 & 0.26 & 0.70 & 1.23 & 1.24 & 3.64 \\
\hline $8 \mathrm{q}$ & 3.21 & 0.55 & 0.35 & 1.61 & 2.25 & 2.66 & 6.43 \\
\hline $12 q$ & 4.74 & 0.81 & 0.36 & 2.90 & 3.45 & 4.21 & 11.02 \\
\hline DSGE & \multicolumn{7}{|c|}{ Percentage gains $(+)$ or losses $(-)$ relative to $\operatorname{VAR}(1)$ model } \\
\hline $1 q$ & 32.72 & 50.92 & 19.06 & 5.37 & 35.46 & -22.35 & 7.36 \\
\hline $2 q$ & 30.58 & 37.26 & 5.02 & -3.87 & 32.05 & -47.83 & -1.23 \\
\hline $4 q$ & 29.54 & 51.24 & -6.31 & -6.04 & 36.87 & -50.90 & -0.75 \\
\hline $8 q$ & 33.49 & 63.83 & -39.38 & 2.61 & 29.21 & -24.02 & 8.53 \\
\hline $12 q$ & 44.85 & 63.77 & -71.19 & 31.72 & 29.71 & 3.94 & 36.53 \\
\hline
\end{tabular}




\section{Appendix F.13.2. Conditional forecasts}

Table F.21 shows the forecast performance of the DSGE model in a conditional forecasting setup for Austria according to the methodology briefly described in Appendix F.12 above. As noted there, for this procedure consumption shocks are controlled to match the exogenously given paths of exports and imports in the DSGE model. The DSGE model delivers a fairly reasonable forecast performance in comparison to the VARX(1) model, which includes the same exogenous predictors. However, the DSGE model forecast performance deteriorates with respect to the unconditional case. This becomes most cleary visible when the DSGE forecast performance is looked at for consumption, which obviously decreases due to the controlling of consumption shocks to match the exogenous predictors. With this method, even though the overall forecast performance of the DSGE model increases with respect to the unconditional case, a price has to be paid with the distortion of the general equilibrium framework underlying the DSGE model that decreases its forecast performance. This is less so for Austria than for the Euroa Area, as the additional information of exogenously given exports and imports seems to largely outweigh the distortion of the endogenous variables in the model in the small open economy setting. Accordingly, except for consumption, DSGE model forecasts do not deteriorate to a large degree with respect to the unconditional case, sometimes even improving slightly, such as in the short horizon (1q, 2q) for GDP forecasts, and for almost all horizons for investment forecasts.

Table F.21: RMSE-statistic for conditional forecasts of Austrian variables for different forecast horizons of DSGE in comparison to a VARX(1) model.

\begin{tabular}{lcccccc}
\hline & GDP & $\mathrm{dP}$ & Hours & Wage & CONS & INV \\
\hline VARX(1) & \multicolumn{7}{c}{ RMSE-statistic } & for & different & forecast & horizons & \\
$1 \mathrm{q}$ & 0.49 & 0.59 & 0.22 & 0.68 & 0.63 & 1.95 \\
$2 \mathrm{q}$ & 0.68 & 0.55 & 0.38 & 0.83 & 0.92 & 2.92 \\
$4 \mathrm{q}$ & 1.20 & 0.44 & 0.88 & 1.21 & 1.10 & 3.98 \\
$8 \mathrm{q}$ & 2.57 & 0.48 & 2.10 & 2.73 & 1.99 & 4.79 \\
$12 \mathrm{q}$ & 3.80 & 0.56 & 3.53 & 5.09 & 3.40 & 6.20 \\
DSGE (conditional forecasts) & Percentage & gains & $(+)$ or & losses $(-)$ & relative to VARX(1) & model \\
$1 \mathrm{q}$ & -11.65 & 36.83 & 7.78 & 21.39 & -176.10 & 42.54 \\
$2 \mathrm{q}$ & -12.43 & 26.68 & 21.55 & 5.37 & -142.39 & 47.01 \\
$4 \mathrm{q}$ & 30.61 & 12.25 & 44.80 & 1.18 & -196.79 & 41.30 \\
$8 \mathrm{q}$ & 49.16 & 22.64 & 56.52 & 44.40 & -137.04 & 51.45 \\
$12 \mathrm{q}$ & 60.39 & 0.79 & 63.95 & 64.58 & -90.46 & 62.57 \\
\hline
\end{tabular}

Table F.22: RMSE-statistic for conditional forecasts of euro area variables for different forecast horizons of DSGE in comparison to a VARX(1) model.

\begin{tabular}{|c|c|c|c|c|c|c|c|}
\hline & GDP & $\mathrm{dP}$ & Euribor & Hours & Wage & CONS & INV \\
\hline $\operatorname{VARX}(1)$ & \multicolumn{7}{|c|}{ RMSE-statistic for different forecast horizons } \\
\hline $1 \mathrm{q}$ & 0.42 & 0.23 & 0.09 & 0.13 & 0.33 & 0.39 & 1.13 \\
\hline $2 q$ & 0.68 & 0.26 & 0.15 & 0.26 & 0.56 & 0.66 & 1.56 \\
\hline $4 \mathrm{q}$ & 1.11 & 0.30 & 0.23 & 0.54 & 1.03 & 1.24 & 2.38 \\
\hline $8 \mathrm{q}$ & 1.93 & 0.46 & 0.36 & 0.94 & 2.00 & 2.64 & 3.76 \\
\hline $12 \mathrm{q}$ & 2.45 & 0.69 & 0.68 & 1.47 & 3.13 & 4.14 & 6.21 \\
\hline DSGE (conditional forecasts) & \multicolumn{7}{|c|}{ Percentage gains $(+)$ or losses $(-)$ relative to VARX(1) model } \\
\hline $1 \mathrm{q}$ & -68.98 & 29.02 & -43.69 & -65.51 & 30.67 & -349.40 & -12.13 \\
\hline $2 q$ & -58.91 & 0.50 & -46.91 & -64.52 & 21.58 & -283.06 & -33.19 \\
\hline $4 \mathrm{q}$ & -54.60 & -18.39 & -69.63 & -75.74 & 26.30 & -216.25 & -53.73 \\
\hline $8 \mathrm{q}$ & -39.15 & 13.59 & -82.79 & -101.04 & 20.80 & -102.65 & -47.63 \\
\hline $12 q$ & -27.69 & 22.05 & -25.59 & -66.90 & 24.24 & -49.66 & -2.97 \\
\hline
\end{tabular}

The conditional forecasting comparison between the DSGE and VARX models is depicted in Table F.22. Here, 
consumption forecasts by the DSGE model further deteriorate with respect to the VARX(1) model. Additionally, the DSGE model is now outperformed by the VARX model for GDP, hours worked, and investment forecasts for almost all forecast horizons. The additional distortion resulting from the controlled consumption shocks restrains the forecasting capabilities of the DSGE model more severely in the case of the much larger and less open EA economy. Here, the additional information of exogenous exports and imports between Austria and the EA, which only accounts for a very small amount of economic activity in the EA, does not suffice to counter-balance the distortion introduced by the controlled shocks within the DSGE model. 